$M=-E A=72: 1158$
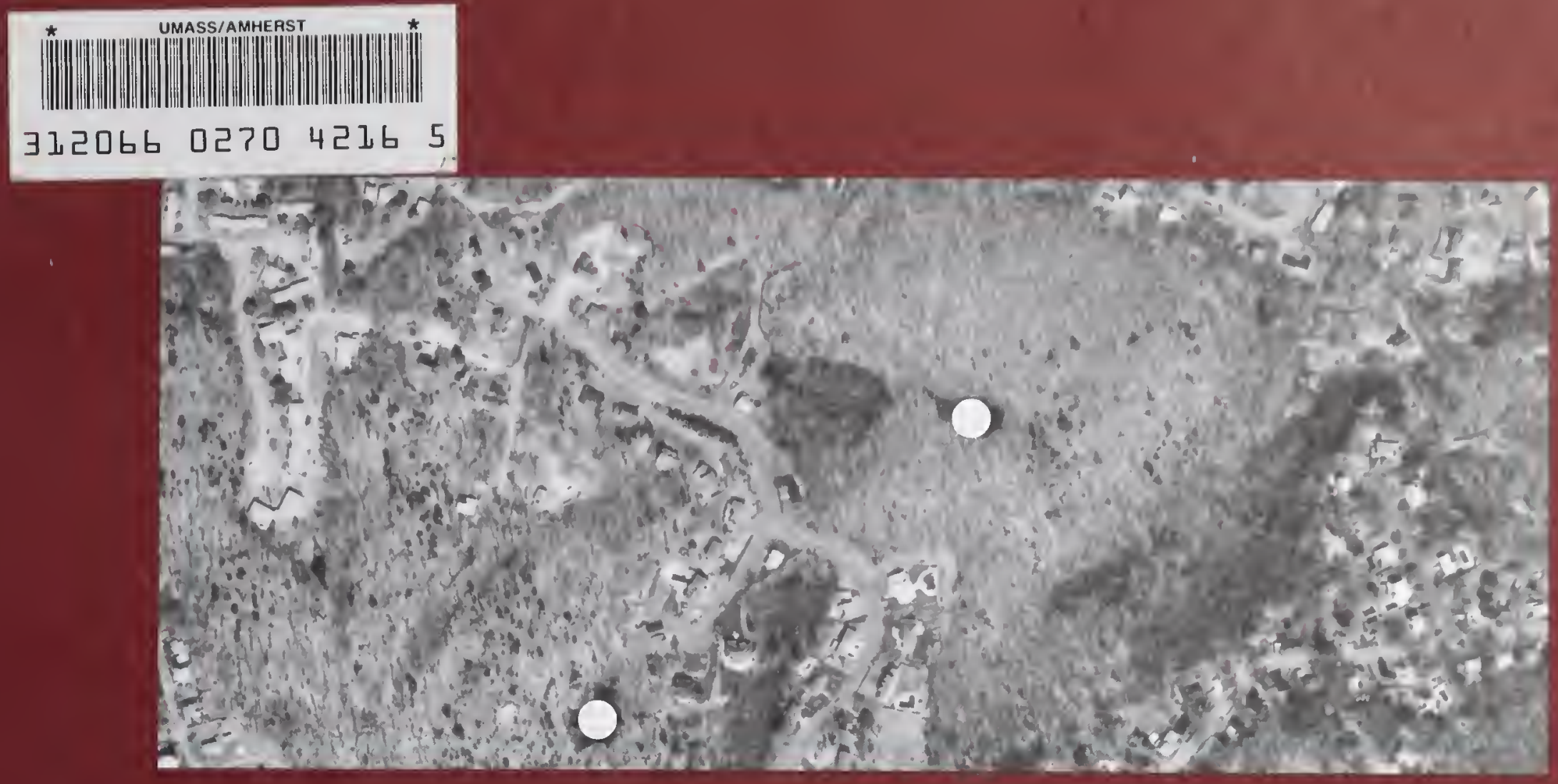

\title{
Massachusetts Aerial Photo Survey of Potential Vernal Pools
}

Spring 2001

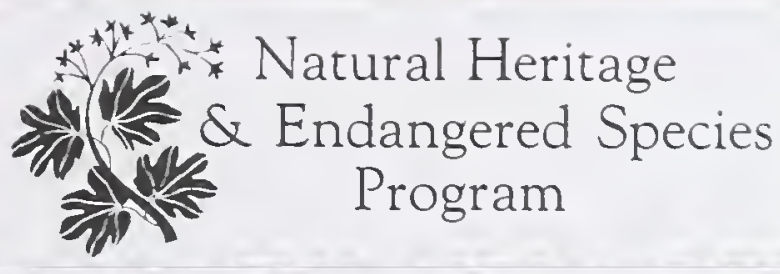

Massachusetts Division of Fisheries \& Wildlife 


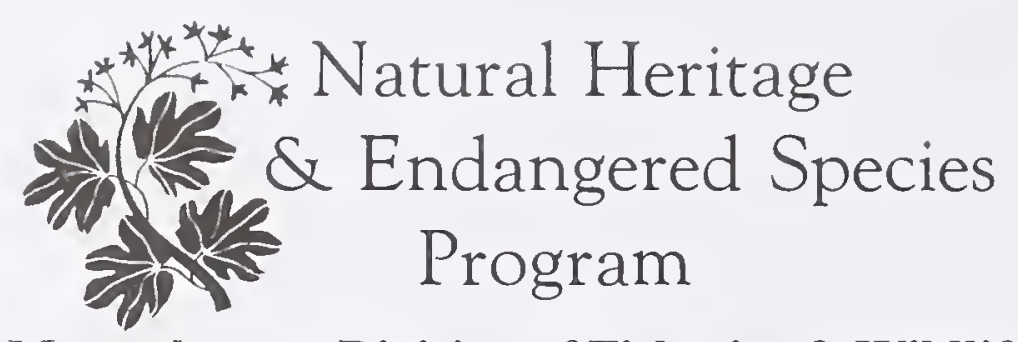

\section{Massachusetts Division of Fisheries \& Wildlife}

Route 135, Westborough, MA 01581

www.state.ma.us/dfwele/dfw/nhesp/heritage.htm

(508) 792-7270 ext. 200, fax (508) 792-7821

The Natural Heritage \& Endangered Species Program's goal is the protection of the state's native biological diversity through a comprehensive program of biological inventory and scientific research, species and habitat management and restoration, environmental impact review, and conservation planning. The Program is funded largely by the Commonwealth's General Fund as well as by voluntary contributions to the NH\&ES Fund on Massachusetts' income tax forms and by the Inland Fish \& Game Fund. The Program also is an active participant in the evaluation and selection of lands purchased by the Division of Fisheries \& Wildlife.

With support from

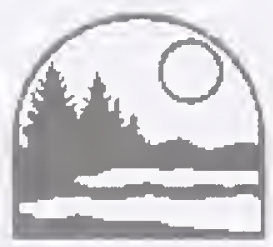

Executive Office of

Environmental Affairs

Commonwealth of Massachusetts

This project was supported by bond funds made available by the Executive Office of Environmental Affairs. Bond funds supporting the Massachusetts Aerial Photo Survey of Potential Vernal Pools also supported a series of seven vernal pool workshops for educators held throughout the Commonwealth in the spring of 2001. The Massachusetts Aerial Photo Survey of Potential Vernal Pools has been funded as a component of the Natural Heritage Program's BioMap Project, a statewide effort to identify and map areas of critical conservation concern. BioMap will result in an important tool for prioritizing open space protection, acquisition and community preservation planning, as well be valuable to state and federal environmental agencies, local conservation commissions, planning boards and land trusts.

Copies of this publication are available through the Massachusetts Division of Fisheries \& Wildlife's Natural Heritage \& Endangered Species Program, Route 135, Westborough, MA 01581, (508) 792-7270 ext. 200. 


\section{Massachusetts Aerial Photo Survey of Potential Vernal Pools}

SPRING 2001

Matthew R. Burne Vernal Pool Ecologist

Natural Heritage \& Endangered Species Program Massachusetts Division of Fisheries \& Wildlife Route 135, Westborough, MA 01581 


\section{Acknowledgments}

Thanks are due to the following people for their help in the realization of this major undertaking. This survey has been an underlying goal of the Natural Heritage Program's vernal pool work for nearly 7 years, and the project's conception and ultimate execution has been aided by many people along the way.

Special thanks to Henry Woolsey and Patricia Huckery, Dr. Elizabeth Colburn, Scott Jackson, Leo Kenney, Jim MacDougall, Dr. Steven Meyer, Heidi Roddis, Janice Stone, and Dr. Bryan Windmiller

Thanks also to:

Kyla Bennett, Collette Blais, Jack Buckley, Arthur Burgeron, Alan and Janet Burne, Matthew Cloutier, Charles Costello, Lisa Dennehy, Robert Durand, Andy Finton, Suzanne Fowle, Aleda Freeman, Dr. Thomas French, David Gabriel, Chris Gaughan, Robert Golledge, David Goodwin, Shirley Griffin, Ed.D, Melissa Griffiths, Michael Harney, Christian Jacqz, Dr. David King, Alicia LeFort, Wayne MacCallum, Stafford Madison, Amy Maher, Sharon McGregor, Mike McHugh, Dr. Scott Melvin, Joan Milam, Peter Mirik, Stephanie Neid, Jessica Patalano, Jane Pierce, Jessica Schedlbauer, Tim Simmons, David Szczebak, Richard Tomczyk, Christine Vaccaro, Alison Whitlock, and Sally Zielinski. 


\section{Preface}

The Massachusetts Executive Office of Environmental Affairs seeks to engage citizens of the Commonwealth in the study, appreciation, and protection of vernal pool habitat. The Natural Heritage \& Endangered Species Program of the MA Division of Fisheries \& Wildlife is the state agency entrusted with the responsibility to oversee the official vernal pool certification program and to pursue research, education and outreach efforts that will enhance appreciation and protection for vernal pools in the state. This publication presents the first comprehensive aerial photo survey of potential vernal pools in Massachusetts. It is a statewide inventory of potential vernal pools that have been identified from aerial photographs. This survey represents a tremendous leap forward in the protection of this resource by providing, at a glance, the most complete picture available to date of the number and distribution of vernal pools across the Commonwealth.

Rather than on printed maps, the locations of photo-identified vernal pools are presented on a compact disc, developed by MassGIS, which is found at the back of this booklet. The compact disc contains a simplified version of the MassGIS Runtime Data Viewer with statewide USGS topographic maps and all of the potential vernal pools identified during this project. While the potential vernal pool data does not identify all vernal pool habitats in the state (many are not visible on aerial photographs), this will, nonetheless, provide a great tool for the conservation of many vernal pools.

The Massachusetts Aerial Photo Survey of Potential Vernal Pools does not replace the role of official state certification of vernal pools in the protection of these habitats. However, it does provide interested parties with valuable information on the occurrence of potential vernal pools that can then be verified in the field. School groups, land trusts and non-governmental organizations, local boards and commissions, landowners and environmental consultants should find the information presented useful in many ways. 


\section{Trespass}

The Executive Office of Environmental Affairs (EOEA) urges Massachusetts' citizens to take interest in vernal pool study, appreciation, and protection. However, EOEA strongly recommends that anyone interested in field verification of potential vernal pools or vernal pool certification obtain landowner permission prior to conducting any data gathering. No one pursuing official vernal pool certification should trespass on legally posted property under any circumstances. Please refer to the model letter for landowner permission (Appendix A) for help in drafting a letter seeking permission.

The Natural Heritage \& Endangered Species Program of the Massachusetts Division of Fisheries \& Wildlife maintains a file for every vernal pool that is certified. All information contained in these files, including the official field observation form and it's contents, are a part of the public record and may be requested through an official documents request. 


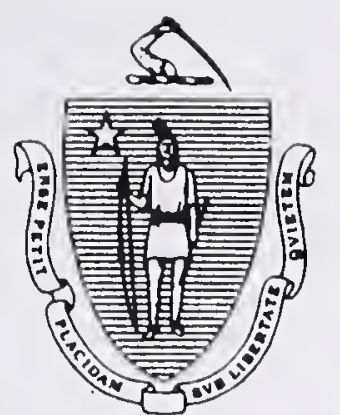

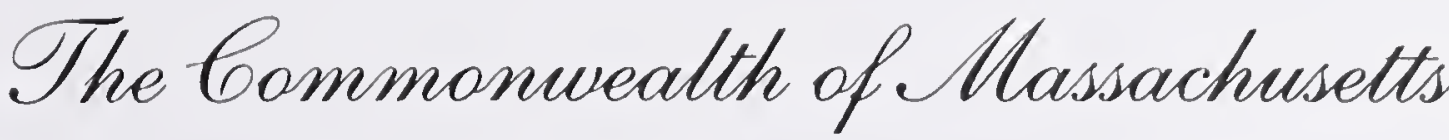

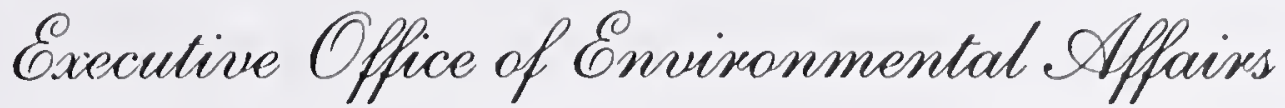 \\ 100 Cambridge Ptreet, Boston, MA 02202}

\section{ARGEO PAUL CELLUCCI \\ GOVERNOR}

JANE SWIFT

LIEUTENANT GOVERNOR

BOB DURAND

SECRETARY

Spring, 2001

Tel. (617) 727-9800

Fax (617) 727-2754

http://www.magnet.state.ma.us/envir

Dear Concerned Citizen,

Dear Concerned Citizens,

As Massachusetts' Secretary of Environmental Affairs, one of my top priorities is to help citizens reconnect to the natural world. A principal component of this goal is to create opportunities for children and adults to physically explore their environment. The Massachusetts Aerial Photo Survey of Potential Vernal Pools provides an important tool that will help the citizens of Massachusetts connect with these wonderful habitats that are found across our landscape.

Vernal pools are unique wetlands that support diverse and valuable wildlife communities, including many state-listed rare species, such as species of mole salamanders and the graceful, intricate fairy shrimp. Vernal pools come in a diversity of forms, but all are characterized by springtime ponding, a lack of reproducing fish populations, and the wildlife communities that are adapted to these conditions. Despite their variety in size and physical characteristics, they are all very important to the long-term preservation of biodiversity in our communities.

The Executive Office of Environmental Affairs (EOEA's) Vernal Pool Initiative seeks to engage citizens of the Commonwealth in the appreciation, study and protection of vernal pool habitat. This statewide inventory of potential vernal pools, through educational outreach and publications, will foster both interests in and understanding of vernal pool habitat.

Using a series of aerial photographs indicating potential vernal pools across the state as a guideline, citizens will join experts in the field to identify and certify vernal pool habitats. State laws protecting vernal pools from intrusive actions require physical assessment of the site for certification. Thus, field verification of potential vernal pools is essential to their protection.

I encourage school groups, children and parents, land trusts and non-governmental organizations, local boards and commissions, landowners and environmental consultants to join EOEA in this important initiative. If you choose to participate, please be certain to obtain permission to access any private or public property before searching for vernal pools.

I hope you take advantage of this opportunity and I look forward to your participation.

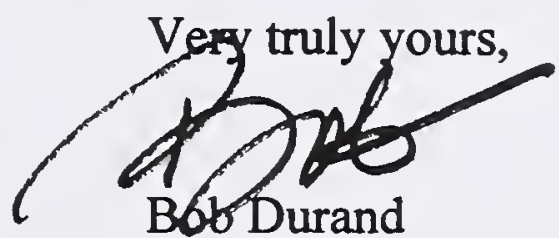


Digitized by the Internet Archive in 2013 with funding from

Boston Library Consortium Member Libraries 


\section{Aerial Photo Survey of Potential Vernal Pools}

\section{Contents}

Aerial Photographic Interpretation of Vernal Pools

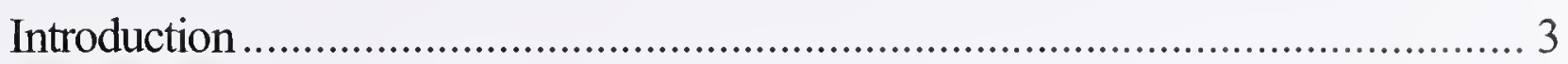

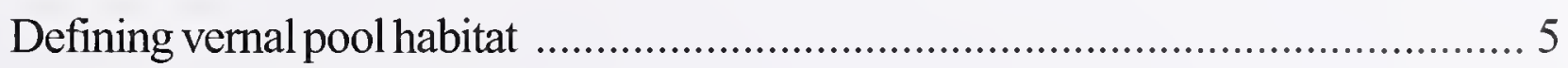

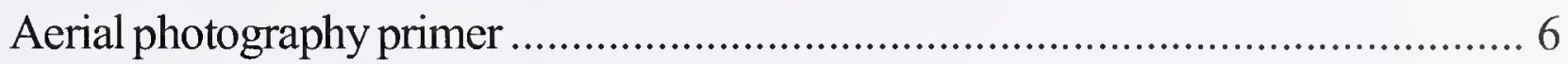

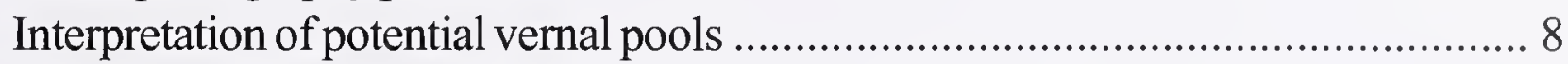

The Massachusetts Aerial Photo Survey of Potential Vernal Pools .................... 10

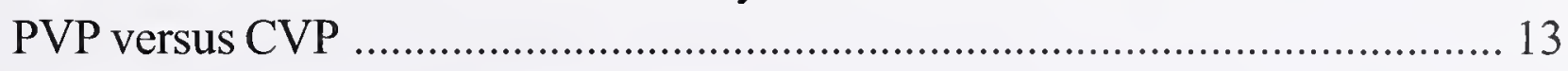

Vernal pool protection in Massachusetts ....................................................... 14

Using the MassGIS Oata Viewer and Potential Vernal Pool Data

NHESP Potential Vernal Pool Metadata: Synopsis of the

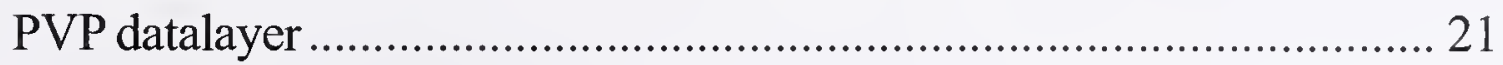

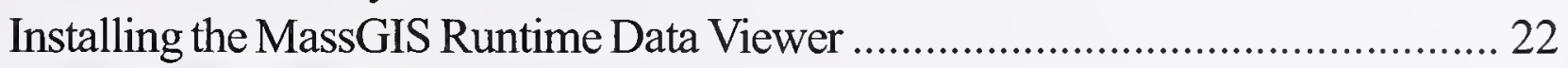

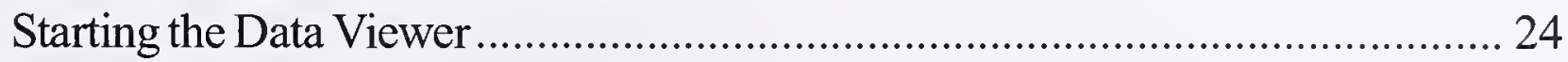

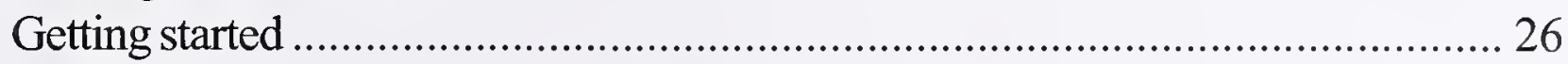

Introduction to ArcView and the MassGIS Data Viewer .................................. 28

Resources

Official Guidelines for the Certification of Vernal Pool Habitat

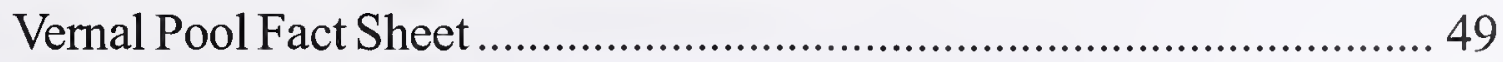

Certification Criteria ....................................................................... 53

Vernal Pool Field Observation Form (perforated) ............................... 57

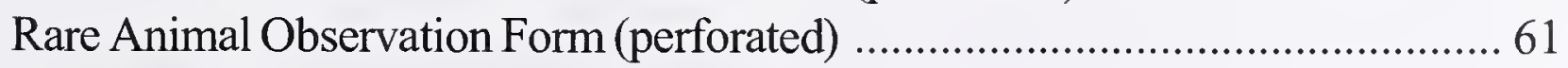

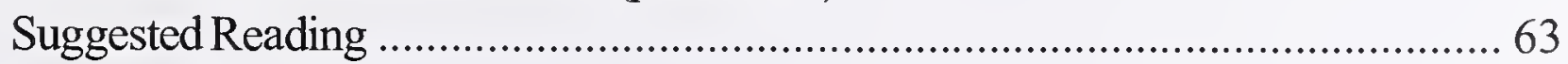

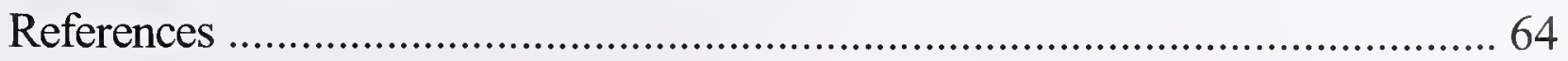

Appendices

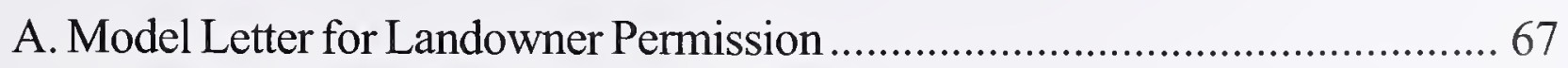

B. Vernal Pool Protection - the Local Bylaw ..................................................... 71 



\section{Aerial Photographic Interpretation of Vernal Pools}

Introduction

Defining vernal pool habitat

Aerial photography primer

Interpretation of potential vernal pools

The Massachusetts Aerial Photo Survey of Potential Vernal Pools

PVP versus CVP

Vernal pool protection in Massachusetts 



\title{
Aerial Photo Survey of Potential Vernal Pools
}

\author{
Aerial Photographic Interpretation of Vernal Pools
}

\section{Introduction}

Interest in vernal pool ecology and the biology of the plants and vertebrate and invertebrate animals that rely on vernal pools has been growing tremendously in Massachusetts, around New England, and beyond. The value of vernal pool habitat as a living classroom, for its diversity of wildlife and ecological processes, has resulted in the inclusion of vernal pool study at many grade levels in school systems throughout the Commonwealth. The importance of vernal pools to the conservation of amphibian and invertebrate wildlife, as well as biodiversity more generally, across the state has also been recognized in recent years. Vernal pools that have been officially "certified" by the Massachusetts Division of Fisheries and Wildlife (DFW) receive important protection under several state wetland protection regulations. Since the certification program relies on the public to collect documentation, it has led to a considerable increase in public awareness and participation in the protection of these important wildlife habitats, as well as the state's other wetland resources, by individuals, community groups, non-government organizations, and local and state government agencies.

Prior to this aerial survey, no comprehensive vernal pool inventory had ever been attempted in Massachusetts. However, the DFW's Natural Heritage \& Endangered Species Program (NHESP) maintains a database of all certified vernal pools, the only statewide database concerning these habitats. This database has grown slowly since it was established in 1988. Data generated by voluntary efforts to identify and document vernal pools constitutes the vast majority of the information it contains. This has resulted in a patchy distribution of certified vernal pools, focused in areas that have had active individuals and groups working to identify them, rather than reflecting the true distribution of vernal pool habitat throughout the state (Figure 1). Reliance on this source of information results in no clear picture of the abundance, distribution or conservation status of vernal pool habitat across Massachusetts. Protection of vernal pools is therefore also inconsistent across the state and 
focused in those areas that have undergone extensive, localized inventories. It is difficult to perform effective or pro-active conservation planning or management for the protection of vernal pool habitats and the biodiversity that they support without first knowing their distribution and the degree to which they are protected.

Aerial photographic interpretation (photogrammetry) enables rapid and large-scale

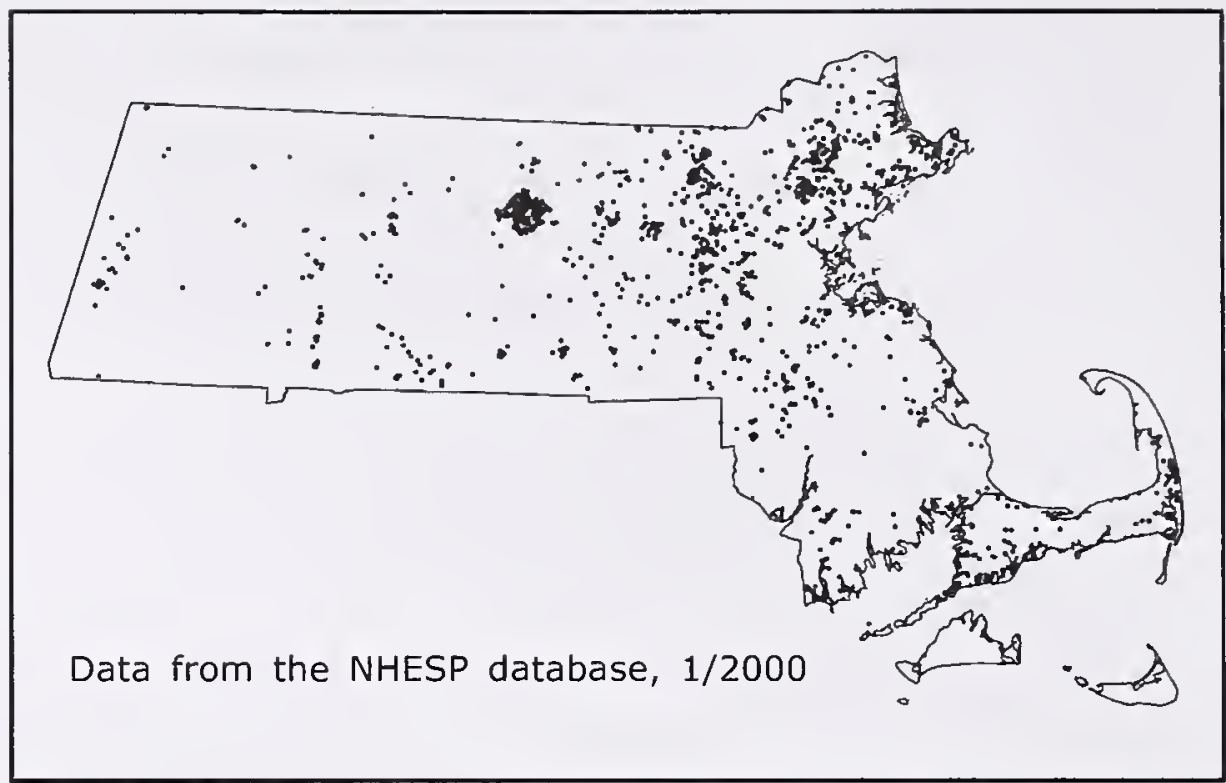

Figure 1: Distribution of Certified Vernal Pools in MA inventories of natural communities and landscape features. Vernal pools are generally visible on certain types of aerial photographs, permitting their inventory by photogrammetry. However, in Massachusetts, vernal pools are defined by the wildlife that use them rather than by the physical characteristics that make them visible on aerial photographs. Since wildlife can not actually be seen on aerial photographs, vernal pools identified on aerial photographs are known as "potential vernal pools" (PVPs) due to the possibility that they do not support vernal pool indicator wildlife. Several scientific studies in Massachusetts have proven that aerial photographic interpretation is highly effective for the identification of potential vernal pools which likely support populations of indicator wildlife (discussed below in Interpretation of Potential Vernal Pools). Aerial photo interpretation represents the best presently available tool for conducting a statewide inventory of potential vernal pool habitat. The NHESP has conducted this survey by interpreting potential vernal pools from $1: 12,000$ scale color infra-red aerial photographs. The potential vernal pools identified during this survey have been digitized in the Massachusetts Geographic Information System (MassGIS), and will be included in the MassGIS library of data. A compact disc has been developed and is included as a part of this publication which contains a stand-alone Runtime Data Viewer software package, selected MassGIS data layers, and the USGS topographic maps of the state. The data viewer allows anyone with an IBM-compatible computer (running Windows $95,98,00$ or NT with a minimum of 32MB RAM) or Macintosh capable of running emulation software to view a map of the state with the USGS topographic maps, some data including town boundaries and major hydrological features, and the points representing all of the potential vernal pools. Zooming into a particular area of interest will allow individuals to print detailed maps of potential vernal pools for use in the field. The potential vernal pool data set 
is also available on the MassGIS website (www.ma.state.us/mgis) which allows anyone with internet access to create maps and print them out from a standard internet browser.

\section{Defining vernal pool habitat}

In Massachusetts, vernal pools are defined rather broadly. They are distinguished primarily by indicator wildlife species and the absence of fish, rather than by physical characteristics such as hydroperiod, landscape position or vegetative community. Vernal pools are generally defined as basin depressions where water is confined and persists for at least 2 months during the spring and early summer of most years, and where reproducing populations of fish do not survive. Specifics regarding hydroperiod, vegetative characteristics, connections to other wetlands and waterbodies and other physical characteristics are the stuff of great debate. What is relied upon above all else is the documented presence of obligate or facultative indicator wildlife.

Vernal pool indicator species (Table 1) are generally able to use wetlands of tremendously varied physiographic conditions if the breeding habitat remains

\section{Obligate species \\ Mole salamanders Spotted Blue-spotted Jefferson Marbled \\ Wood frog \\ Fairy shrimp}

Facultative species Spring peeper American toad Green frog Pickerel frog Gray treefrog Four-toed salamander Spotted turtle Caddisfly larvae Dragonfly larvae Fingernail clams Amphibious snails

Table 1: Some vernal pool indicator species flooded for at least 2 months and is free of established, reproducing fish populations. Defining vernal pool habitat by indicator species rather than specific physical characteristics means that there is a wide diversity of habitat characteristics found in vernal pools. Blue-spotted salamanders (Ambystoma laterale) are as likely to be found breeding in a dense, shrub-dominated wetland as they are a classic kettlehole depression. Hydroperiods, landscape position and vegetation characteristics, among other physical characteristics, run the gamut. Vernal pool habitat therefore occurs in deep kettlehole depressions, among the small pockets of standing water in wooded swamps with pit and mound topography, in open marshes, shrub swamps, fens, interdunal swales, and other wetlands that are free of established, reproducing fish populations, and that contain standing water for at least 2 months in the spring and summer of most years. Vernal pools may be very shallow, holding only 5 or 6 inches of water at their maximum depths, or they may be quite deep. On average though, pools tend to hold 
2-3 feet of water during the spring time maximum flooding. They may be extremely small, fewer than 100 square feet in some cases, or reach several acres in size.

Among the debates over characteristics of the wetlands that may be called vernal pools, the very term is often argued. "Vernal pool" is an apt name for the spring-time pools of California where the term was coined. There, temporary pools are filled with annual spring (vernal) rains and reliably dry by early summer. Vernal pools in Massachusetts tend to begin filling in the fall, and among those that dry every year, many hold water well into the summer or even early fall. In Massachusetts the term is technically a misnomer, but has become inextricably linked to these seasonally-flooded wildlife habitats. Terms such as autumnal pools, seasonal forest ponds, and seasonally flooded depressions may describe these habitats more accurately, but have not begun to replace the widely-used "vernal pool."

\section{Aerial photography primer}

Aerial photo interpretation is used extensively for the inventory and mapping of landscape features, both natural and man-made. Photo interpreters can use tools such as a mirror stereoscope (Figure 2) to view the landscape in an effort to identify features of interest for a particular project. Photographs of the landscape can be taken with satellites from space or with cameras from airplanes resulting in a view looking straight down at the earth's surface. When photographs are taken from directly overhead, a unique perspective is gained that allows the photo interpreter to see landscape features that might be difficult or impossible io distinguish from other vantages. Aerial photographs can be taken such that two sequential photographs viewed under a mirror stereoscope produce a 3-dimensional view of the earth's surface. This phenomenon allows

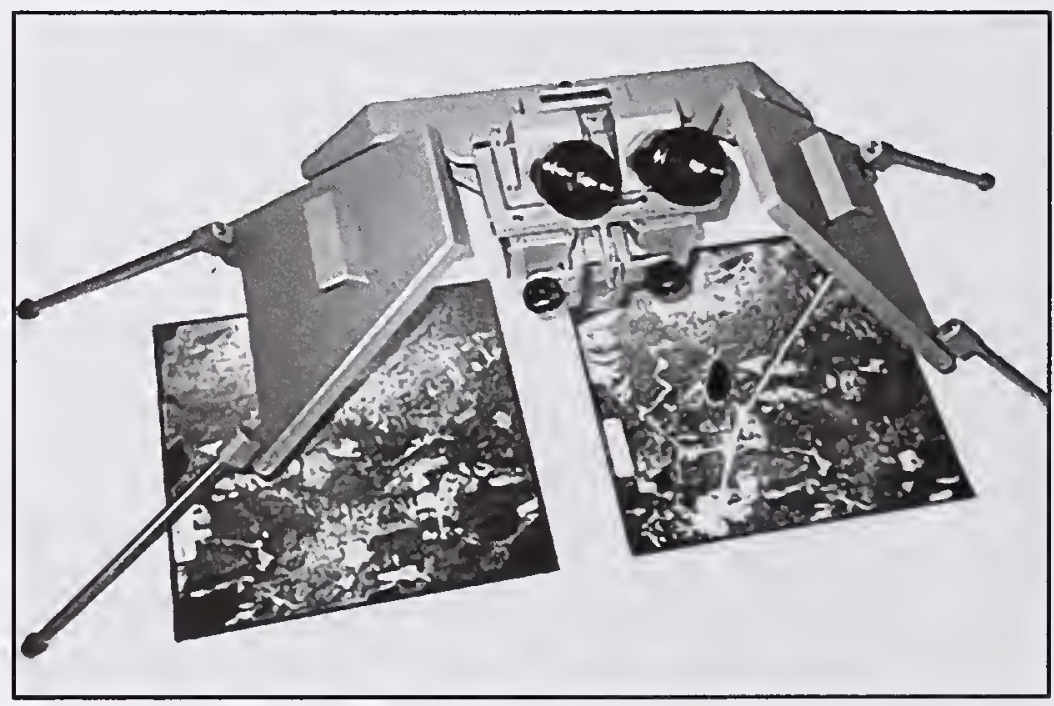

Figure 2: Mirror stereoscope photo interpreters to read topographic features of the ground such as hills and depressions, and even allows the measurement of an object's height. Different landscape features can be emphasized in aerial photographs by selecting from a wide array of possible scales, emulsions (e.g. black and white versus color), and time of year that the images are taken, all of which are discussed below. 


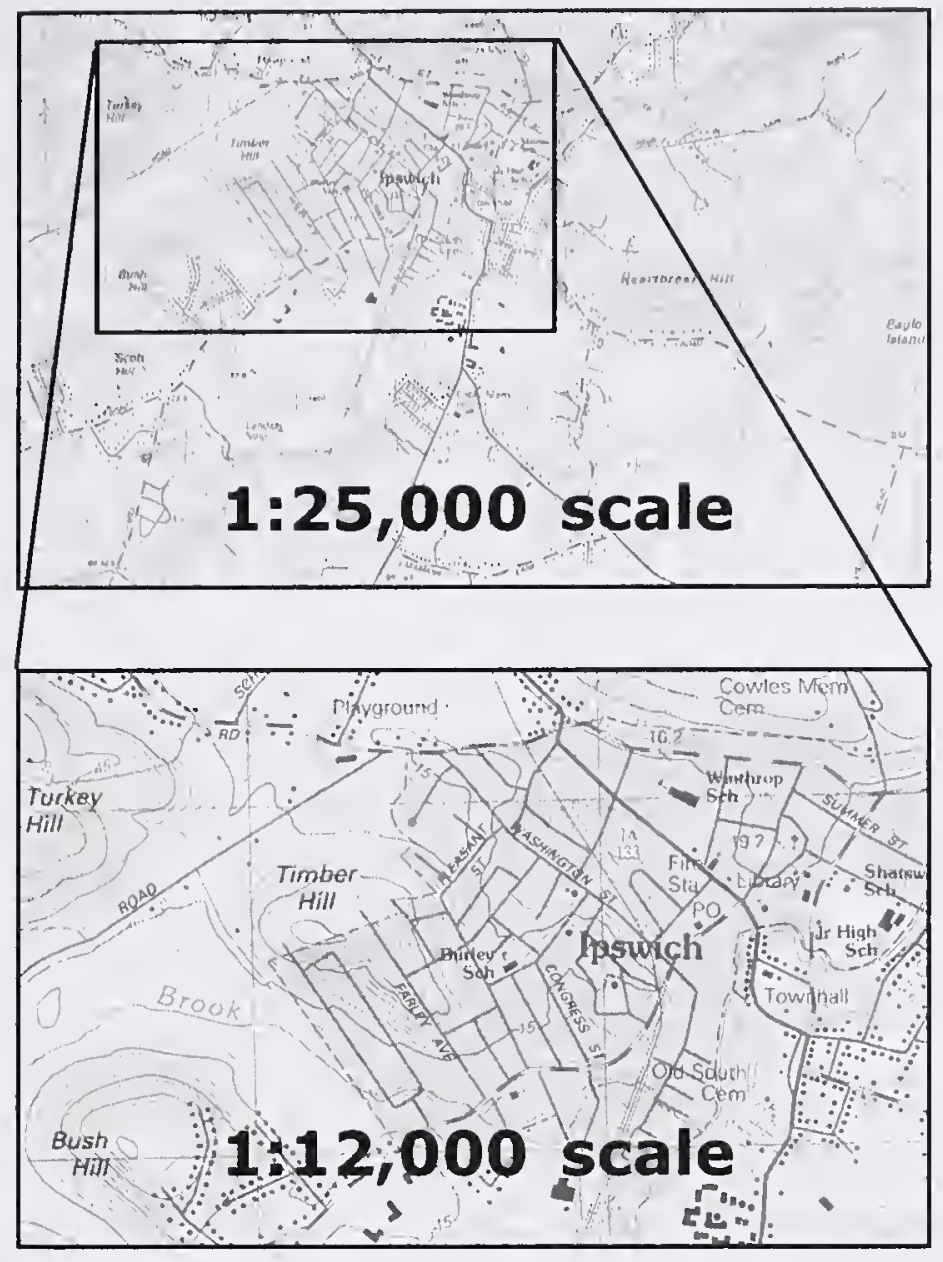

Figure 3: Map scale comparison
The scale of a photograph refers to the number of units (e.g. inches) on the ground surface that the same unit on the photograph represents. For instance, the photographs used to create this survey are at a scale of 1:12,000. On these photos, one inch represents 12,000 inches (or 1000 feet) on the ground. Smaller scale photography (e.g. 1:25,000) provides a view of much more of the earth's surface, while larger scale photography, such as 1:12,000, shows considerably more detail (Figure 3 ). However, covering large areas with larger scale photography requires many more individual pictures and much more time to interpret. In selecting the appropriate photographic scale for a particular project, photo interpreters balance the benefit of greater detail with the costs of increased effort associated both with obtaining and interpreting greater numbers of photographs. 1:12,000 scale photographs allow for fairly small vernal pools $\left(<100^{\prime}\right.$ diameter) to be identified, yet cover the state with a reasonable number of individual images (approximately 10,000).

Aerial photographs are available in different film emulsions such as black and white, true color and color infra-red (CIR). Color infra-red film is very commonly-used in wetland and vegetation mapping. It is sensitive to wavelengths of light from the infra-red portion of the light spectrum. Different types of vegetation reflect various amounts of infra-red light and create unique "signatures" that allow photo interpreters to distinguish different vegetation types (conifer versus deciduous trees), associations, and even individual species. This type of film is also very useful to wetland mapping efforts since standing water appears dark blue to black and is quite distinctive.

The time of year at which photographs are taken is also an important tool in highlighting various features of the landscape that might be of interest. In areas of deciduous trees, prior to "leaf-out" in the spring, the ground surface can be clearly seen. Leaf-off photography is very useful in distinguishing the edges of water bodies that are obscured as leaves come out on canopy trees, and is critical to detecting small features on the landscape that can be completely obscured when the tree canopy is fully leafed-out. As the spring progresses, a period of early leaf emergence, called "first blush," can be photographed to 
help distinguish between different hardwood tree species. Full leaf-out photographs are useful in identifying major vegetation associations, but are nearly useless for identifying small features underneath the tree canopy.

\section{Interpretation of potential vernal pools}

Use of color infra-red (CIR) leaf-off aerial photography for interpretation of wetlands is particularly effective. Open water bodies appear as black features and different vegetation types have distinctive signatures that allow skilled interpreters to distinguish between various plant species and communities. "Classic" vernal pools, isolated basin depressions with little or no vegetation, are readily interpreted from this type of photography. Without leaves obscuring the forest floor, the standing water of springtime vernal pools stands out within topographic depressions. For the classic pool, size becomes a primary consideration. Very small pools at the lower limit of resolution (< 60 ' diameter) are unreliably interpreted at the scale of 1:12,000. Surrounding forest cover also becomes important as size decreases. Coniferous forest cover obscures all but the pools that are large enough to create a gap in the canopy. Pools that have well-developed shrub or emergent vegetation are often easily identified by the standing water and vegetation "signatures" on spring-time CIR photography.

Several studies conducted in Massachusetts have demonstrated the effectiveness of aerial photo interpretation of vernal pool habitat. The first study to specifically address this tool for use in vernal pool identification was a Master's thesis by Janice Stone (1992) at the University of Massachusetts Amherst. She showed that 1:4800 scale black and white aerial photographs could be used effectively to identify vernal pools that were providing habitat to obligate vernal pool-breeding species (mole salamanders, wood frogs and fairy shrimp). While this proved that aerial photography could be used for identifying vernal pools, the scale of photography was not useful for large areas, such as a statewide inventory. The NHESP performed a small-scale test of the effectiveness of 1:12,000 scale color infra-red aerial photographs in 1996. The use of this scale and emulsion proved highly effective, with greater than $90 \%$ of the interpreted "potential vernal pools" verified in the field as providing habitat to vernal pool obligate species (unpubl. data, NHESP). Brooks, Stone and Lyons (1998) reported that interpretation of 1:12,000 scale CIR photography for seasonal forest ponds, wetlands that typically function as vernal pool habitat, was very effective in the large Quabbin Reservoir 
watershed. They reported that the quality of photography and experience of the interpreter resulted in very limited errors of commission (identifying something, such as a tree shadow, as a seasonal forest pond that was not actually a waterbody), less than $5 \%$. Furthermore, among a sample of interpreted seasonal forest ponds, greater than $85 \%$ that were field verified during the spring amphibian breeding season were found to function as vernal pool habitat. In 1999 the NHESP conducted its second trial using 1:12,000 scale CIR photographs across a randomly selected sample of aerial photographs in Barnstable, Plymouth, Essex, Middlesex and Worcester Counties. Errors of commission were extremely low $(<3 \%)$, and greater than $80 \%$ of the potential vernal pools that were field-verified were providing breeding habitat to vernal pool indicator species (unpubl. data, NHESP). The year in which this second test was conducted experienced an extremely dry spring where many vernal pools dried up completely as early as the end of April. This affected the number of pools that could be confirmed to provide vernal pool habitat. It is expected that, in a more typical year, even better results would have been achieved.

While aerial photo interpretation is very effective in the identification of potential vernal pools, it is not a fool-proof method of inventorying all vernal pool habitats that exist in the survey area. Two types of error occur in any resource mapping using aerial photographs: errors of commission and errors of omission. When interpreting vernal pool habitat, errors of commission are those in which a feature on the photograph is identified as a vernal pool when, in fact, it is not. Shadows of large trees can be mistaken for a small ponded water body, for example. The quality of $1: 12,000$ scale CIR photography is excellent. However, as interpreters attempt to identify pools that are extremely small, the reliability of the interpretation becomes compromised (Brooks et al, 1998). Errors of commission also occur when a water body is identified as a vernal pool when it does not, in fact, meet the required physical or biological characteristics required to classify it as a vernal pool. For instance, a ponded waterbody might dry extremely quickly after a significant rain storm filled it. Photo interpreters will often be unable to distinguish these very ephemeral waterbodies from more permanent ones that will function as vernal pools. These types of errors occur infrequently, but must be acknowledged in any survey produced by aerial photo interpretation. Errors of omission are the other common error in aerial photo interpretation. These occur when an existing feature, such as a vernal pool, is overlooked. As discussed above, very small vernal pools can not be identified with great reliability in all circumstances. 
This is particularly true in areas where tree shadows may obscure the forest floor and where topographic relief is slight and gives no additional clues to the interpreter. In areas with a lot of evergreen vegetation, it is difficult or impossible to see the forest floor. Photo interpretation of vernal pool habitat, or other features on the ground, is typically very difficult and particularly subject to errors of omission and commission in these areas. Furthermore, as leaf-out progresses through the spring, the forest floor is increasingly obscured in areas of deciduous tree cover when photography is taken later in the year (after early to mid May in Massachusetts), and interpretation can be compromised.

\section{The Massachusetts Aerial Photo Survey of Potential Vernal Pools}

The compact disc enclosed in this publication presents the loci of potential vernal pools in Massachusetts that were identified from 1:12,000 scale color infra-red aerial photographs. This statewide coverage includes the survey of Plymouth and Bristol Counties published in the spring of 2000. The Massachusetts Potential Vernal Pool Survey has been produced for several reasons. It provides an overview of the number and spatial distribution of vernal pool habitats in the state. This provides an important tool for conservation planning with respect to vernal pool habitat. By having an estimate of the number of vernal pools in the region, and a picture of their distribution, it will be possible to better direct acquisition and regulatory protection efforts for vernal pools. Vernal pool education and certification initiatives should also greatly benefit from the production of this survey. It will provide the loci of a tremendous number of potential vernal pools in the state to landowners, school and community groups, non-government organizations and non-profit organizations, as well as local, state and federal government agencies.

Aerial photos used in the Massachusetts Potential Vernal Pool Survey include images acquired in 1993, 1999, and 2000 (Figure 4). While generally of exceptional quality, the Massachusetts Aerial Photo Survey of Potential Vernal Pools contains a few problem areas resulting from photo quality or other related causes. Stereo pairs were not available for the outer arm of Cape Cod (from the eastern half of Brewster/Harwich north to Provincetown) and for all of Nantucket. Photo interpretation therefore was done without the aid of topographic relief or the magnification of a stereoscope. It is expected that more errors of omission and commission will be found in these areas of the state. The coastal dune systems from Barnstable to the outer tip of 


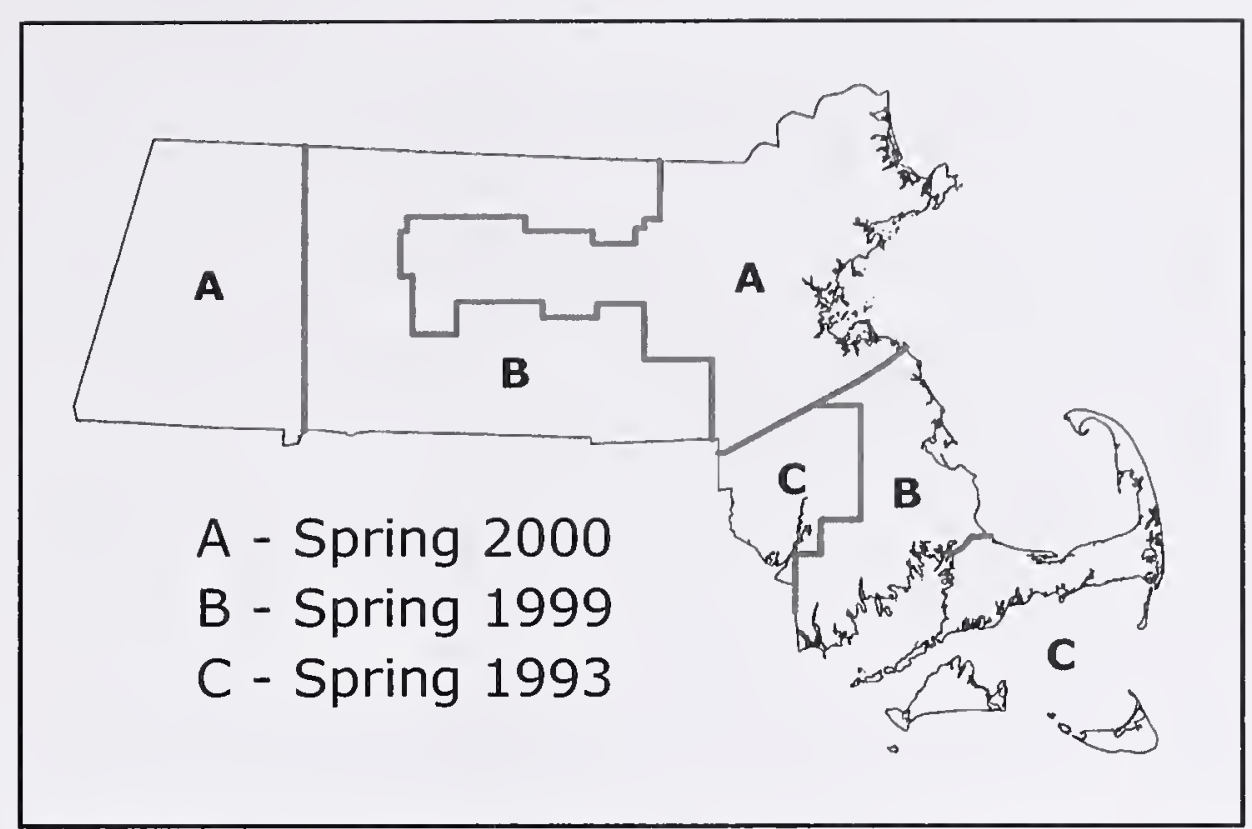

Figure 4: Aerial photo project areas and dates of photography
Provincetown contain tremendous numbers of interdunal swales. These quite often provide breeding habitat for Fowler's and spadefoot toads, facultative invertebrates, and other vernal pool indicator species.

Accurate interpretation of vernal pools among these interdunal swales is difficult however, and it is expected that errors are more common among the potential vernal pools interpreted from

the dune systems of Cape Cod, the Islands, and the north shore. Initial surveys of some potential vernal pools in Bristol County indicate that there may be more errors of commission than in other parts of the state. This may be due in part to comparative wetness of the photos used for interpretation in that county. It is expected that fewer than $80-85 \%$ of potential vernal pools in Plymouth and Bristol Counties will likely support breeding populations of vernal pool indicator wildlife. 1999 photos used for Plymouth County were flown very late in the spring (mid to late May), and suffered from early leaf out conditions which increases the probability of errors of omission. Over the western half of the county, much of the forest floor was obscured by tree canopy leaves, affecting the interpretation of smaller pools that do not have an open tree canopy. The floodplains of the Connecticut River and some of its tributaries were extremely wet in the photography used. This results in a probable underaccounting of the myriad potential vernal pools found among the sloughs, backwaters, and oxbows of large river floodplain systems. The spring 2000 photos for Berkshire County had some areas of snow which obscure all features. As a result, approximately 16,000 acres in southern Berkshire County (Figure 5) were not interpreted for potential vernal pools. Spring 2000 photos of central Worcester county west of Barre, through Petersham, were extremely dark and therefore lacked sufficient detail for high confidence in the interpretation of potential vernal pools in that portion of the state.

Photo interpretation itself has limitations and sources of error. Very small vernal pools are difficult to identify even with the highest quality photography. Pools as small as $\sim 42^{\prime}$ diameter (0.0042" on the photograph) 
were occasionally identified. However, pools smaller than about $50-60$ ' in diameter could not reliably be identified. Pools between $60^{\prime}$ and $125^{\prime}$ diameter were easily confused with tree shadow and some types of man-made features. Pools of $125^{\prime}$ diameter ( $1 / 8$ " on the photographs) and larger could be reliably identified when photos were of fair to excellent quality, and where evergreen trees were not dominant. The upper size limit of potential vernal pools is quite difficult to establish, and is generally

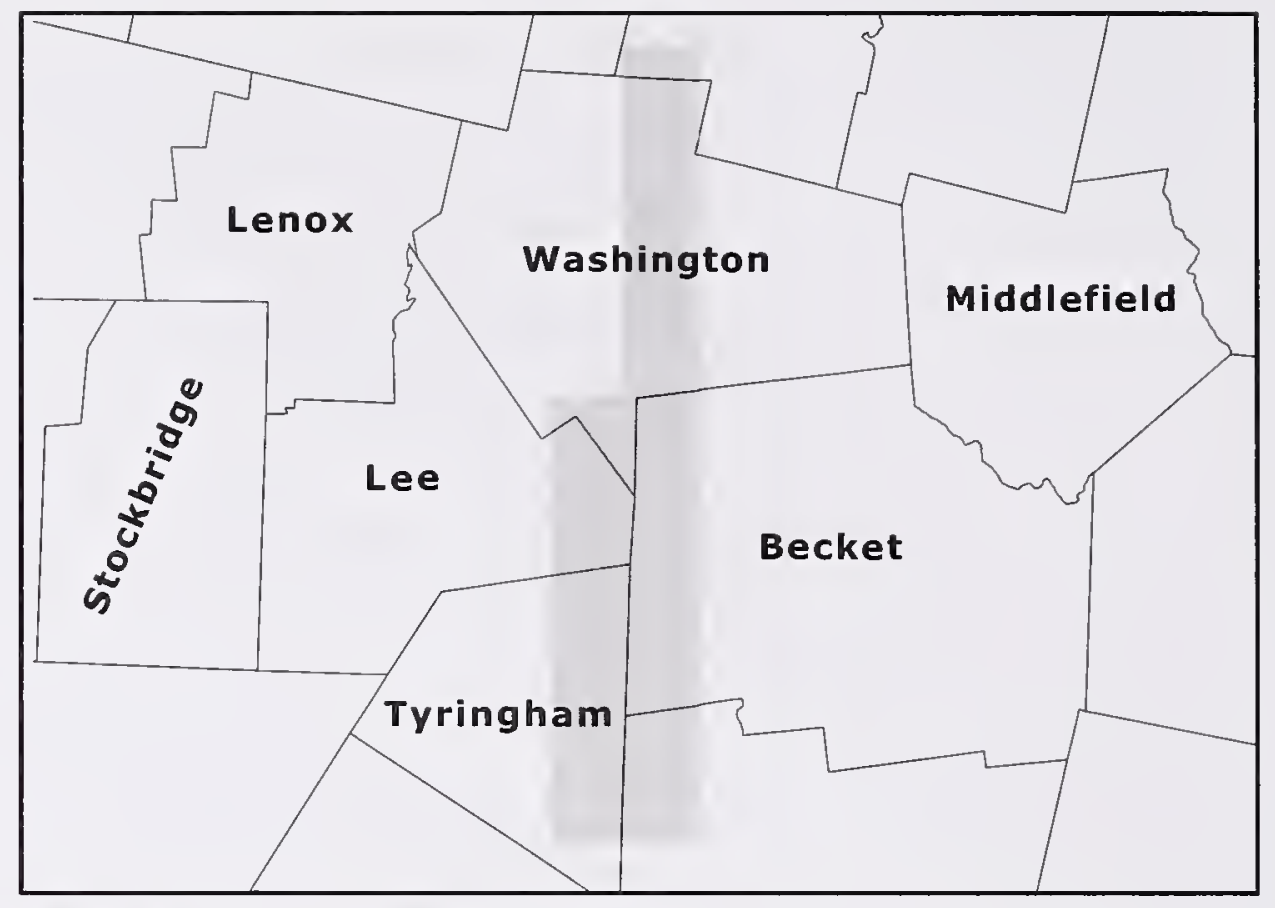

Figure 5: Area affected by snow in So. Berkshire Co. a subjective call. Some very large features were pulled out as potential vernal pools when connections to other water bodies did not appear to exist, and where vegetation signatures suggested that the hydroperiod was not permanent. Farm ponds and other obviously man-made waterbodies were generally avoided where it was possible to do so. Furthermore, any potential vernal pool with more than $50 \%$ of the shore line in managed vegetation (lawns, crops, etc.) was not included as a rule.

It is important to understand that this potential vernal pool survey does not include all vernal pools in the state. Omission due to unfavorable conditions in the landscape topography, pool physiography and/or photograph quality (i.e. errors of omission, discussed above) result in vernal pools that are missed by photo interpretation. Furthermore, vernal pool habitat occurs in a wide variety of landscape settings, including within forested swamps, bogs, and other wetlands; within these settings vernal pools will typically not be photo interpreted, but nonetheless provide legitimate and valuable vernal pool habitat.

MassGIS has produced a special compact disc with the Potential Vernal Pool datalayer, select MassGIS data for the state of Massachusetts, and a stand-alone Runtime Data Viewer application. Instructions for installing the data viewer begin on page 22. The potential vernal pool data may be viewed over USGS topographic maps and select MassGIS data to help identify the exact loci of pools. Additional datalayers can be downloaded from the MassGIS website (www.state.ma.us/mgis), including black and white aerial photographs and boundaries of conservation and open space lands, for example, to create customized maps with the runtime data viewer. 


\section{PVP versus CVP}

Potential vernal pools (PVP) identified in this survey are not to be confused with certified vernal pools (CVP). Evidence of amphibians or invertebrates using a vernal pool, in addition to proof that the pool does not support an established, reproducing fish population must be presented to the Natural Heritage \& Endangered Species Program for certification to obtain official standing as a certified vernal pool under state wetlands protection laws. Potential vernal pools identified in this survey do not automatically receive protection under the Massachusetts Wetlands Protection Act Regulations (310 CMR 10.00), nor under any other state or federal wetlands protection laws that have specific language protecting certified vernal pools. However, the Wetlands Protection Act regulations allow the local conservation commission to protect the wildlife habitat value of any resource area when it is demonstrated to be important to wildlife. This demonstration can be through the presentation of clear scientific evidence (such as that required for official certification) at any time during the public hearing process.

It is important to note that there are considerable differences in the precision with which the locations of vernal pools are mapped in both the potential vernal pool and certified vernal pools data layers. The potential vernal pools identified by aerial photo interpretation are actually located with much greater precision than the points representing certified vernal pools in the MassGIS. Potential vernal pools are digitized at a scale of approximately 1:12,000 on rectified orthophotographs. At that scale, points representing potential vernal pools have a precision equal to less than $+/-15$ feet or so from the center of an interpreted pool. Note that as the view of a map in the data viewer is zoomed in to larger and larger scales, the point representing a potential vernal pool will migrate away from the true center of the pool because the point was drawn at 1:12,000 scale. Certified vernal pools are currently digitized by generating a latitude and longitude number measured on a paper 1:25,000 scale USGS topographic map. Measurements made on these maps have a precision of approximately $+/-50$ feet in any direction. Therefore, when comparing the PVP layer to the CVP layer there may well be some disagreement between the two points representing the same vernal pool. It may appear that the two layers do not match up when looking at points representing the same pool. The local conservation commission is sent copies of the maps that are submitted to the NHESP for certification. To be certain 
about the location of a certified vernal pool relative to potential vernal pools that you might be working with, visit the conservation commission office and ask to view the file they received from the NHESP when the pool was certified. In addition, the layers are not exactly the same; some certified vernal pools can not be seen on the aerial photographs (for various reasons) and are therefore not included in the PVP data, and the vast majority of potential vernal pools have not been certified.

So please take care in interpreting the differences in the PVP and CVP datalayers, understanding that there will be inconsistencies between the two, both real and perceived.

\section{Vernal pool protection in Massachusetts}

Massachusetts has long been one of the most progressive states in the nation in protecting wetlands. It has been a leader in the protection of vernal pools through implementation of regulations and programs that have resulted in the identification and regulation of more than 2000 of these important wildlife habitats. Vernal pools are protected under the Massachusetts Wetlands Protection Act regulations (310 CMR 10.00), Surface Water Quality Standards (314 CMR 4.00), subsurface sewage disposal regulations (Title 5: $310 \mathrm{CMR}$ 15.000) and the Forest Cutting Practices Act regulations (304 CMR 11.00). Many communities across the Commonwealth have also enacted additional protection through local bylaws (see Appendix A) that can significantly increase the protection of vernal pools beyond that which state regulations provide.

Wetlands Protection Act. Prior to 1986, the wildlife habitat function of wetlands was not protected by the Massachusetts Wetlands Protection Act (WPA, M.G.L. c. $131 \S 40$ ). Revisions to the Act in 1986 added wildlife habitat as a protected "statutory interest" to be considered when permitting work in and around wetlands. Vernal pools were recognized as important but often overlooked wildlife habitats. However, their protection was not made automatic because "it would be unfair to applicants to require them to conduct difficult, timely, expensive, and often inconclusive searches for possible vernal pools" (Wetlands Protection Act Regulations Preface, 1987). Thus, the vernal pool certification program was developed for use with the Wetlands Protection Act regulations to identify and map vernal pools that meet established physical and biological criteria. The program is administered by the Natural Heritage \& Endangered Species Program (NHESP) of the Massachusetts Division of Fisheries and Wildlife. The 
certification program was developed to inform applicants, conservation commissions and regulators of the occurrence of vernal pool habitat in advance of project proposals.

Through the Massachusetts Wetlands Protection Act regulations, local conservation commissions regulate building and development that is proposed within and adjacent to wetlands across the state. The Act protects wetland functions, referred to as the "interests of the Act." Its regulations (310 CMR 10.00) define wetland resource areas, the inland and coastal wetlands that fall under the jurisdiction of the Act, and establish presumptions of significance for each resource area. These presumptions establish the interests of the Act that are supported by each jurisdictional wetland type. Presumptions of significance are rebuttable upon a clear showing, through the presentation of scientific evidence, that a wetland resource area functions in a manner that is inconsistent with the presumptions in the regulations for that wetland type. All jurisdictional inland wetlands except Isolated Land Subject to Flooding (ILSF) and portions of Bordering Land Subject to Flooding (BLSF) are presumed significant to the protection of wildlife habitat. ILSF is defined as "isolated depression or closed basin [wetlands] without an inlet or an outlet" that, at least once a year, "confine standing water to a volume of at least 1/4 acre-feet and to an average depth of at least six inches." Since ILSF does not carry a presumption of significance to wildlife habitat, it cannot be protected for the wildlife habitat interest unless it is shown, by a preponderance of evidence, that it is significant to that interest. The official vernal pool certification program was originally developed to document cases where ILSF and BLSF were functioning as vernal pool habitat, and therefore significant to the protection of the wildlife habitat value protected by the Act. It is notable that in the years since 1987, the NHESP has found no instance where an ILSF does not function as vernal pool habitat.

In collaboration with biologists and regulators, the NHESP developed the official vernal pool certification program. Criteria were established for the documentation of the physical and biological characteristics of vernal pool habitat consistent with the definition in the regulations. The process typically involves volunteer effort in the documentation of the physical and biological characteristics of vernal pool habitat and submission to the NHESP for review. If the vernal pool meets the requirements of the official Guidelines for the Certification of Vernal Pool Habitat, the NHESP certifies the pool and notifies the local conservation commission and the Massachusetts Department of Environmental Protection's (DEP) Regional Office. Biennially, the NHESP creates and distributes maps with the locations of certified vernal pools for use by town conservation commissions, DEP staff, and project applicants to be able to identify certified vernal pools during the permitting process.

The NHESP certifies any depressional area where vernal pool indicator species are documented, provided that it holds water for at least 2 months during the spring and summer of most years and is free of established fish populations. However, certification of a vernal pool does not mean that the pool is automatically protected by the Wetlands Protection Act 
regulations; certified vernal pools are not themselves jurisdictional wetlands. If a certified vernal pool does not occur within a wetland protected by the Act, there is no jurisdiction over that pool, and the pool is therefore not protected under the Wetlands Protection Act. However, when a certified vernal pool falls within a jurisdictional wetland (e.g., ILSF or Bordering Vegetated Wetland), the regulations protect the pool and up to 100 feet beyond its boundary, referred to as the "vernal pool habitat." The vernal pool and associated "habitat" must exist within the boundaries of a jurisdictional wetland; no upland areas are protected under the Wetlands Protection Act (there is an exception to this under the Rivers Protection Act, discussed below). The NHESP defines the boundary of vernal pools, wherever they occur, as the maximum observed or recorded extent of flooding in a confined basin depression, or evidence of the same (e.g. leaf staining, etc.).

The regulations protect the wildlife habitat value of a certified vernal pool through general performance standards for proposed projects (310 CMR 10.57(4)(a)3 and (b)3). There is no threshold, or minimum size project, that is presumed to have no impact on certified vernal pool habitat, and no alteration of vernal pool habitat is permissible that would "impair [the resource area's] capacity to provide important wildlife habitat functions." Therefore, any project that would alter a certified vernal pool must demonstrate that there would be no substantial reduction in the pool's capacity to provide food, shelter, migratory and breeding areas, and overwintering areas for amphibians, or food for other wildlife. No changes to the topography, soil structure, plant community composition and structure, or hydrologic regime are permissible if, after 2 growing seasons, the habitat functions listed above would be substantially reduced.

Rivers Protection Act. The Wetlands Protection Act was again amended in 1996 (originally proposed as a separate Act, the Rivers Protection Act was ultimately passed as an amendment to the WPA), establishing a new wetland resource area called the Riverfront Area that extends 200 feet from the banks of perennial streams. The regulations (revised 1997) for this new resource area include specific protection for vernal pools, both certified and not. Where a vernal pool within the Riverfront Area is certified prior to the filing of a Notice of Intent, there is a strict performance standard that prohibits any project that will have any adverse effect on the wildlife habitat value of the vernal pool. For vernal pools that are not certified, yet are identified with evidence from a competent source during project review, a project must have "no significant adverse impact" on its ability to provide vernal pool habitat. 
Specific standards for uncertified vernal pools are a departure from the vernal pool protection under the remainder of the Wetlands Protection Act regulations.

The Riverfront Area encompasses all lands within 200 feet of perennial streams. The wildlife habitat value of the entire 200 foot-wide Riverfront Area may be protected under 310 CMR 10.58. Therefore, unlike the protection provided to the wetland resource areas by the remainder of the Act, the provisions for Riverfront Area allow protection of the important habitat functions of uplands adjacent to vernal pool habitat. A growing body of research indicates the tremendous importance of upland areas to wetlanddependent wildlife populations (Burke and Gibbons, 1995; Dodd and Cade, 1998; Semlitsch, 1998). Surrounding uplands provide critical non-breeding habitat for animals that are largely terrestrial after completing their larval stage. Both vernal pools and adjacent uplands that occur within the Riverfront Area are protectable. Protection of uncertified vernal pools and adjacent uplands were important developments in the protection of vernal pool habitat developed under the Riverfront provisions of the Wetlands Protection Act. All vernal pool habitat, certified or not, within the Riverfront Area is protected, as is the associated upland, non-breeding habitat occurring within the 200 foot Riverfront Area.

Surface Water Quality Standards. The current Massachusetts Surface Water Quality Standards (314 CMR 4.00) were adopted in 1990 by the DEP's Division of Water Pollution Control to protect public health and enhance the quality and value of the water resources of the Commonwealth. The Standards implement the Massachusetts Clean Water Act (M.G.L. c.21, \$26-53), "which directs the Division to take all action necessary or appropriate to secure to the Commonwealth the benefits of the Federal [Clean Water] Act. The objective of the Federal Act is the restoration and maintenance of the chemical, physical and biological integrity of the Nation's waters" (314 CMR 4.01(4)). Before the US Army Corps of Engineers may issue a federal Clean Water Act permit for activities proposed in "waters of the United States" (federal wetlands) that occur within the Commonwealth, a project must obtain a 401 Water Quality Certification (314 CMR 9.09). 401 Water Quality Certifications are issued by the DEP for projects that meet the requirements of the Massachusetts Surface Water Quality Standards (314 CMR 4.00).

The Surface Water Quality Standards designate certified vernal pools as Class B Outstanding Resource Waters (ORWs, 4.06(2)(a)). They are protected by antidegradation provisions (314 CMR 4.04(3)) that prohibit any new or increased discharge of pollutants. "No discharge of dredge or fill 
material shall be allowed to a [certified] vernal pool." (314 CMR $4.06(1)(d)(11))$. These regulations relate directly to the federal Clean Water Act. Therefore, the vernal pool must occur within a wetland under federal jurisdiction, and the activity proposed must also trigger federal jurisdiction. Similar to the Wetlands Protection Act, the protection provided by the Surface Water Quality Standards end at the boundary of the jurisdictional wetland, in this case a water of the United States, as determined by federal wetland delineation standards.

Title 5. Title 5 of the Massachusetts Environmental Code (310 CMR 15.000) protects certified vernal pools by establishing minimum setbacks from their boundaries for subsurface sewage disposal (septic) system components. Septic tanks must be sited at least 50 feet, and soil absorption systems (leach fields) and their reserves a minimum of 100 feet from the boundary of a certified vernal pool. The leach field setback may be reduced to 50 feet where an applicant provides hydrogeologic data that demonstrates that the location of the leach field is hydraulically down-gradient of the vernal pool.

The effective implementation of these regulations requires local boards of health to check with their conservation commission for the locations of certified vernal pools before permitting septic system plans. Title 5 only protects vernal pools certified prior to application for septic system permits.

Forest Cutting Practices Act. The Forest Cutting Practices Act regulations protect vernal pools from certain forest harvesting impacts, and include protection for both certified and uncertified vernal pool habitat. Harvesting around certified vernal pools is restricted to cutting no more than $50 \%$ of the basal area of trees within 50 feet of the pool. The regulations require that no trees or tree tops be felled in vernal pool depressions and that skidder trails not traverse them. They also prohibit their use as staging areas. Vernal pools that have not been officially certified but are located by a service forester may also be protected. The regulations contain guidelines for activities around these pools that are similar to the requirements for forestry practices performed near certified vernal pools. 


\section{Using the MassGIS Data Viewer and Potential Vernal Pool Data}

NHESP Potential Vernal Pool Metadata:

Synopsis of the PVP datalayer

Installing the MassGIS Runtime Data Viewer

Getting started

Introduction to ArcView and the MassGIS Data Viewer 



\section{NHESP Potential Vernal Pool Metadata: Synopsis of the PVP datalayer}

-January 2001

\section{OVERVIEW}

This datalayer identifies the locations of potential, unverified, vernal pool habitat. Vernal pools are small, shallow ponds characterized by lack of fish and annual or semi-annual periods of dryness. Vernal pool habitat is extremely important to a variety of wildlife species including some amphibians that breed exclusively in vernal pools, and other organisms such as fairy shrimp which spend their entire life cycles confined to vernal pool habitat.

Potential vernal pools visible on aerial photographs were interpreted and digitized on the MassGIS This datalayer does not include every vernal pool in Massachusetts. Many vernal pools have not been identified due to unfavorable conditions in the landscape topography, pool physiography and/ or photograph quality. Furthermore, vernal pool habitat occurs in a wide variety of landscape settings, including forested swamps, bogs, and other wetlands. Vernal pools within these settings were not typically interpreted, but are nonetheless legitimate and valuable vernal pools. Also, field verification of all potential vernal pools in this study will identify errors such as the inclusion of features that are not actually vernal pools.

Potential vernal pools identified in this survey are not to be confused with Certified Vernal Pools. Data pursuant to the official "Guidelines for the Certification of Vernal Pool Habitat" must be collected in the field and presented to the Massachusetts Natural Heritage \& Endangered Species Program to obtain official certification for a vernal pool. Potential vernal pools identified in this survey do not receive protection under the Massachusetts Wetlands Protection Act Regulations (310 CMR 10.00), or under any other state or federal wetlands protection laws.

\section{PRODUCTION}

Potential vernal pools were identified from 1:12,000 scale, color infra-red (CIR), leaf-off aerial photographs flown between late March and Early May. Statewide coverage included photos taken in 1993 (Bristol, Barnstable, Nantucket and Dukes Counties), 1999 (Plymouth, northern and southern Worcester, and eastern Franklin, Hampshire and Hampden Counties), and 2000 (Essex, Middlesex, Suffolk, Norfolk, central Worcester, western Franklin, Hampshire and Hampden, and Berkshire Counties). Using stereo pairs under a mirror stereoscope, the approximate centers of pools were located. These points were digitized in a heads-up manner onto the MassGIS black and white digital orthophotos at a scale of approximately 1:12,000.

\section{ATTRIBUTES}

The datalayer contains a field called Pvp_id that identifies each Potential Vernal Pool by a unique alphanumeric code. The digits correspond to the Town names in alphabetical order.

\section{AVAILABILITY}

This datalayer may be made available to EOEA agencies and EOEA cooperators for certain projects. The legend that MUST accompany this datalayer on all maps is:

\section{"NHESP Potential Vernal Pools: NOT equivalent to Certified Vernal Pools"}




\title{
Installing the MassGIS Runtime Data Viewer
}

\author{
PC System Requirements \\ Hard Drive: $\quad$ 40MB for Data Viewer software \\ RAM: $\quad 32$ megabytes \\ Operating System Windows 95 or higher (including NT) \\ CD-ROM drive
}

Note: If you currently have a version of the MassGIS Runtime Data Viewer on your machine, or if you have had it in the past and not completely removed it (including any program or data folders), this disk will not run properly. Instructions for a complete uninstall are on page 25 .

\section{Step-by-step instructions}

1) Close any programs that are running before running the installation

2) Insert CD into the CD-ROM tray

3) Determine the letter designation of your CD-ROM drive. You will need this after installing the program when you run it for the first time. If you are unsure of the letter designation for the drive

a) Open Windows Explorer

b) Scan the list in the left window for the CD-ROM icon. It should be labeled with "Potentialvernalp [drive letter]"

c) Make note of the drive letter

\begin{tabular}{|c|c|c|c|c|}
\hline \multicolumn{5}{|l|}{ (2) Exploring - Potentialvemalp (E) } \\
\hline Eile Edit Viewr Go Favonites Iools Holp & & & & $\theta$ \\
\hline \multicolumn{5}{|l|}{ Address $\Leftrightarrow \mathrm{E}:$} \\
\hline All Folders & Name & Size & Type & 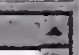 \\
\hline (1) Desklop & Jola & & File Folder & \\
\hline & Gisdala & & File Folder & \\
\hline 79 My Computer & Program & & File Folder & \\
\hline (t) $(\mathrm{C})$ & A__inst32iex_ & $284 \mathrm{~KB}$ & EX_File & \\
\hline (t) $(\mathrm{D})$ & 曾_isdel & 8KB & Application & \\
\hline (7) Polentialvemalp [is: & [.]._sys1. cab & $201 \mathrm{~KB}$ & CAB File & \\
\hline 7. Private@FE.CPent 25@Servers on 'Street Talk. & a]_user1.cab & $46 K B$ & CAB Fle & \\
\hline \multirow{2}{*}{$\begin{array}{l}\text { 1. Arev on 'StreetTalk KWorkGroup@PWE. CPent 2E } \\
\text { T WorkGroup@FWE.CPent.25@Servers on 'Streel - }\end{array}$} & [a] data tag & IKB & TAG File & \\
\hline & (1) datal cab & $1,553 \mathrm{~K} \mathrm{~B}$ & CAB File & -1 \\
\hline II $\quad 1 \quad 1$ & & & & $1 \sqrt{6}$ \\
\hline
\end{tabular}
designation, and close Windows Explorer

4) Click the Start button at the Windows Desk Top

5) Click Run...

6) Type E:ISetup.exe

Note, you must type the letter of your own CDROM drive, as determined in step 3, above. It may not be $\mathrm{E}$ as in this example

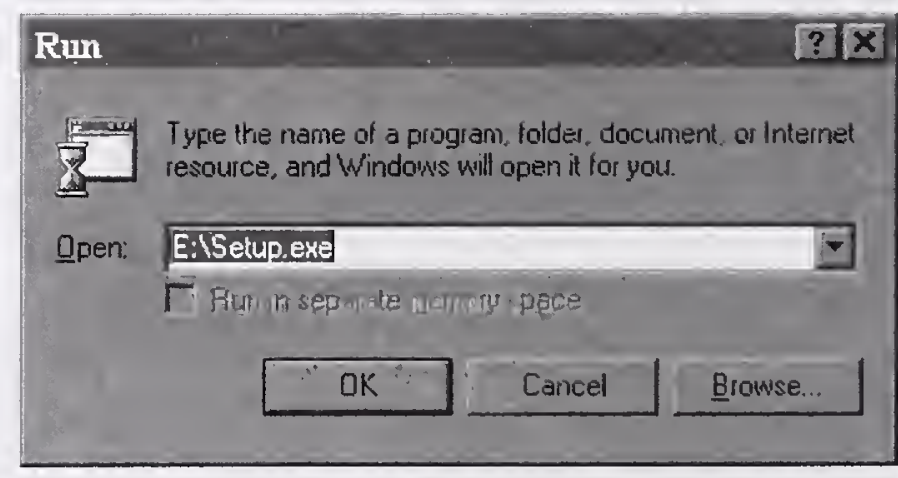

\section{7) Click OK}


Steps 8 - 11 refer to the dialog boxes that come up during installation

8) Welcome dialog box

Click Next

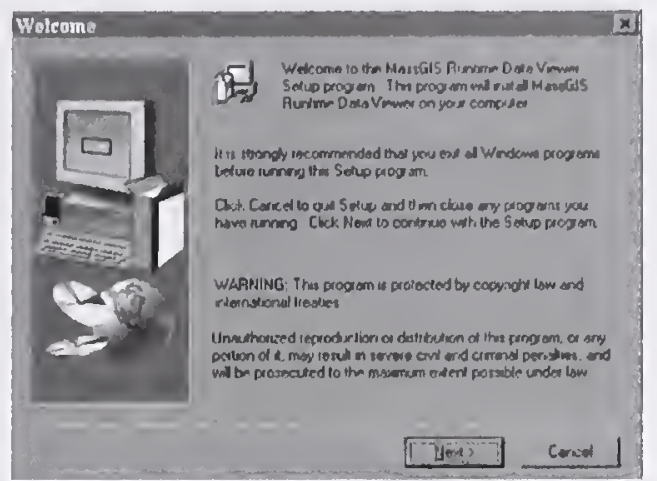

Select Components

9) Select Components dialog box

a) Be sure both boxes are checked

b) Confirm that Destination Folder is on your hard drive and labeled massgis

c) Click Next

10) Select Program Folder dialog box You will use the default "MassGIS Runtime Data Viewer." Click Next
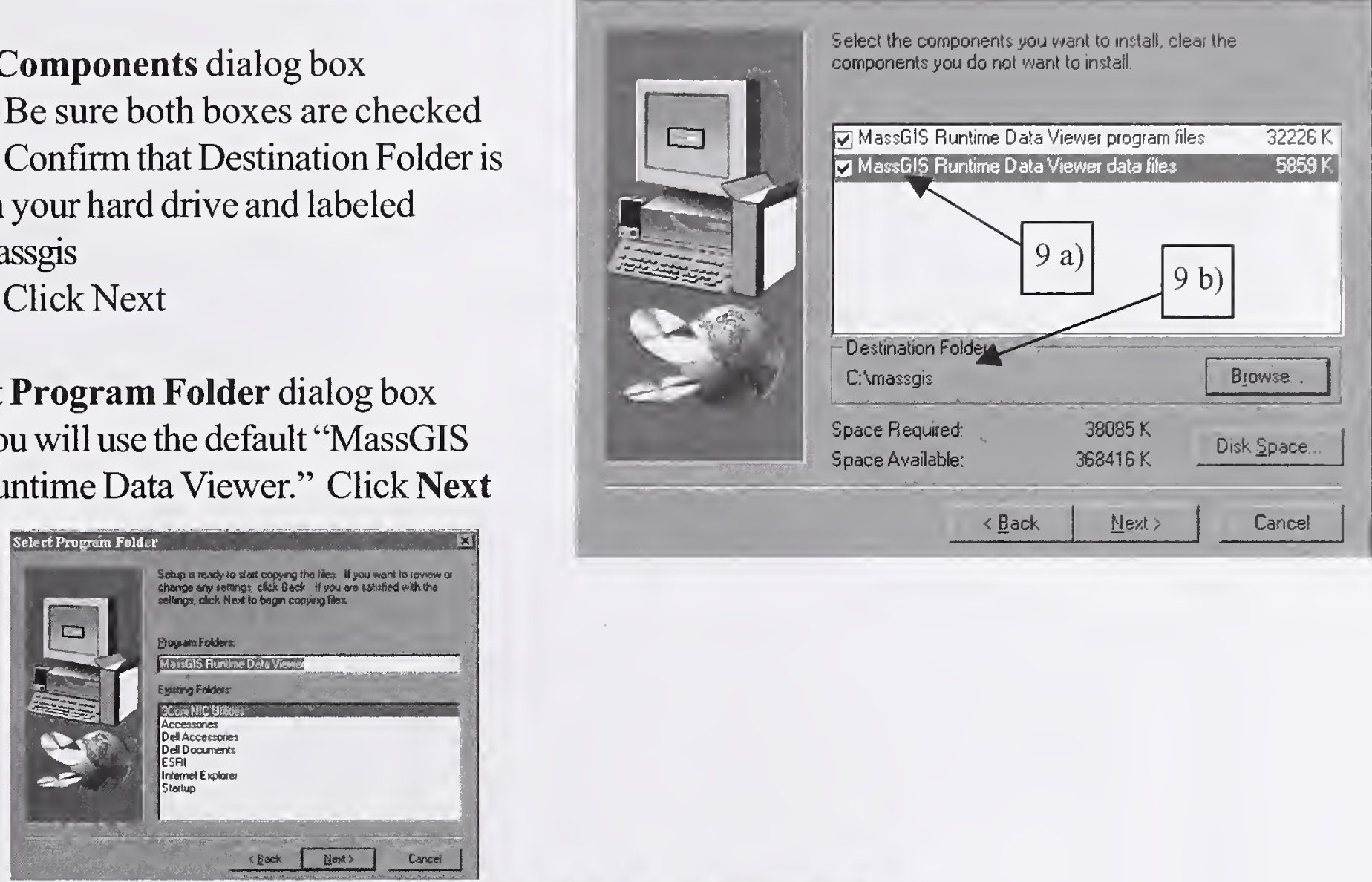

11) Information dialog box Click Next

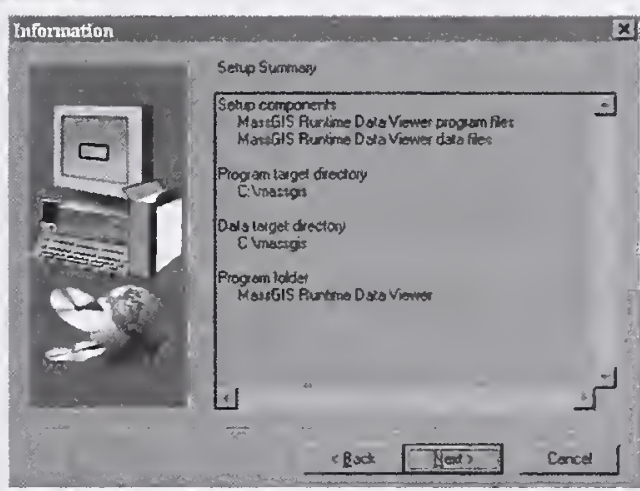

Copying will begin

12) Click OK when installation is complete 


\section{Starting the Data Viewer}

Note: The first time you start the Data Viewer you will be prompted to enter the letter of the $C D$-ROM drive (step 18). This tells the program where to look for files when it is running. If you enter the wrong drive letter, you will see an error message, and the program will not run properly. If this happens you will need to entirely remove the program and any folders it created, then repeat the installation procedure. Further instructions follow the start-up procedure below.

13) Be sure the GIS Runtime Data Viewer CD is in the

CD-ROM drive. Click the Start button in Windows

14) Click Programs

15) Click on the MassGIS Runtime Data Viewer folder

16) Click on the MassGIS Runtime Data Viewer programicon

17) The MassGIS Runtime Data Viewer will start
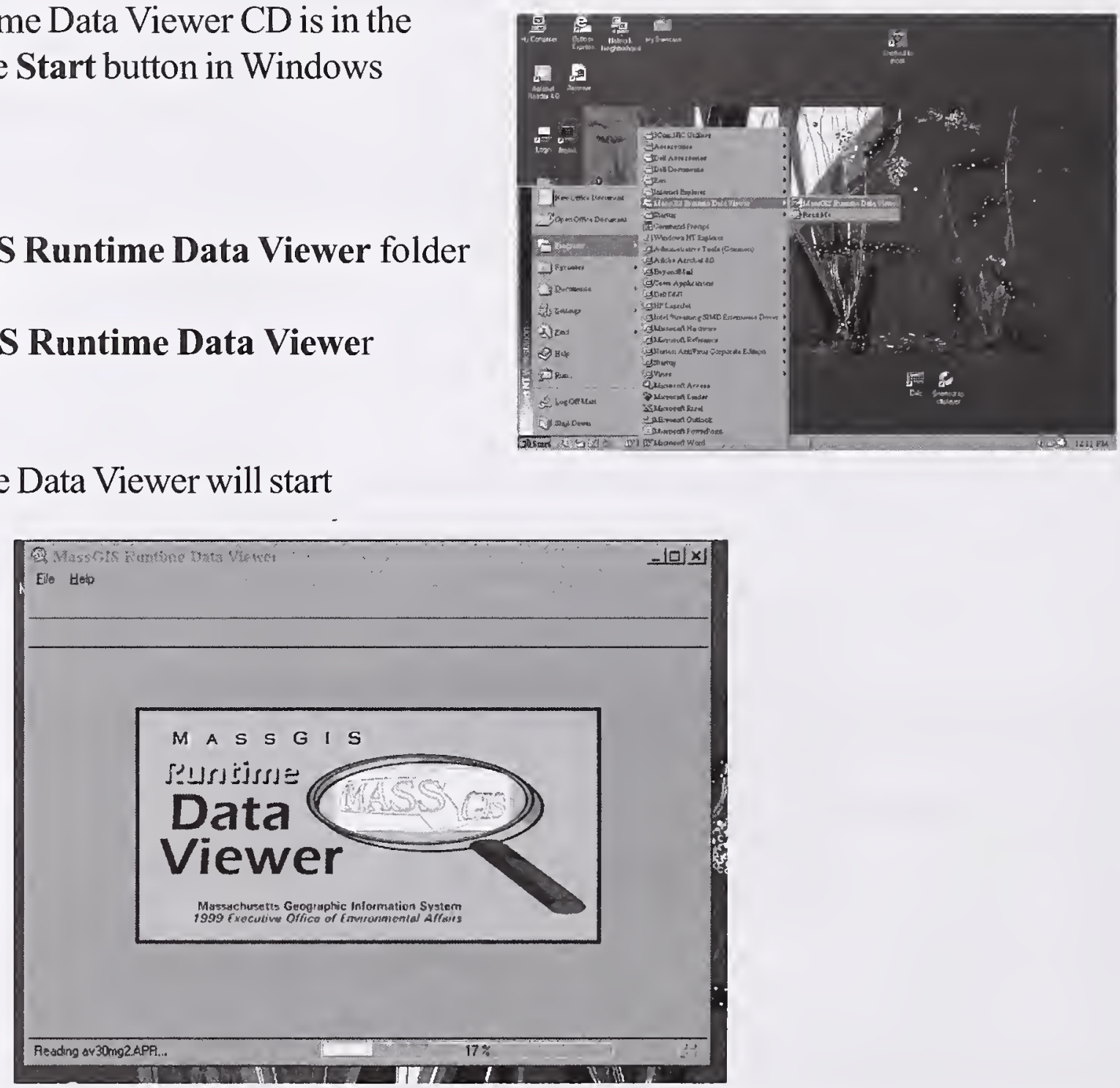

18) A dialog box will prompt you to enter the letter designation of your CD-ROM drive

Type the letter of your drive and click OK

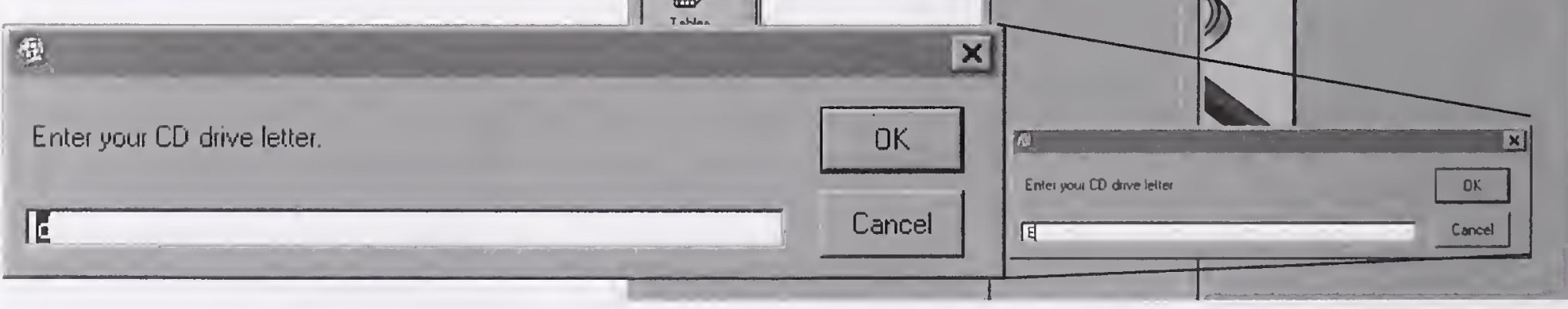


19) If you type the wrong letter at this dialog box, you will see an error message

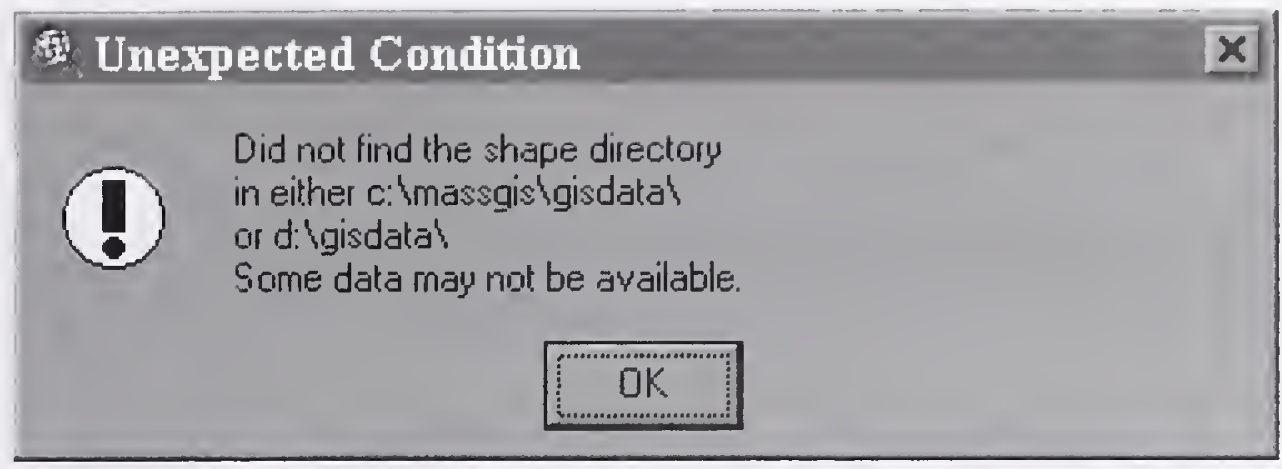

The program will not work properly until it has been removed entirely from the computer and reinstalled. If you get this error message,

a) Close the Data Viewer by clicking the small $\mathrm{x}$ in the upper right hand corner

b) Select Yes when asked if you really want to quit

c) Click Start at the Windows Desk Top

d) Click on Settings

e) Select Control Panel

f) Double click the Add/Remove Programs icon

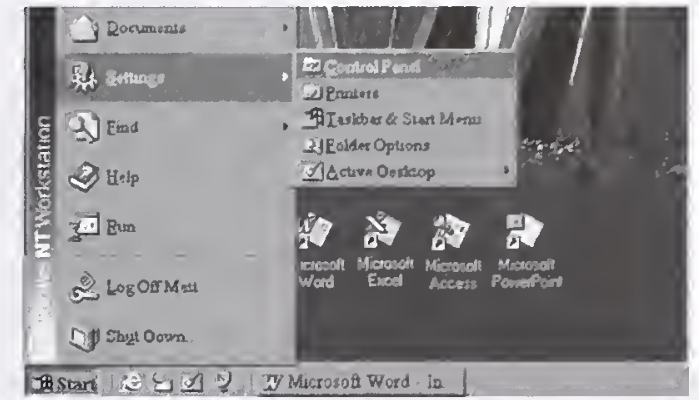

g) Scroll down to MassGIS Runtime Data Viewer and double click

h) Select Yes when prompted to confirm file deletion

i) Click OK when done This may remove shared files in the process. Select Yes when asked to confirm

j) Close Add/Remove Programs dialog box

k) Close Control Panel

l) Open Windows Explorer

Locate the massgis folder on the hard

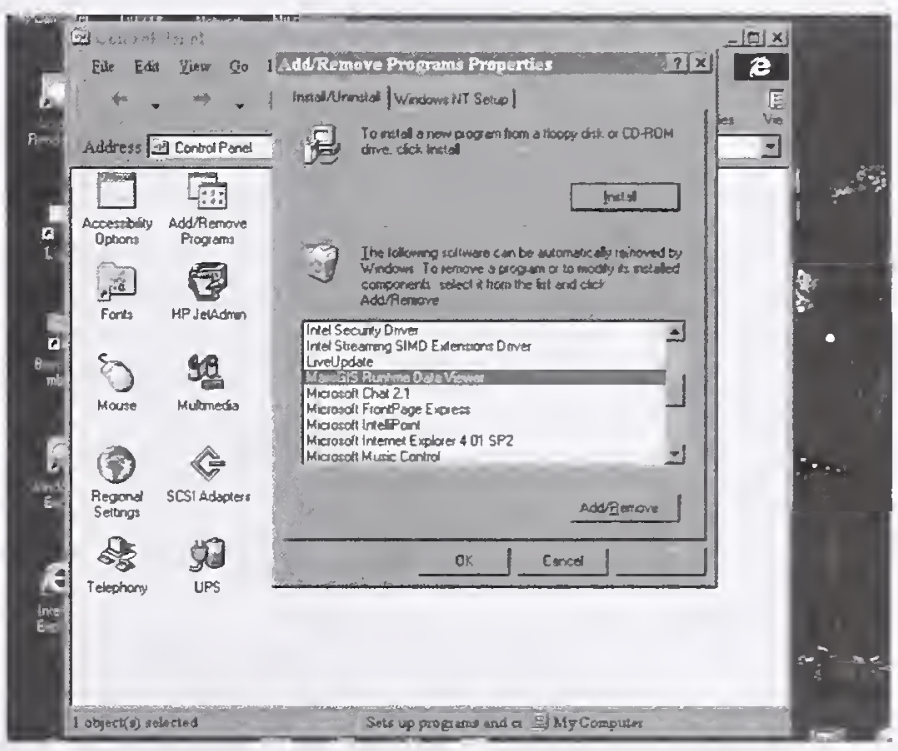
drive $(C)$ and manually delete it. This is important - the reinstalled program will still not work if this folder is not removed

m) Close Windows Explorer

20) Repeat steps 1-18.

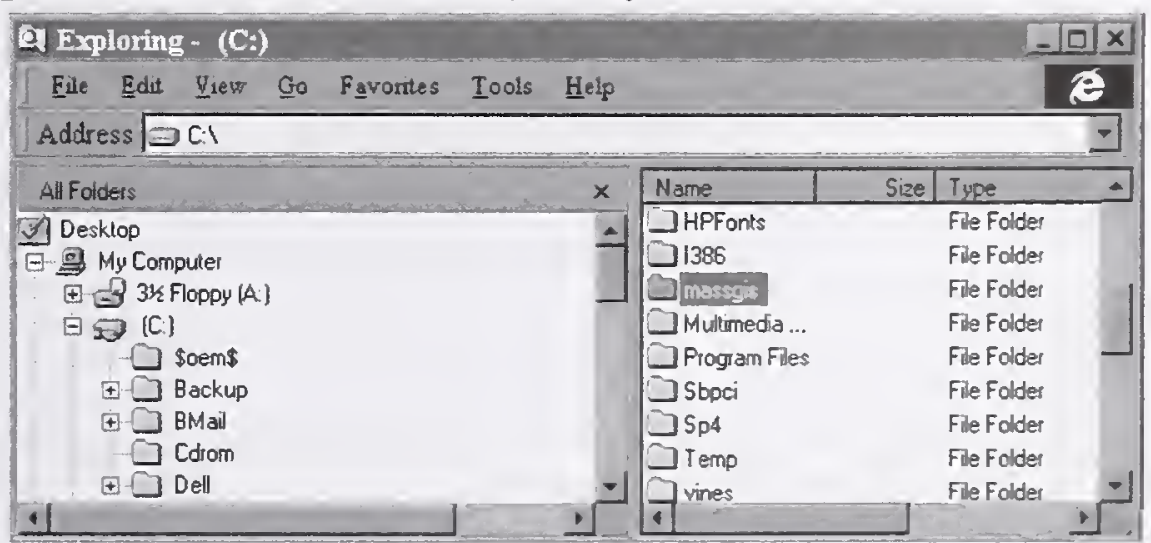




\section{Getting started}

The next 2 pages will provide a quick overview on how to zoom in to a particular town and bring in the USGS topographic maps to the map that you are presented with on starting the Data Viewer. You will also bring in the potential vernal pool datalayer into your view. This is just the beginning of what the Mass GIS Runtime Data Viewer is capable of. The CD contains 5 lessons that were created by Shirley L. Griffin, Ed.D. These cover in more depth the ArcView/Data Viewer interface, operation and manipulation of "Themes" in ArcView, using theme tables and querying data, and making and formatting maps. After completing installation, open Windows Explorer and open the Imassgisldataldocs folder on the hard drive. Examples 1 - 5 are labeled exIpic, ex2pic, etc. Double click to open in MS Word.

1) Open the MassGIS Data Viewer by following steps 13-17. You will only be asked to type the letter of the CD-ROM drive the first time you open the program. You will be presented with a map of the state (see page 24 ).

2) Zoom in to a specific town by clicking on the $Z$ button in the tool bar. Scroll down to MA Towns. Double click, then select a town from the list.

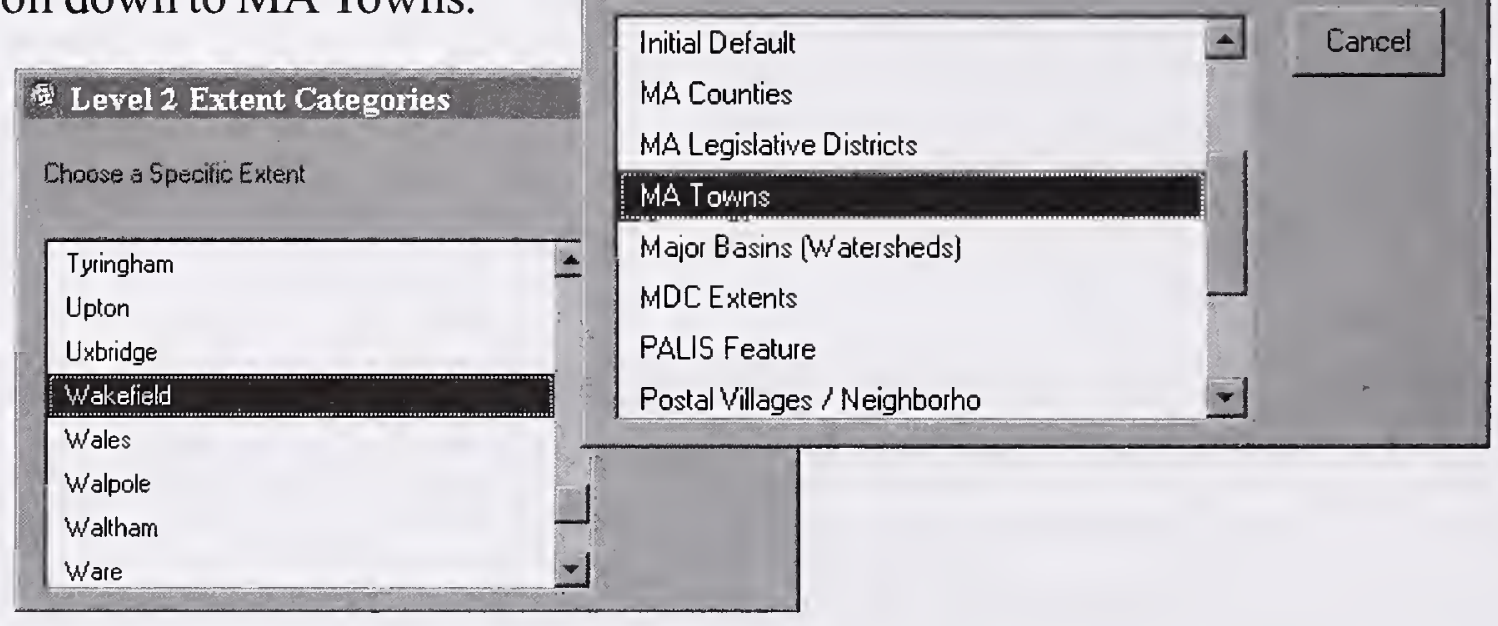

3) Add datalayers to your view by clicking on the A button in the tool bar. Only a few of the MassGIS datalayers were included on the enclosed CD. The available data will come up in the list when you click the A button. For example, add the USGS topographic maps to your view by clicking on the A button and double clicking USGS Topographic Maps. Repeat these steps to add the Potential Vernal Pool datalayer to your view. You should be sure to zoom into a relatively small area (e.g. one town); the topo maps will take a very long time to draw otherwise.

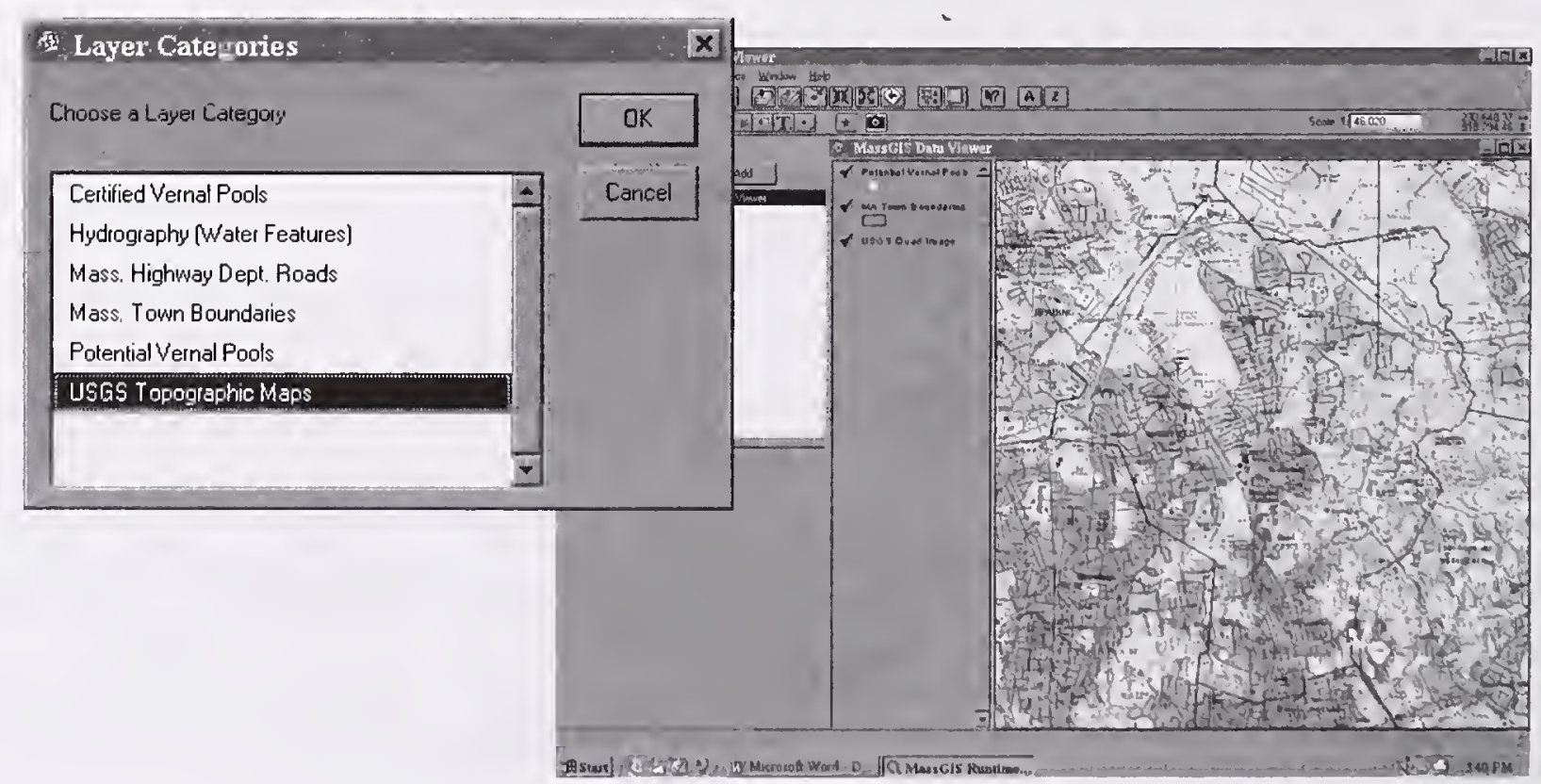


4) You will now see the potential vernal pool datalayer over the USGS topographic maps for the part of the state you have displayed. Zoom in further by using the magnifying glass in the tool bar. Either click on the arca you want to see (zooming in gradually to the point that you clicked) or click and drag a square around the area to zoom in quickly.
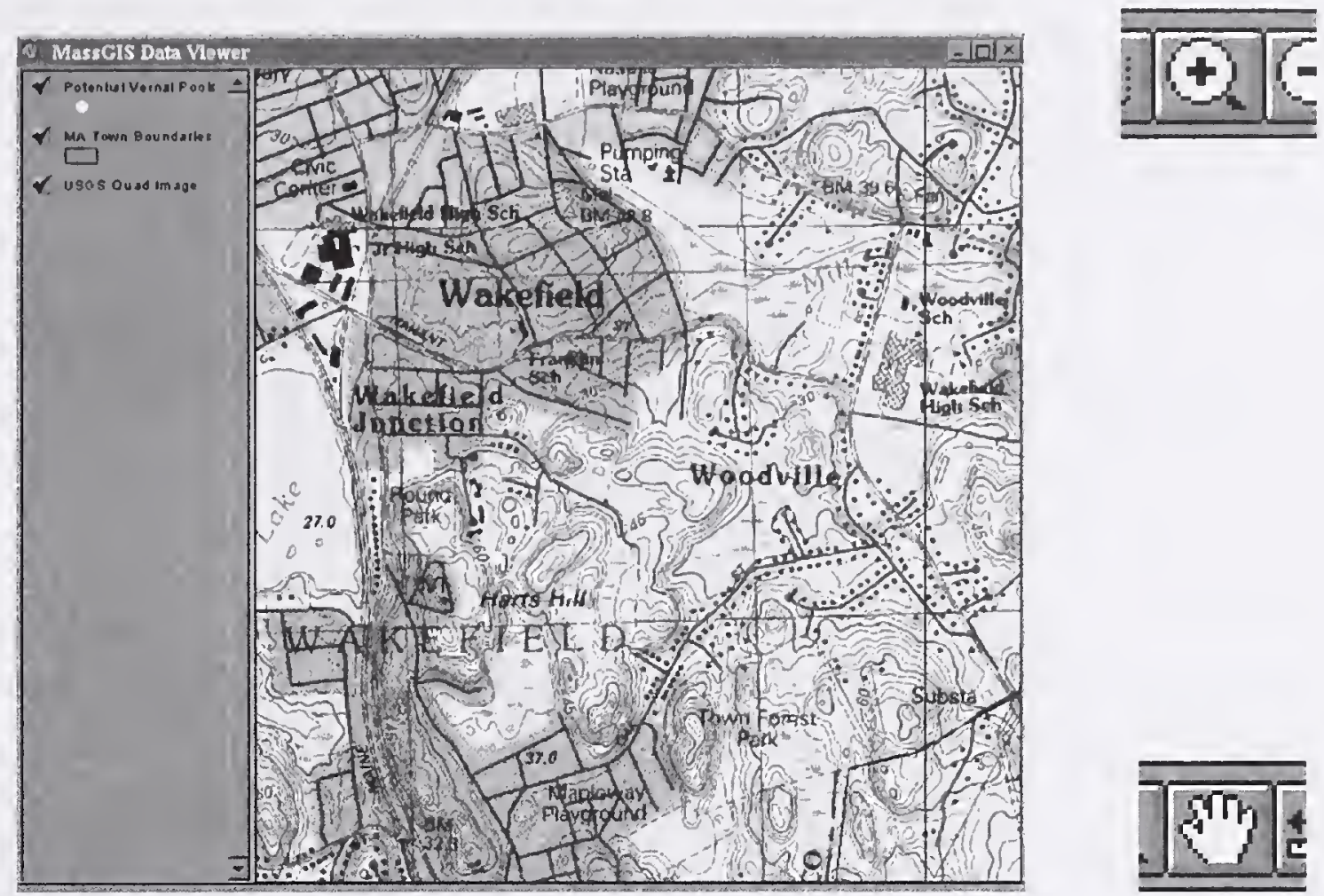

Use the hand tool to pan, moving the map in order to center a particular feature or to be sure to include a road or building in the view that you'd like to be able to see.

There are a number of other tools available for manipulating the maps, measuring distances, zooming in or out to different extents, etc. See pages 26 43 for a broad introduction to the MassGIS Runtime Data Viewer and ArcView environment, as well as the examples 1 - 5 contained on the program disk.

If the potential vernal pools are added but not visible, look at the table of contents on the left margin of the map. Make sure there is a line that says Potential Vernal Pools, that the small check box to the left is checked (if not, just click on the box), and that it is at the top of the list. If that line is positioned below the topographic maps it will be covered by the maps in the view. Click on the potential vernal pool line, holding the left mouse button down, and drag it to the top of the table of contents.

This can be printed out, or can be brought into a Layout to add a legend, title, etc. See Exercise 5, Making a Layout (Map), in the mass $\backslash$ dataldocslex5pic.doc file on the CD. 


\section{Introduction to ArcView and the MassGIS Data Viewer}

Courtesy of the MassGIS office. Some of the topics and functions presented will not apply to the Runtime Dataviewer, but are presented as part of this general overview

\section{Contents}

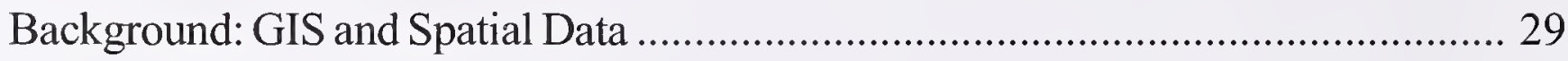

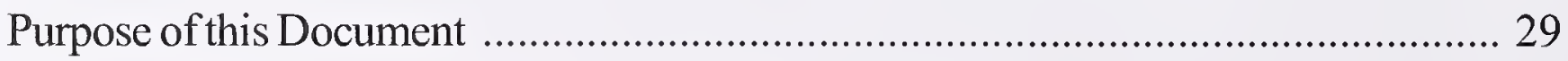

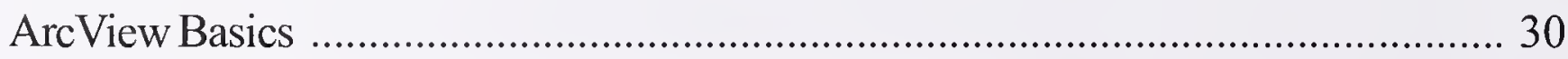

Graphical User Interface and Desktop Structure

ArcView Projects

Opening, Saving and Closing your Project

View Documents and Themes

Working with Themes in a View Window

Enhancing your View

Printing your View

Using Help

The MassGIS Data Viewer

Brief Description

Overview of Customization Approach

Description of Specific Customizations

Additional Buttons

Additional VIEW Menu Choices

Additional THEME Menu Choices

Additional EDIT Menu Choices

Opening the MassGIS Data Viewer

Closing the MassGIS Data Viewer

Typical MassGIS Data Viewer Sessions
A. Viewing data around a site
B. Adding and editing features in shape-file themes

Summary of Other Advanced ArcView Features

MassGIS Data Viewer Quick Reference 


\section{Background: GIS and Spatial Data}

ArcView is one of a number of powerful, easy-to-use geographic information system (GIS) software applications. In the last few years, such applications have begun to provide non-technical users the means to directly access sophisticated spatial analysis and mapping tools. ArcView (made by Environmental Systems Research Institute, Inc. (ESRI), makers of ARC/INFO) is an interactive data visualization and analysis tool. It is used to organize, explore, query, and map spatial data (information referenced to locations defined by precise geographic coordinates). This capability is powerful, since an estimated $80 \%$ of data used in business and government has a locational component.

Information that relates to such geographic units as addresses, ZIP codes, rivers, towns, and regions is commonly gathered and stored in databases to be used for a wide range of purposes. What has not been commonplace, however, is the ability to visualize and interpret these data in a manner consistent with its spatial organization. More often than not, tables, charts, and statistics are produced to list or summarize the data stored in spreadsheets or databases. While useful tools, these do not lend themselves to easy interpretation when comparisons across areas and among multiple geographic units is necessary.

This more complex data representation is the domain of GIS. GIS software should be understood as an enhanced database system that stores the actual geographic coordinate location of data along with all the routinely stored descriptive or attribute information about the location. Special tools are also included which utilize this coordinate information and allow for mapping and geographic analysis of the data in addition to the traditional tables, charts, and statistics.

\section{Purpose of this Document}

This document is an introduction to the graphical user interface (GUI) and the basic data visualization tools of ArcView Version 3.0a. It is by no means a comprehensive treatment of all ArcView's features. It is designed to help a novice user to get up and running with the software and includes instructions on how to use the extensive on-line help system which can serve as a further tutorial and reference for the user motivated to learn more.

Also covered in this document is an explanation of the features of a customized ArcView project known as the MassGIS Data Viewer. This Viewer is available in three versions: one for those who have a full copy of ArcView 3.0a, one for those who have a full copy of ArcView Version 2.1; and another which includes a run-time version of ArcView for those who do not have a full copy of ArcView Version 3.0a).

Although written for users of the MassGIS Data Viewer, this document can also be used by those requiring just an introduction to ArcView itself. In this case, the section on the MassGIS Data Viewer can be ignored. In either case, it should be noted that this document is written based on the Microsoft Windows version of ArcView and assumes the reader is familiar with working in the Windows environment. However, the UNIX and Macintosh versions of ArcView are very similar and users of those operating systems should also find this document useful. 


\section{ArcView Basics}

\section{Graphical User Interface and Desktop Structure:}

Like any typical Windows-based application, ArcView employs a graphical user interface (GUI) as the framework for user interaction. As indicated in the figure below, this framework is contained within the ArcView application window. The application window can be resized, minimized, maximized, and moved around just like any other window.

\section{ArcView Application window and Graphical User Interface (GUI)}

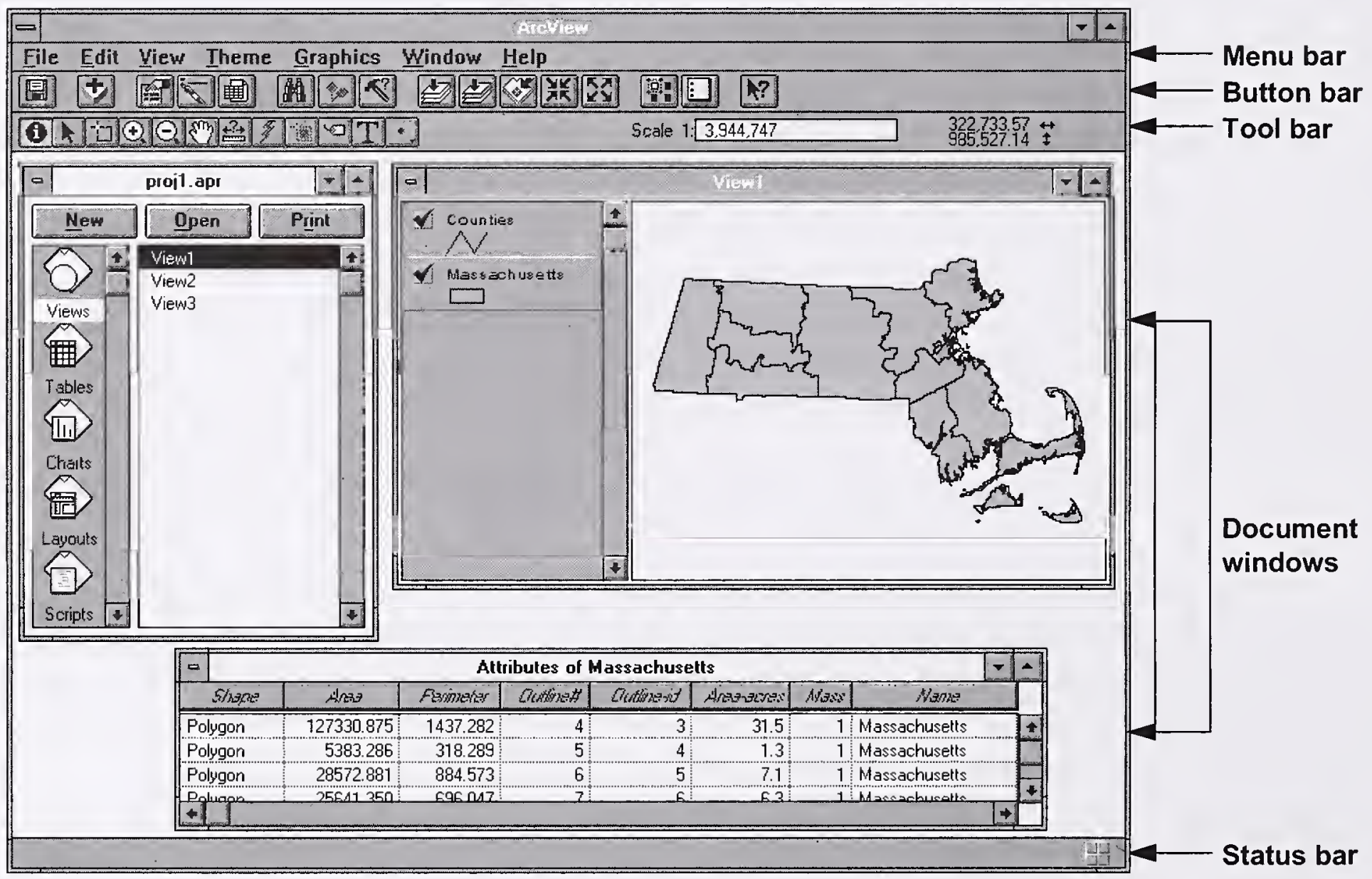

The ArcView GUI consists of the following basic components:

The menu bar provides access to ArcView operations in a pull-down menu.

The button bar provides quick access to commonly-used operations also available from the menu bar.

The tool bar accesses operations that are performed with the screen cursor. Each tool defines a unique action for the cursor to perform.

The status bar displays a one-line description of a menu choice, button, or tool, as the cursor is moved over (without selecting) it. This is very useful as a help feature for determining the function or purpose of the various menu, button, and tool options. The status bar also reports measurements, displays system messages, and shows a progress bar for lengthy operations. Document windows are the ArcView windows within which you perform your work. The four GUI bars are context sensitive and reflect the options relevant to the active 
document window in which you are working at any given time. The active document window is indicated by a highlighting of the window's top title bar. In the figure above, the window entitled "View l" is active, and therefore, the menus, buttons, and tools showing are those pertinent to this view document. The Project document window is a special window that manages the other documents in the project (see next section).

\section{ArcView Projects:}

An ArcView project is a collection of associated documents that work together during an ArcView session. Projects are stored in a single file with the ".apr" extension and provide an organized way to manage the status of the various documents (views, tables, charts, layouts, and scripts) as you work. Projects manage how and where documents are displayed, maintain current selections from the documents, and define the appearance of the Application window.

The Project window contains a title bar with the name of the active project (e.g. proj1 apr in the figure above) and acts as a gateway to the other documents in the project. Each icon in the Project window represents a class of documents. Clicking one of these icons "opens a gate" to documents of that class. At any given time, there can be only one active project and hence, one Project window to access and manage project components.

\section{Opening, Saving and Closing your Project:}

A project can be opened by double-clicking its name from the Windows File Manager. Alternatively, it is possible to set up an ArcView icon in Windows Program Manager that starts a specific project by default when ArcView is started. If ArcView has been started without a default project (or if the last project was closed), the ArcView File menu will provide the means to open a project. If, in future sessions, you will be wanting to return to your project in the state in which you have developed it in the current session, you should periodically save the project. If you have made any changes to the project, ArcView will give you the opportunity to save your project when you close it or exit ArcView.

Project level operations such as these are typically found under the File menu of the ArcView GUI. However, exactly what can be accomplished from the File menu differs depending on the context of the application and project:

When ArcView has been started without a default project (or if you just closed the project on which you were working), the File menu contains:

New Project: Create a new project.

Open Project...: Open an existing project.

Exit: Exit ArcView.

With the Project window active, the File menu contains:

New Project: Close and optionally save current project and create a new project.

Open Project...: Close and optionally save current project and open another project.

Close Project: Close and optionally save current project (does not exit ArcView).

Save Project: Saves the project in its current form.

Save Project As...: Saves the project in its current form as a different project name.

Extensions:...: Adds extra ArcView modules called extensions to the project.

Exit: Close and optionally save current project and then exit ArcView. 
With a non-Project window (e.g. View) active, the File menu contains:

Close: Closes the current window in the project (not the project itself).

Close All: Closes all the windows in the project (not the project itself).

Set Working Directory: sets the default directory to save to.

Save Project: Same as when Project window active.

Print...: Brings up print dialog box.

Print Setup...: Brings up print setup dialog box.

Export...: Brings up table export dialog box.

Exit: Same as when Project window active.

Note that the project can also be saved by clicking the Save Project button (left-most button in the Button bar with the floppy disk icon).

\section{View Documents and Themes:}

ArcView View Window

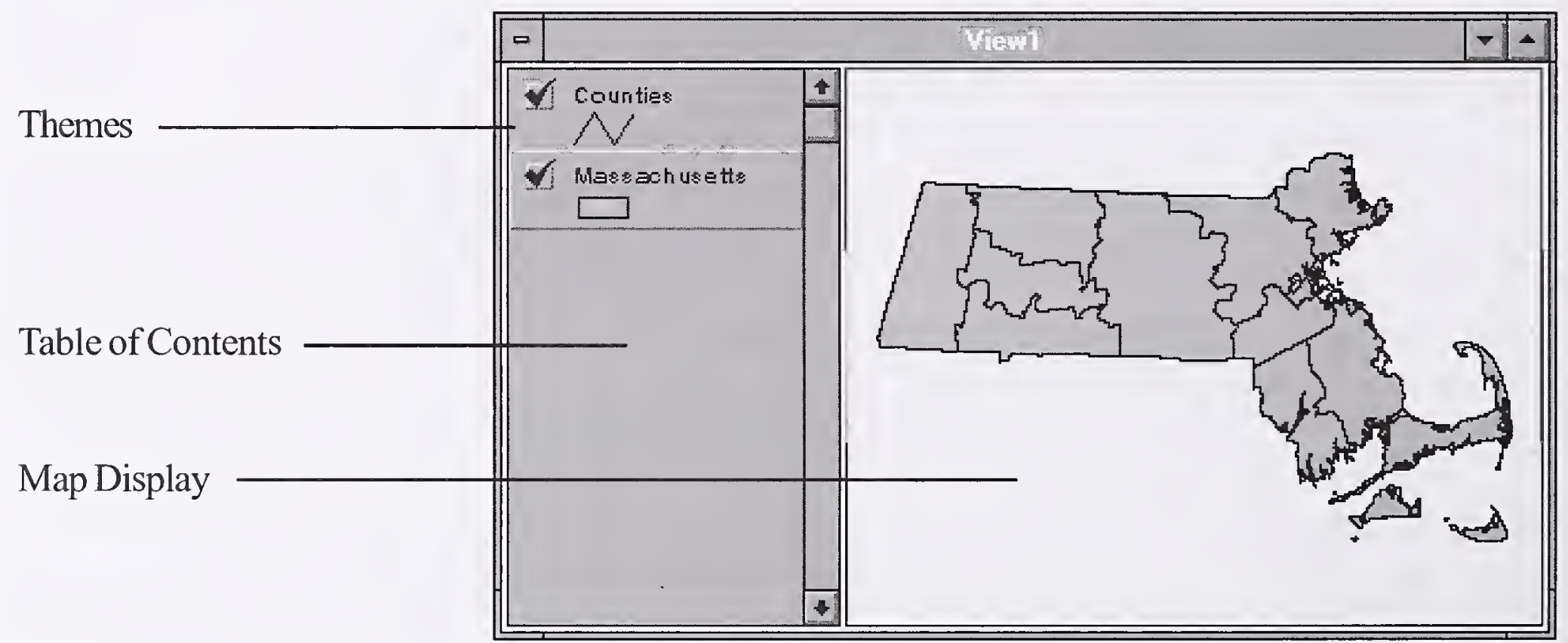

A "view" is the primary document type which supports the interactive display and query of spatial data organized into "themes". A "theme" can be thought of as a reference to a database containing information about a particular set of geographic features with similar characteristics (e.g. roads, towns, wells, etc.). A view defines the themes you use and how to display them, but it doesn't contain the geographic data files themselves. Since the themes in the view only reference these source data files, the view is dynamic because it reflects the current status of the source data. If the source data changes, a view that uses this data will automatically reflect the change the next time the view draws.

A view document is controlled by a view window which consists of a map display area and a table of contents (see figure above). The table of contents reflects the themes which are 
drawn in the map display area of the view. Furthermore, the view allows the user to manage how the various themes are classified and symbolized according to the theme's legend. The process of adding a theme involves specifying where the spatial database you wish to display is located. In addition to the native ArcView spatial data format, the spatial database formats supported by ArcView include: ARC/ INFO coverages and libraries; dBASE, INFO, and text files containing point location coordinates; and various image formats.

View documents (like all other ArcView documents) are listed in and managed from the Project window. To work with views, select the Views icon in the Project window, and then:

To open an existing view, double-click its name or select the view's name and click the Open button.

To create a new view, click the New button. There can be more than one view in a project (only one can be active at any given time) and each can contain any of the available themes.

To add a theme to a view, first make the view active (by creating or opening it, or clicking on its title bar if it is already open). Then choose Add Theme from the View menu or click the Add Theme button to display the Add Theme dialog box. Once a theme or themes are added they can then be manipulated within the view (see following section).

\section{Working with Themes in a View Window:}

\section{View GUI Buttons and Tools}

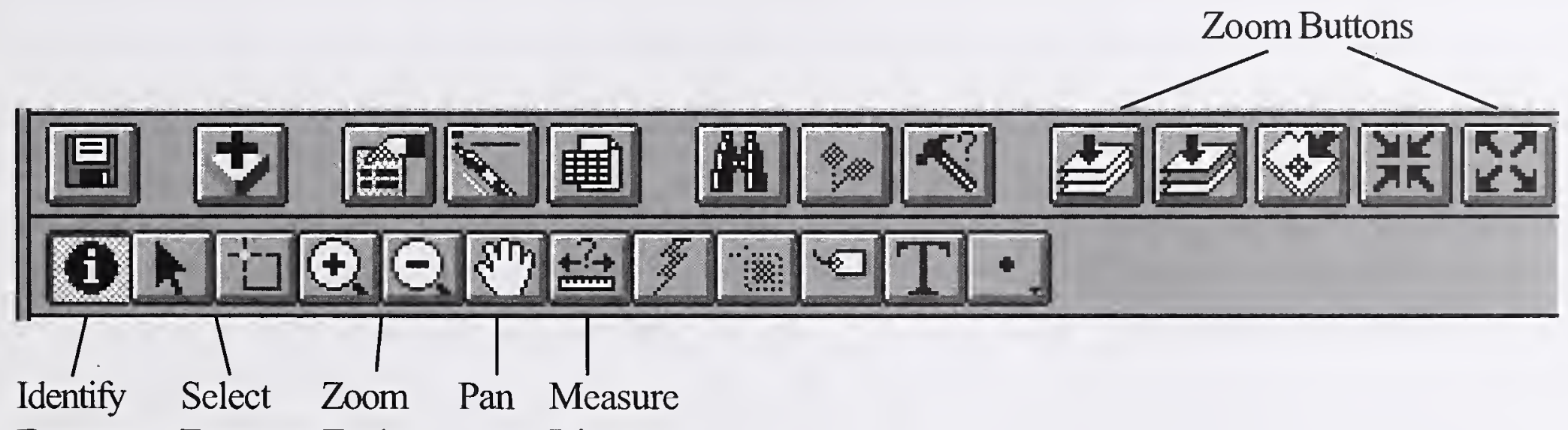

Features Features Tools Distance

There are two general classes of operations that can be performed on themes in a view: viewspecific; and theme-specific. An asterisk (*) following an operation's name indicates that the operation can be performed via one of the buttons or tools from the view GUI illustrated in the figure above. The other operations are accomplished by interacting directly with the view table of contents or via the view GUImenus. 
View-specific operations (apply to all themes in the view):

Panning \& zooming*: Use the Pan and Zoom tools and buttons to changed the size and position of the map display. Panning repositions the focus of display without changing its scale. Zooming in (or out) decreases (or increases) the scale of the display as it focuses on different areas.

Measuring distance*: The Measure tool reports the accumulated distance between points that are clicked in the view.

\section{Theme-specific operations (apply to individual themes in the view):}

Identifying features*: The Identify tool displays the attributes of a specific feature in the theme by clicking on it.

Selecting features*: The Select Feature tool selects a single feature in the theme by clicking on the feature or selects many features at once by clicking and dragging a rectangular area around the desired features. Certain operations can then be performed on selected features. Making active: Clicking on a theme's name in the table of contents makes it active. When a theme is active it appears raised off the table of contents, and is available for theme-specific operations. Multiple themes can be made active by holding down the shift key while clicking. Turning on and off: Clicking the check box in the table of contents for a theme toggles the theme on and off. This is for display purposes only and is not the same as adding and deleting themes.

Changing display order: ArcView draws themes sequentially starting with the theme at the bottom of the table of contents. Each successively higher theme is drawn on top of the last. To change the drawing order of a theme, hold the mouse button over the theme in the table of contents and drag the theme up or down to a new position in the list.

Editing Legends: Make a theme active and then choose Edit Legend from the Theme menu or press the Legend Editor button, or double-click on a theme's name to bring up the Legend Editor. From here a theme's symbolization and classification can be modified.

Deleting a theme: To delete a theme(s), make it (them) active and choose Delete Theme(s) from the Edit menu.

Editing a theme: Only themes that have ArcView shape files as their data source can be edited. To edit a shape file-based theme, make it active and choose Start Editing from the Theme menu. Search Help for "editing a theme" for further information on native ArcView tools for editing themes.

Note that there are other buttons, tools, and menu choices which interact with views which offer more sophisticated ways of accomplishing some of the basic operations described here. Additional functions not fully described in this document are also available. Remember: to get a brief description of the purpose of an icon button or tool, just move your cursor over it (without clicking) and read the status bar. Also see the section on Using Help below. 
Enhancing your View:

For various purposes (e.g. titles, annotation) it may be desirable to add a short descriptive text string to the view. To do this:

1. Select the "T" icon tool from the View document tool bar.

2. Click on the desired location for the text in the View display area. This will bring up the "Text Properties" dialog box.

3. Enter the text in the box and click OK.

4. Double-clicking the text graphic object will bring up the "Text Properties" dialog box again should the text (or other options in the dialog box) need to be edited.

5. To change the font, select Show Symbol Palette from the Window menu. This will bring up the Palette Manager. Click on the ABC icon in the Palette Manager to bring up the Font Palette, and then change the font properties as desired.

You may also want to experiment with the Label tool for labeling specific features, and the Draw tool for drawing graphic shapes on the view.

Printing your View:

There are a number of ways to print a view: the view display area can be printed alone; an ArcView Layout can be used to include legend, scale and other map composition elements; the ArcView session window can be captured directly from the screen and then pasted into another program for printing.

The way in which you print is also determined by the hardware platform on which ArcView is running. For instance, when ArcView is running on the workstation, printing a view directly from ArcView generally requires a postscript printer that is directly accessible on the network. For windows platforms, you must make sure that the appropriate printer drivers are loaded and that you have selected the appropriate printer. Of course, regardless of the platform on which ArcView is running, if the printers available are only black and white, the printed map may be difficult to interpret.

\section{Using Help:}

ArcView's on-line help system provides reference and "how to" information. Here's where you'll find on-line topics that cover key concepts, step-by-step instructions, and context-sensitive help for specific commands and dialog boxes. By clicking the highlighted text within Help, you can jump to other topics related to the one you're reading.

To get a list of Help topics:

Choose Contents from the Help menu or press F1.

To get help on a specific menu item, button, tool, or document:

Click the Help button, then click the particular command, button, tool, or document.

To get help on a dialog box with which you're working:

Move the cursor to the dialog box and press F1. 
To search for Help on a specific topic:

1. Choose Search from the Help menu (or, if Help is already open, choose the Search button at the top of the Help window) to bring up the Search dialog box.

2. In the uppermost box, type the first few letters of a word or phrase relating to the topic you want to search for. As you type, Help displays new words and phrases in the list box directly below the one in which you're typing. You can back up if you've made a mistake or select the phrase and replace it with other text.

3. Double-click the word or phrase related to your subject (or select it, and choose the Show Topics button). The list box in the lower portion of the dialog box displays the relevant topics for the word or phrase you selected.

4. In this lower list box, double-click the topic you want to go to (or select it, and choose the Go To button). 


\section{The MassGIS Data Viewer}

\section{BriefDescription:}

The MassGIS Data Viewer is a customized ArcView project that uses the ArcView Avenue object-oriented programming language. It consists primarily of a few key enhancements to the native ArcView view document GUI described above. These enhancements are designed to make it even easier to work with spatial data (see below). The MassGIS Data Viewer was created specifically to be distributed and work with MassGIS data. However, it was also designed to be generic enough to work with any other spatial data supported by ArcView.

\section{Overview of Customization Approach:}

The basic functionality of native ArcView described in the preceding sections is fairly straightforward. Nevertheless, there are a few areas that tend to present problems for the novice user and to prove tedious for the more advanced users: the addition of themes to a view and their subsequent symbolization and classification; and the ability to zoom to a specific location.

Adding themes requires some detailed knowledge about the structure, naming conventions, and physical disk location of the source data files. On a stand-alone PC where one manages one's own data this may not be a problem. However, in a networked environment, data may be stored and maintained across multiple machines and multiple disks, all of which tend to change periodically. This places an overly cumbersome burden on the user to keep track of all these "technical details". Furthermore, even if one knows these details, having to constantly navigate up and down file paths, or having to type long path strings becomes more than a minor inconvenience. Once a theme has been added, the process of symbolizing and classifying themes using the legend editor also becomes time consuming. Even if a theme's symbolization and classification is saved, the problem of keeping track of data paths and file names for these saved legend files recurs. Again, this problem may not be so severe if this were managed at a single PC level.

Also, while the normal zoom tools are useful it is often desirable to be able to directly focus in on a specific area. To get exactly where you want to be often requires multiple zooms and pans with the view redrawing each time.

The MassGIS Data Viewer was designed specifically to address these and a couple of other minor limitations of native ArcView. However, it was decided that these enhancements should supplement rather than replace the native ArcView functionality. So, the MassGIS Data Viewer is not a customized project that has only a limited range of utility. Everything you can do in native ArcView can be done in this project as well. This approach allows novice users to slowly acquaint themselves with ArcView without initially getting hung up by some of its more difficult functions. The custom features described below are integrated with the rest of ArcView in a way that attempts to clearly distinguish the customized features from the native features. It is expected that, initially, novice users will use primarily the customized features. As they become more accustomed to working in ArcView, they can then gradually begin to explore its many other features. 


\section{Description of Specific Customizations:}

The MassGIS Data Viewer customizations are primarily evidenced by the presence of two new lettered buttons; various new choices at the top of some menus for the view document entitled "Mass GIS Data Viewer".

Some of the features of the MassGiS Data Viewer are disabled in the Runtime version of the project. This is a limitation of the ArcView Data Publisher, which was used to create the Runtime version. The disabled features appear in bold italics in the list below and on the Quick Reference page at the end of this document.

(With the 12/29/97 release of the MassGIS Data Viewer for ArcView 3.0a, the "A" and "Z" buttons and all the other Viewer customizations will work for all View windows that the user creates.)

\section{Additional Buttons for a View document}

Two new buttons can be found to the right of the normal view document buttons.

A The "A" button functions the same as the Add Inventory Theme menu choice described below.

Z The "Z" button functions the same as the Zoom to Specific Extent menu choice described below.

The "dog" button (to fetch an address) to the right of the query builder (hammer) button:

\section{Address Match}

Places a symbol on a TIGER street grid, on the correct side of the street, for an address you specify. You can use this feature whether or not you know the zip code of the address. (Note: Index files are needed for ArcView to do an address match and are created for each town. ArcView will try to put the index files with the source data, if this directory is not write-protected. If the index files are saved with the data, the address matching script will be able to reuse these files for any future address matching. However, is a good idea to have your data write-protected. If the directory is write-protected, the index files will be stored in the project's working directory (look under the Project menu, the Properties choice). If the index files are saved in the working directory, they are only useful when the TIGER coverage remains in the view. Once the TIGER coverage is removed from the view, these files are essentially useless. The files will be named tig1.idx, tig2.idx, etc, so if they are in your working directory, you should delete these files periodically. Also, the script will re-index the TIGER file of a previously indexed town if the user changes the input of whether they know the zip code of the address.)

The "scissors" button performs a cookie-cutter clip of one theme on another. Suppose that you wanted to find out how many miles of roads were in a certain town. Since roads do not stop at the town boundaries, you would have to use the town polygon as a cookie cutter to cut out all the roads so that you could add up their length. To use this tool, highlight the polygon or polygons that you want to use as the cookie cutter. Then make the theme active that you want to be cut. Now, click on this button and answer the questions 


\section{Additional Buttons for a Layout document}

\section{Make layout's View frame proportional to the View window.}

The square button to the left of the printer button when a layout document is active.

Create a viewframe on the layout, and choose which view you want represented in it.

With the viewframe highlighted, click on this button. The viewframe's proportions should change so they are equivalent to the view window's proportions.

\section{Make a multicolumn legend}

This tool leads you through the process of making a legend in the layout that has more than one column. You can also choose whether to represent your polygons as rectangles or ovals.

\section{Place a graphic of a table in the layout}

Use this tool to draw a rectangle on your layout where you would like to place a table. Then, follow the instructions to choose which table and which fields to use.

\section{Additional VIEW Menu Choices}

\section{Resize View}

Resizes the view based on computer's resolution and saves project

\section{Zoom to Query}

Sets the view extent to selected features in the active theme. If no features have been selected, a standard Query dialog is presented, and the extent is set to the features that match the selection criteria.

\section{Zoom to Specific Extent}

Sets the view extent to the extent of a specific area (either pre-defined or user-defined).

Choosing a zoom extent category from the first list brings up a second list from which the specific area is then chosen.

\section{User Extent Manager}

Save and delete user-defined extents.

Choosing Save Current Extent prompts you to enter a name for the extent. This named extent then becomes available under the User-defined Extents zoom category list accessed via Zoom to Specific Extent described above.

Choosing Delete Saved Extent brings up a list of all the saved user-defined extents. Picking one will delete it from the list.

\section{Add Inventory Theme}

Add pre-defined themes to the view.

Choosing a theme category from the first list brings up a second list from which the specific theme is then chosen. Making a choice here may actually bring up more than one theme at once (e.g. Choosing Roads from the Infrastructure category will add both the Highways and Roads themes to the view).

\section{Reset the Project}

Update the Theme and Zoom Inventories and clear the View.

This should be done when changes are made to tables that normally load when the Viewer is first installed. There are two levels of update: Inventory and Reset View: 
Update Theme \& Zoom Inventories updates the choices available through Add Inventory Theme and Zoom to Specific Extent

Reset View and Update Inventories updates the inventories and clears the Viewer window, deleting all the themes and zooming to the default extent.

Overview

Create a small overview window to control and display the extent of the view.

This window displays one theme from the MassGIS Data Viewer view, along with a red rectangle showing the current extent of the Viewer view. Draw a new rectangle in the Overview window, or drag the existing rectangle to change the Viewer extent.

\section{Read/Write Graphics $O D B$ file}

Writes graphics out to an ODB file, or reads them into the project from an ODB file.

This can help you get your graphics from one project to another.

\section{Additional THEME Menu Choices}

Describe

Brings up a box with information (including field descriptions and codes when available) on the active theme.

\section{Change Symbolization}

Changes the legend of the active theme to another pre-defined legend. Choose from the list presented. If only one choice is presented (that of the current legend), there are no alternate pre-defined legends for the theme.

\section{Make Subset}

Creates a new theme containing only selected features in the active theme. If no features have been selected, a standard Query dialog is presented, and the new theme contains only features meeting the criteria entered.

\section{Make Buffer}

Creates a buffer around a line or around or inside a polygon for the active theme. The resulting buffer is a graphic.

\section{Additional EDIT Menu Choices}

\section{Copy/Save/Restore Document}

Saves and restores documents to ODB files. You can save your Views, Layouts, and other documents out into ODB files which are separate from the project.

\section{Registration}

Advanced feature: available on computers connected to an ArcInfo server (see the "MassGIS

Data Viewer Developer Reference" for instructions on configuring an ArcInfo server).

Register, or "geo-reference", an image (such as a scanned map) to the coordinate system of the

MassGIS Data Viewer view. A registered image can be displayed along with other data in the

Viewer view.

Make Annotation

Write a file to create Annotation in ArcInfo based on text in the view. 


\section{Opening the MassGIS Data Viewer:}

Opening sav30mg2.apr is just like opening any other ArcView project. However, certain things happen during startup unique to this project. The first time sav30mg2.apr is opened, a number of initialization procedures are run that set up the default project (creates the "MassGIS Data Viewer" view, and puts up a default theme or themes at a certain default extent). These are the same procedures that are run when you choose Reset Project from the View menu of the "MassGIS Data Viewer" view. What happens during subsequent project startup depends on how the project was saved the previous time (see next section).

\section{Closing the MassGIS Data Viewer:}

In general, closing sav30mg2.apr is just like closing any other ArcView project. Again, certain things happen during shutdown unique to this project. If the project has been modified (such as adding themes, moving windows, or creating new documents) in your first session, upon closing the project, you will be prompted to save it just like in native ArcView. Choosing yes will cause the project to be saved in its modified state. The next time you open the project the initialization procedures will be bypassed thereby returning to the saved modified state. Choosing no will cause the project to return to its original state. Re-initialization will then occur the next time the project is opened.

As noted, once the project has been saved with modifications reinitialization will no longer occur. However, in certain situations (such as when there are multiple users of the project working with different themes), it may be desirable to force a reinitialization upon startup. This is when you don't want to save your current session and you don't want the last session to be saved either. To force a reinitialization, first delete the "MassGIS Data Viewer" view document from the Project window. Then save when you close the project. The next time the project is opened, initialization will occur. Of course, the project can be reinitialized at any time by choosing Reset Project from the View menu of the "MassGIS Data Viewer" view. 


\section{Typical MassGIS Data Viewer Sessions:}

\section{A. Viewing data around a site}

The following steps are recommended to view data around a particular site:

1. Open the MassGIS Data Viewer project.

2. Make sure the "MassGIS Data Viewer" view is active (click on it).

3. Zoom to the rough area which you are interested in viewing by using the "Z" button or the Zoom to Specific Extent menu choice from the View menu.

4. Add some themes to the view via the " $A$ " button or the Add Inventory Theme menu choice from the View menu. As themes are added it is suggested to further zoom and pan (using the regular ArcView zoom and pan tools) to the smallest area possible which still covers the area in which you are interested. If many themes are added to a view covering a large extent, the time for the view to redraw whenever the view changes can become very long. Zooming in first will minimize this time. Also, it is advisable to delete any themes that are not needed. Another option is to turn off certain themes (by unchecking them in the table of contents) until you finally focus in on the area in which you are interested.

5. Add any additional themes to complete the view.

6. If you are zoomed in to an area extent to which you will likely be returning at some future point, you should use the User Extent Manager from the View menu to save the extent. This will facilitate returning to this precise area later.

7. Close the project (see section above).

\section{B. Adding and editing features in shape-file themes}

The following steps are recommended to add (digitize) features to and edit a shapefile theme:

1. Zoom to the appropriate area and put up the necessary themes (see A. above).

2. Make the intended shapefile theme active by clicking on it in the view table of contents.

3. Select Start Editing from the Theme menu. The theme's check box in the view table of contents will then have a dashed outline to indicate that the theme is in digitize mode.

\section{To add a new shape to the theme:}

a. Click-and-hold on the Draw tool (rightmost icon in the view tool bar). The Draw tool is a pull-down tool from which you select the type of shape you want to draw. Its icon is the currently selected shape (along with a small black mark in the lower right corner indicating its pull-down nature). The possible shapes are point, two-point line, multi-point line (polyline), rectangle, circle, and irregular polygon. Only shapes which create the feature type of the shape theme you are editing can be drawn. For example, if you are editing a shapefile made up of polygons, only rectangles, circles, and irregular polygons can be drawn.

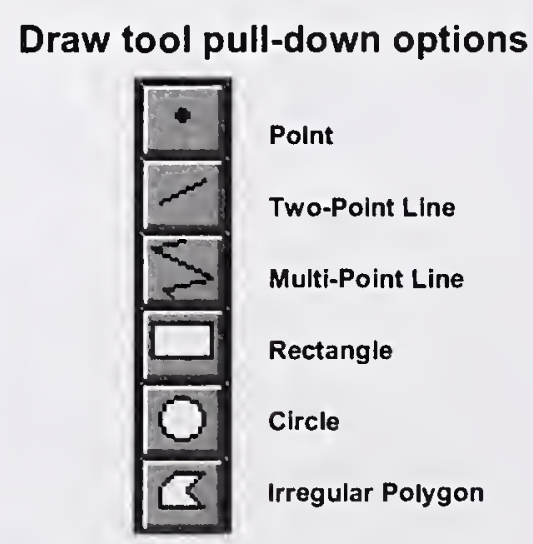

b. Use the mouse to delineate the feature in the view.

The way in which this is done depends upon the specific draw tool: for points, click once; for two-point lines, click once for the starting point and once for the ending point; for multi-point lines and irregular polygons, click once for each vertex, 
double-clicking the last vertex to indicate the shape is complete; for rectangles and circles, click and drag, releasing when the shape is the desired size.

c. After the shape is drawn, a data entry window will appear. Enter the appropriate attribute information for this shape and click OK. Clicking cancel will save the default attribute information (it will not delete the shape).

\section{To edit existing shapes in the theme:}

a. Select the Pointer tool.

b. Click on the shape you want to edit. Selection handles ( 8 solid black squares) will appear at the extent of the selected shape feature.

You can move the shape when you see the double-headed cursor. Click-drag the shape and drop it in the desired location.

To stretch or shrink the entire shape, grab one of the selection handles and drag in the appropriate direction.

To reshape the shape, move its vertices. Clicking on the selected shape will clear the selection handles and cause the vertex handles to appear at each of the shape's vertices. Reshape the shape by moving the mouse until the cursor appears as a crosshair on the vertex you want to reposition. Click-drag the vertex to the new position.

To delete the shape, choose Delete Graphics from the view Edit menu. Note that the Cut Graphics and Copy Graphics can be used like normal cut and paste tools. c. Note that there are some more advanced editing techniques. Search Help for "merge operations" and "snapping" for more information.

6. Select Stop Editing from the view Theme menu to get out of digitizing mode. If you want to edit another theme, you must first choose Stop Editing on the current theme and then start again from Step 2. 


\section{Summary of Other Advanced ArcView Features}

The following are some of the key tasks you can accomplish with ArcView that have not been discussed to this point:

- Display tabular data on a view.

- Import tabular data and then join it to the data in a view to display it geographically.

- SQL to retrieve records from a database and display them on a view.

- Geocode tables containing addresses and display them.

- Select features according to their attributes (attribute queries).

- Select features based on their proximity to other features (theme on theme queries).

- Find places where certain features coincide.

- Summarize and generate statistics on the attributes of features.

- Create charts showing the attributes of features.

- Lay out a map and print it. 


\section{MassGIS Data Viewer Quick Reference}

Information on ArcView is available via the Help menu. This reference sheet lists the additional features available in the Mass GIS Data Viewer view. These features are described in more detail starting on Page 11 of Introduction to ArcView and the MassGIS Data Viewer. Features that are disabled in the Runtime version appear in bold italics.

\section{Additional VIEW Buttons}

A The "A" button functions just as the Add Inventory Theme menu choice described below

2 The "Z" button functions just as the Zoom to Specific Extent menu choice described below

Q9 The "dog" button fetches an address and places a symbol on the TIGER street grid

W. The "scissors" button performs a cookie-cutter clip of one theme on another

\section{Additional VIEW Menu Choices}

Resize View

Resizes the view based on computer's resolution and saves project

Zoom to Query

Sets the view extent to selected features in the active theme

Zoom to Specific Extent

Sets the view extent by choosing from a menu of pre-defined and user-defined choices

User Extent Manager

Save and delete user-defined extents.

Add Inventory Theme

Add themes to the view by choosing from a menu of pre-defined choices

Reset the Project

Update the Theme and Zoom Inventories and clear the View

Create/Delete Overview

Creates/deletes a small overview window to control and display the extent of the view

Read/Write Graphics $O D B$ file

Writes graphics out to an ODB file, or reads them into the project from an ODB file

\section{Additional THEME Menu Choices}

Describe

Displays information (data source, field descriptions, etc.) on the active theme(s)

Change Symbolization

Make Subset

Changes the legend of the active theme to another pre-defined legend

Make Buffer

Creates a new theme containing only selected features in the active theme

Creates a buffer around a line or around or inside a polygon

\section{Additional EDIT Menu Choices}

Copy/Save/Restore Document

Saves and restores documents to $\mathrm{ODB}$ files

Registration Advanced feature: available on computers connected to an ArcInfo server

"Geo-reference" an image to the coordinate system of the MassGIS Data Viewer

Make Annotation

Write a file to create Annotation in ArcInfo based on text in the view

Additional Layout Document Buttons / Tool

Make layout's Viewframe proportional to the View window

Make a multicolumn legend

屋] Place a graphic of a table in the layout 



\section{Resources}

Official Guidelines for the Certification of Vernal Pool Habitat Vernal Pool Fact Sheet

Certification Criteria

Vernal Pool Field Observation Form

Rare Animal Observation Form

Suggested Reading

References 



\section{Division of \\ Fisheries \& Wildifie}

Wayne F. MacCallum, Director

$$
\text { Guidelines for the Certification of Qernal Pool Gabitat }
$$

\section{Vernal Pool Fact Sheet}

\section{What are Vernal Pools?}

Vernal pools are temporary bodies of fresh water that provide critical habitat for many vertebrate and invertebrate wildlife species. "Vernal" means spring, and indeed, many vernal pools are filled by spring rains and snowmelt, only to dry up during the hot, dry months of summer. However, many vernal pools are filled by the rains of autumn and may persist throughout the winter. Vernal pools are quite often very small and shallow; vernal pools that support rich communities of vertebrate and invertebrate animals may measure only a few yards across. However, vernal pools of several acres occur throughout Massachusetts.

\section{Where are Vernal Pools Found?}

Vernal pools are common in Massachusetts, occurring in every town in the state. Vernal pools are found across the landscape where small woodland depressions, swales or kettle holes collect spring runoff or intercept seasonally high groundwater tables. Although many people associate vernal pools only with dry woodland areas, vernal pools also occur in meadows, river floodplains, interdunal swales, and large vegetated wetland complexes. Vernal pool habitat occurs wherever water is contained for more than 2 months in the spring and summer of most years and where no fish are present.

\section{Why are Vernal Pools Valuable?}

Vernal pools constitute a unique and increasingly vulnerable type of wetland. Vernal pools are inhabited by many species of wildlife, some of which are totally dependent on vernal pools for their survival. Vernal pools do not support fish because they dry out annually or at least periodically. Some may contain water year round, but are free of fish as a result of significant drawdowns that result in extremely low dissolved oxygen levels. The wood frog (Rana sylvatica) and the four local species of mole salamander (Ambystoma spp.) have evolved breeding strategies intolerant of fish predation on their eggs and larvae; the lack of

Some state-listed species that may be found in vernal pools

\section{Species}

Blue-spotted salamander (Ambystoma laterale) ${ }^{2}$

Jefferson salamander (Ambystoma jeffersonianum $)^{2}$

Marbled salamander (Ambystoma opacum) ${ }^{2}$

Four-toed salamander (Hemidactylium scutatum) ${ }^{3}$

Eastern spadefoot toad (Scaphiopus holbrookii) ${ }^{2}$

Spotted turtle (Clemmys guttata) ${ }^{3}$

Wood turtle (Clemmys insculpta) ${ }^{3}$

Blanding's turtle (Emydoidea blandingii) ${ }^{2}$

1 Status pursuant to the MA Endangered Species Act - T: Threatened; SC: Special Concern

2 Obligate species require vernal pool habitat to successfully breed

3 Facultative species may use vernal pools but do not require them

fish populations is essential to the breeding success of these species. Other amphibian species, including the American toad (Bufo americanus), green frog (Rana clamitans), and the red-spotted newt (Notophthalmus viridescens), often exploit the fish-free waters of vernal pools but do not depend on them. Vernal pools also support rich and diverse invertebrate faunas. Some invertebrate species, such as fairy shrimp (Eubranchipus spp.), are also entirely dependent upon vernal pool habitat. Invertebrates are both important predators and prey in vernal pool ecosystems. Vernal pools are an important habitat resource for many birds, mammals, reptiles and amphibians, including many state-listed rare species. 


\section{Vernal Pool Protection}

The Massachusetts Wetlands Protection Act Regulations (310 CMR 10.00), the Massachusetts Surface Water Quality Standards (314 CMR 4.00) used to administer section 401 of the federal Clean Water Act, the Massachusetts Environmental Code: Title 5, and the Forest Cutting Practices Act regulations all provide protection to vernal pools that have been officially certified. The regulations for both the Wetlands Protection Act and Forest Cutting Practices Act also provide protection to vernal pools that have not been certified if their occurrence is adequately documented during permit review. Protection under any of these laws requires the following:

1) the vernal pool occurs in an area subject to the jurisdiction of the regulations; and

2) the activities proposed are regulated.

The Massachusetts Wetlands Protection Act regulations (310 CMR 10.00) protect certified vernal pools and up to 100 feet beyond the boundary of the pool (referred to as the "vernal pool habitat"), by preventing alterations which would result in the reduction of the wildlife habitat value of the certified vernal pool. A certified vernal pool is not automatically protected by these regulations, though. Certified vernal pools must occur within a resource area that comes under the jurisdiction of the Act before they receive protection. Similarly, the 100 feet around the vernal pool does not extend into non-jurisdictional upland or the buffer zone of a resource area. Though the regulations specify performance standards for vernal pools that are located in Bordering or Isolated Land Subject to Flooding (BLSF and ILSF respectively), vernal pools that occur within any wetland resource area are protected for their wildlife habitat value under the Wetlands Protection Act. Performance standards may be applied by a conservation commission to protect vernal pools that occur in any jurisdictional wetland resource area.

Vernal pools that are not certified may also be protected by a local conservation commission or the DEP if credible scientific evidence is presented up until the end of the appeals period for a Superseding Order of Conditions issued by the DEP. A conservation commission, or the DEP on appeal, can incorporate protective conditions into an Order of Conditions that would prevent the alteration of the wildlife habitat value of the pool and its 100 foot "vernal pool habitat" if they occur within a regulated wetland even though it is not certified.

Each DEP Regional Office has at least one Vernal Pool Liaison who should be contacted for all questions related to the protection of both certified and uncertified vernal pools. Since regulatory authority rests with the Department, they are best able to answer questions about what may or may not happen in or around vernal pools. Your regional liaison may be reached at the following addresses:

Northeast Regional Office

Wayne Lozzi

203-A Lowell Street

Wilmington, MA 01887

(978) 661-7600

Central Regional Office

Marielle Stone

627 Main Street

Worcester, MA 01608

(508) 792-7650
Southeast Regional Office

Daniel Gilmore

20 Riverside Drive

Lakeville, MA 02347

(508) 946-2700

Western Regional Office

Karen Hirschburg

State House West, 4th Floor

Springfield, MA 01103

(413) 748-1100 
The Massachusetts Surface Water Quality Standards (314 CMR 4.00) administer Section 40l of the fcderal Clean Water Act and protect certificd vernal pools. Under thesc regulations, any certified vernal pool is classificd as an Outstanding Resource Watcr (ORW). The regulations, administcred by the DEP, strictly prohibit discharges of solid or liquid fill within certified vcrnal pools. Storm drainage from roads and rooftops as well as solid fill are prohibitcd within the boundaries of the pool. As is the case with the Wctlands Protection Act however, the certificd vernal pool as well as the proposed activity must be within the jurisdiction of these regulations - the state's Clean Water Act - before it receives this protection.

The Massachusetts Environmental Title 5 (310 CMR 15.000) regulates the siting and construction of subsurface sewage disposal (septic) systems in the state. A system's septic tank and distribution box must be located a minimum of 50 feet, and the leaching field a minimum of 100 feet, from the boundary of a certified vernal pool.

The Massachusetts Forest Cutting Practices Act Regulations (3.04 CMR 11.00) protect certified vernal pools from certain forestry impacts. Harvesting requirements limit cutting to no more than $50 \%$ of the trees within 50 feet of a certified vernal pool. They also require that trees or tree tops not be felled in certified vernal pools, and restrict the use of pools as staging areas or skidder trails. Guidelines, similar to the regulations, are established for activities planned near uncertified vernal pools identified by consulting foresters.

\section{The Vernal Pool Boundary}

The extreme edges of vernal pool habitat represent one of the most ecologically valuable portions of these habitats. Shallow water at the edge of a pool is generally the first to thaw in the spring. This provides early access to the pool for the earliest breeding species. The shallow water zones also tend to be significantly warmer than the deeper portions of a vernal pool throughout the spring. Egg masses of early breeding amphibians benefit from the warmer water temperatures at the pool edges that promote rapid egg development.

The boundary of vernal pool habitat must incorporate the shallowest reaches of the pool. Where there is no distinct and clear topographic break at the edge of a pool, the maximum observed or recorded water level represents the ecological boundary of the vernal pool. This boundary is evident and should be delineated by leaf staining and other indicators of hydrology outside of the peak-flood stage of early spring (March through early April in most cases).

*PLEASE NOTE* The boundary of vernal pool habitat may be defined differently for the purpose of state or federal protection.

The physical, on-the-ground, boundary of a certified vernal pool is not established when a certification number is issued. Field observations of maximum flood levels, or of indicators of the maximum water level, must be made to determine the boundary. The boundary must be established based on field observation of water level indicators. The NHESP, in certifying a vernal pool, does not visit the pool, and as such does not establish the actual boundary through the certification process. Therefore, in recording observations of vernal pools for the purpose of certification, notes pertaining to observed water level and recognizable landmarks that show maximum flooding are extremely helpful in boundary delineation.

The Wetlands Protection Act regulations allows a project proponent to submit an opinion as to the extent of a certified vernal pool that is based upon a theoretical one year storm of a total of 2.7 inches of water in 24 hours. If an opinion based on this theoretical storm event is to be submitted, it should also include ground water that the basin is holding at the beginning of the spring amphibian breeding season. Calculations without groundwater inputs will under-represent the true size of the vernal pool. The DEP has stated in its program policies that ground water inputs should not be ignored in these calculations because it will result in a total volume that may be considerably smaller than the basin holds in any given spring. 


\section{How Can Vernal Pools be Certified?}

The Massachusetts Natural Heritage \& Endangered Species Program administers the official vernal pool certification program. The certification program depends entirely on volunteer effort and the initiative of interested individuals and organizations Interested parties should locate potential vernal pools and then:

1. Contact the Massachusetts Natural Heritage \& Endangered Species Program [(508) 792-7270, ext. 200 or www.state.ma.us/dfwele/dfw/nhesp/heritage.htm] to obtain the official Guidelines for the Certification of Vernal Pool Habitat, along with Vernal Pool Field Observation Forms;

Certification is based on proof that a confined basin depression provides important wildlife habitat consistent with the vernal pool certification criteria in the Guidelines. Animals that use vernal pools at some point in their life cycle are generally divided into two groups:

Obligate Species: those vertebrate and invertebrate species that rely on vernal pools for all or a portion of their life cycle and are unable to successfully complete their life cycle without vernal pools

Facultative Species: those vertebrate and invertebrate species that can use vernal pool habitat for all or a portion of their life cycle, but are able to successfully complete their life cycle in other water bodies

Obligate species serve as direct indicators of vernal pool habitat because they require at least two months of flooded conditions and the absence of established fish populations. When breeding evidence of obligate species is documented, it is not necessary to prove that an established, reproducing fish population does not exist. Facultative species serve as indirect indicators of vernal pool habitat. Therefore, if only facultative species are observed, evidence that there is no reproducing fish population must also be submitted for certification.

2. Fill out and submit a Field Observation Form along with photographic documentation of the physical and biological criteria required by the Guidelines and required maps to the NHESP for review. Photographs (slides or prints) are the preferred type of documentation of the biological certification criteria observed in a vernal pool. The most easily photographed evidence of vernal pool indicator species is egg masses of wood frogs and mole salamanders. These are conspicuous in the early spring and easily distinguished from other amphibian eggs. See the Guidelines for details.

Following receipt of certification materials, the Natural Heritage \& Endangered Species Program assesses the completeness and accuracy of the information and documentation submitted. The NHESP does not field visit pools prior to certification but relies on the presentation of accurate and clear documentation.

After it is determined that a vernal pool meets the physical and biological criteria established in the Guidelines, it will be officially certified by the NHESP. The observer, local conservation commission, regional office of the Department of Environmental Protection and the landowner are notified of the certification. The locations of certified vernal pools are plotted on the NHESP's "Estimated Habitats of Rare Wetlands Wildlife and Certified Vernal Pools" on a biennial basis. These maps are sent to the town clerk and to the conservation commission, and are available for viewing by the public. The NHESP also produces a statewide Atlas of these maps, reproduced at a reduced scale, which is available at cost. The certified vernal pool datalayer is also available in digital format through the MassGIS office. 


$$
\text { Guidelines for the Oertification of Oernal Eool Elabitat }
$$

\section{CERTIFICATION CRITERIA}

Please read and understand the DOCUMENTATION REQUIREMENTS in the next section before submitting vernal pool certification applications.

Documentation of the biological and physical criteria described in this section is necessary to obtain official certification of any vernal pool.

\section{DOCUMENTATION OF ANY ONE OF THE FOLLOWING (1-3) WILL CONFIRM THE EXIST- ENCE OF VERNAL POOL HABITAT AND IS SUFFICIENT FOR OFFICIAL CERTIFICATION}

\section{1) The Obligate Species Method \\ 2) The Facultative Species Method \\ 3) The Dry Pool Method}

\section{1) The Obligate Species Method}

Evidence of a confined basin depression with no permanently flowing outlet AND one or more of the following:

\section{A Breeding* Obligate Amphibian}

Wood frog (Rana sylvatica)

Spotted salamander (Ambystoma maculatum)

Blue-spotted salamander (Ambystoma laterale)**

Jefferson salamander (Ambystoma jeffersonianum)**

Marbled salamander (Ambystoma opacum)**

Eastern spadefoot toad (Scaphiopus holbrooki)**

\section{OR}

1B Adult Obligate Invertebrate

Fairy shrimp (ANOSTRACA: Eubranchipus)

\section{* Acceptable Breeding Evidence}

Documentation of any one of the following proves that an area functions as vernal pool habitat. For the purposes of official certification, if amphibian evidence is submitted it must show evidence of breeding.

1. Breeding Adults

- Frogs and toads: breeding chorus and/or mated pairs

- Salamanders: courting individuals (congressing) and/or spermatophores

2. Egg Masses (two or more are required)

3. Larvae (tadpoles or salamander larvae)

4. Transforming Juveniles

- Frogs and toads: tail remnants evident

- Salamanders: gill remnants evident

\section{** State-listed Species}

State-listed Endangered (E), Threatened (T) and Special Concern (SC) species are protected under the Massachusetts Endangered Species Act (321 CMR 10.60); fill out a Rare Animal Observation Form and submit along with Certification Form. 


\section{Guidelines for the Certification of Pernal Pool Glabitat}

\section{CERTIFICATION CRITERIA \\ Continued}

\section{2) The Facultative Species Method}

Evidence of a confined basin depression with no permanently flowing outlet AND evidence that there is no established, reproducing fish population

AND photographs of two or more of the following:

\section{AMPHIBIANS}

Breeding* Spring peeper (Pseudacris crucifer)

Breeding* Gray treefrog (Hyla versicolor)

Breeding* American toad (Bufo americanus)

Breeding* Fowler's toad (Bufo woodhousii)

Breeding* Green frog (Rana clamitans melanota)

Breeding* Pickerel frog (Rana palustris)

Breeding* Leopard frog (Rana pipiens)

Breeding* Four-toed salamander

(Hemidactylium scutatum) $^{* *}$

Adult or Breeding* Red-spotted Newt

(Notophthalmus v. viridescens)

\section{REPTILES}

Spotted turtle (Clemmys guttata)**

Blanding's turtle (Emydoidea blandingii)**

Wood turtle (Clemmys insculpta)**

Painted turtle (Chrysemys p. pictata)

Snapping turtle (Chelydra serpentina)

\section{INVERTEBRATES}

Predaceous diving beetle larvae (Dytiscidae)

Water scorpion (Nepidae)

Dragonfly larvae (Odonata: Anisoptera)

Damselfly larvae (Odonata: Zygoptera)

Dobsonfly larvae (Corydalidae)

Whirligig beetle larvae (Gyrinidae)

Caddisfly larvae (Trichoptera)

Leeches (Hirundinea)

Freshwater (fingernail) clams (Pisidiidae)

Amphibious, air-breathing snails (Basontmatophora)

\section{3) The Dry Pool Method}

Evidence of a confined basin depression containing no standing water (dry pool)

AND one or more of the following:

Cases of caddisfly larvae (Trichoptera)

Adults, juveniles or shells of either of the following:

Freshwater clams (Pisidiidae)

Amphibious, air-breathing snails (Basommatophora)

Shed skins (exuvia) of dragonfly or damselfly larvae on vegetation along the edge of pool 


\section{Guidelines for the Certification of Nernal Pool Glabitat}

\section{DOCUMENTATION REQUIREMENTS}

Documentation of the biological and physical characteristics listed in the CERTIFICATION CRITERIA must be submitted for official certification of a vernal pool. Photographic prints or slides are the preferred method of documentation, but video tapes of evidence or audio recordings of calling frogs are acceptable. Field notes are encouraged, but are not accepted as the sole source of evidence; they must be submitted along with photographic or taped documentation.

The following field observations must be adequately documented
Label all photographs as follows:

Location of pool (or your tracking number)

Date of photograph

Observer's name

1. Biological criteria:

OR OR

1A Clear photographs or video of obligate amphibian breeding evidence

1B Clear photographs or video of facultative invertebrate or vertebrate species (AND 2B or 2C)

1C Audio tape of frog breeding chorus

2. Fishlessness:

2A Evidence of obligate species per CERTIFICATION CRITERIA (1A above)

OR

OR $2 \mathrm{~B}$ Photograph of dry vernal pool

$2 \mathrm{C}$ Scientific evidence (e.g. seining) that documents the absence of fish

3. Physical criteria:

Clear photographs or video of the vernal pool demonstrating the lack of permanently flowing connections to larger wetlands

\section{MAPPING REQUIREMENTS}

It is critical to provide maps that are accurate and clear when submitting information for state vernal pool certification. A copy of a 1:24,000 or 1:25,000 scale U.S. Geological Survey topographic map is required, and additional maps that clarify the position of the vernal pool must be submitted. There are many maps are acceptable for this purpose, but please note that street maps generally are not. Supporting maps should provide more detail than the USGS topo map.

At least one from each of the following groups must be submitted:

\section{GROUP 1}

\section{USGS topographic:}

The location of the vernal pool must be clearly and accurately marked with an ' $\mathrm{X}$ ' or dot. Be sure to write down the name of the map (found in the bottom right-hand corner) on the copy sent in

\section{GROUP 2}

\section{Aerial photograph}

Large scale (1:12,000 or better) with pool clearly visible

Sketch map with compass directions and distances

Magnetic compass direction and distances from two permanent landmarks within 1000 feet of the pool. Landmarks should be readily identifiable in the field and clearly described on the submitted map

Professional survey or local 1 - or 2-foot contour topographic map Large scale topographic maps or project plans where the depression is evident 


\section{Guidelines for the Certification of Qernal Pool Gabitat}

Examples of maps that can be submitted for certification. A USGS topographic map must be submitted (please note the map name, found in the lower right and upper left corners of the map), along with at least one additional map (see previous page for list).

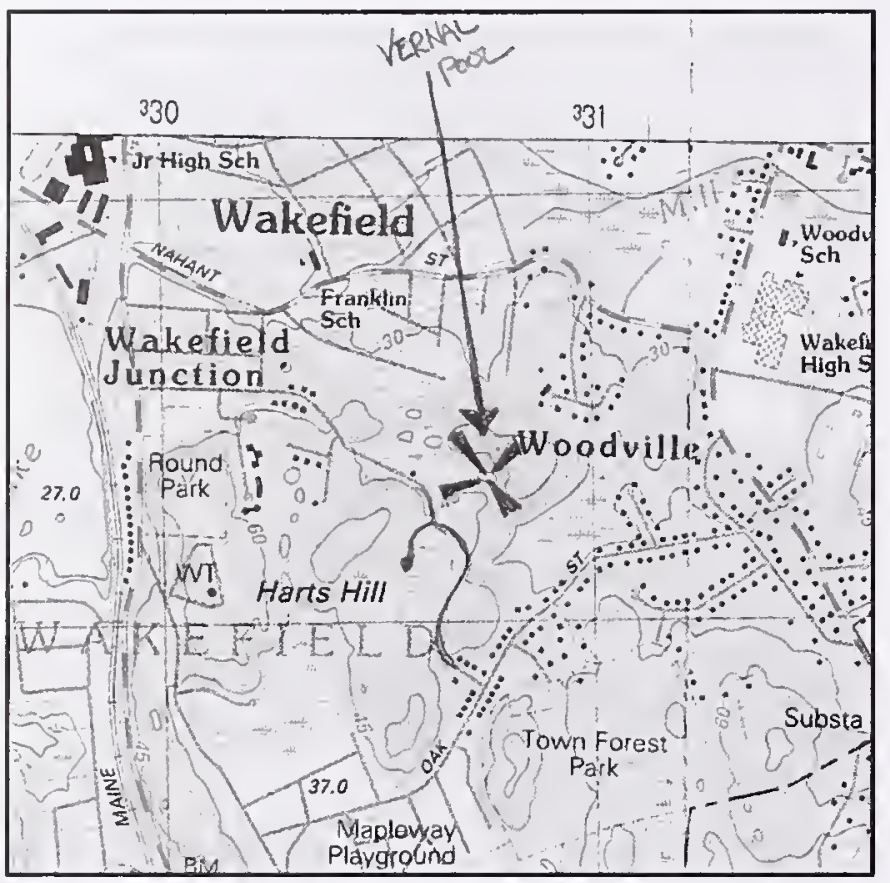

USGS Topographic map section

with pool clearly marked

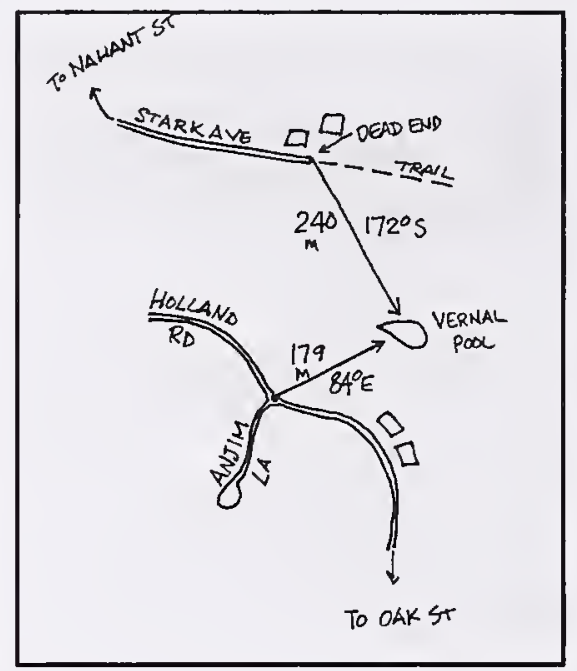

Sketch map with compass directions and distance from landmarks

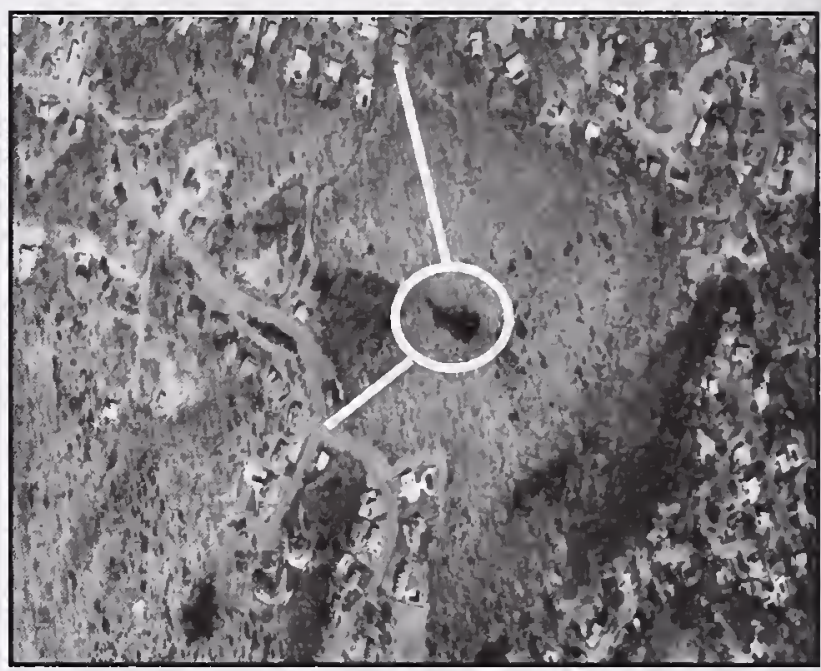

B\&W copy of color infra-red aerial photograph (1:12,000 scale) with pools visible or clearly marked

\section{Field Observation Form}

Application for certification of vernal pool habitat should be made using the standard field observation form (revised in 1999). All requested information should be filled out to the fullest extent possible. Additional directions are provided on the field form.

Please give particular attention to the following items:

Section 1: Written directions to the pool must be provided, noting field markers to help navigation.

Section 2: Please indicate the dates on which evidence was collected, including the year.

Section 3: Indicate the evidence of obligate and facultative species collected at each pool. If egg masses were found, indicate the number of masses discovered.

Section 4 and 5: Check the boxes corresponding to evidence submitted for each pool (in photographs or tape)

Optional Information: Information provided in this section gives the Natural Heritage \& Endangered Species Program a better sense of the type of vernal pools that are being identified through the certification program, and aides in-field identification of the pools should anyone need to visit it. This section is optional, but provides very helpful information.

Section 6: Field forms must be signed at the bottom of page 2.

Incomplete submissions will be returned in full with a letter indicating any missing information. When the requested information has been collected, the application may be resubmitted.

Submit completed applications to:

Vernal Pool Certification

Natural Heritage \& Endangered Species Program

Route 135

Westborough, MA 0158 I 


\section{Pool location}

Town County

USGS Quadrangle name

SERIES $7.5^{\prime} \times 7.5^{\prime}$

SERIES $7.5^{\prime} \times 15^{\prime}$

WRITEN DIRECTIONS TO POOL:

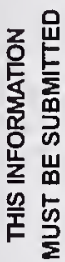

(USE ADOITIONAL PAGES, IF NECESSARY.)

\section{Observation dates}

Last date pool observed

First date pool/species observed

Last date species observed

3 A. Evidence: obligate amphibians Indicate date of observation.

\begin{tabular}{|c|c|c|c|c|c|}
\hline$*=$ RARE SPECIES & $\begin{array}{l}\text { COURTING } \\
\text { ADULTS }\end{array}$ & SPERMATOPHORES & $\begin{array}{c}\text { EGG } \\
\text { MASSES (2+) }\end{array}$ & $\begin{array}{l}\text { SALAMANDER } \\
\text { LARVAE }\end{array}$ & $\begin{array}{c}\text { TRANSFORMING } \\
\text { JUVENILES }\end{array}$ \\
\hline \multicolumn{6}{|l|}{$\begin{array}{l}\text { SPOTTED } \\
\text { SALAMANDER }\end{array}$} \\
\hline $\begin{array}{l}\text { * } \quad \text { BLUE-SPOTTED } \\
\text { SALAMANDER }\end{array}$ & & & & & \\
\hline $\begin{array}{l}\text { JEFFERSON } \\
\text { SALAMANDER }\end{array}$ & & & & & \\
\hline $\begin{array}{l}\text { MARBLED } \\
\text { SALAMANDER }\end{array}$ & & & & & \\
\hline \multicolumn{6}{|l|}{$\begin{array}{l}\text { UNIDENTIFIED MOLE } \\
\text { SALAMANDER }\end{array}$} \\
\hline & $\begin{array}{l}\text { BREEDING } \\
\text { CHORUS }\end{array}$ & $\begin{array}{l}\text { MATED } \\
\text { PAIRS }\end{array}$ & $\begin{array}{c}\text { EGG } \\
\text { MASSES (2+) }\end{array}$ & $\begin{array}{c}\text { FROG } \\
\text { TADPOLES } \\
\end{array}$ & $\begin{array}{l}\text { TRANSFORMING } \\
\text { JUVENILES }\end{array}$ \\
\hline \multicolumn{6}{|l|}{ WOOD FROG } \\
\hline SPADEFOOT TOAD & & & & & \\
\hline
\end{tabular}

\section{Instructions}

FOR COMPLETE INFORMATION ABOUT CERTIFICATION, REFER TO GUIDELINES FOR CERTIFICATION OF VERNAL POOL HABITAT.

PROVIDE ALL OF THE INFORMATION REOUESTED IN BOXES 1-6. IF MORE SPACE IS REOUIRED, ATTACH ADDITIONAL PAGES. INCLUDE ALL REOUIRED PHOTOGRAPHS AND DOCUMENTATION. SIGN THE FORM IN THE AREA PROVIDED ON THE REVERSE SIDE. INCOMPLETE OR UNSIGNED SUBMISSIONS WILL BE RETURNED.

THE FOLLOWING INSTRUCTIONS REFER TO EACH OF THE NUMBERED BOXES.

1. THE $7.5 \times 7.5$ SERIES HAS THE LEGEND " 7.5 MINUTE SERIES" IN THE UPPER RIGHT HAND CORNER ALONG WITH THE ouadrangle name. The $7.5 \times 15$ Minute SERIES IS SO LABELED IN THE UPPER RIGHT HAND CORNER AND HAS THE QUADRANGLE NAME IN THE LOWER RIGHT CORNER.

WRITTEN DIRECTIONS MUST BE INCLUDED.

2 INDICATE THE FIRST AND LAST DATES THAT THE POOL OR ITS BIOLOGICAL COMPONENTS WERE OBSERVED.

3. PART A AND B ARE FOR CERTIFICATION by obligate SPECIES. PART C IS EITHer For ADDITIONAL INFORMATION (APPRECIATED) OR FOR CERTIFICATION BY THE FACULTATIVE SPECIES. IF CERTIFYING BY OBLIGATE SPECIES, PROVIDE A PHOTOGRAPH OF THE POOL HOLDING WATER AND AT LEAST ONE PHOTOGRAPH (OR AUDIO TAPE FOR CHORUSING) OF BREEDING ACTIVITY.

FOR CERTIFICATION BY FACULTATIVE SPECIES, PROVIDE PHOTOGRAPHS OF THE POOL HOLDING WATER AND PHOTOGRAPHS (OR TAPES) OF THE FACULTATIVE SPECIES AS REOUIRED. ADDITIONALLY, PROVIDE A PHOTOGRAPH OF THE POOL

WHEN DRY OR OTHERWISE PROVE THAT IT HAS NO FISH.

\section{B. Evidence: fairy shrimp}

3 C. Evidence: facultative organisms Two or more must be documented. Indicate date of observation.

\begin{tabular}{|c|c|c|c|c|c|}
\hline & & & & & \\
\hline * = RARE SPECIES & $\begin{array}{l}\text { DATE } \\
\text { OBSERVED } \\
\end{array}$ & ACTIVITY OBSERVED & & $\begin{array}{l}\text { DATE } \\
\text { OBSERVED }\end{array}$ & ACTIVITY OBSERVED \\
\hline $\begin{array}{c}\text { BREEDING } \\
\text { SPRING PEEPERS }\end{array}$ & & & PAINTED TURTLES & & \\
\hline $\begin{array}{l}\text { BREEDING } \\
\text { GRAY TREEFROGS }\end{array}$ & & & SNAPPING TURTLES & & \\
\hline $\begin{array}{l}\text { BREEDING } \\
\text { GREEN FROGS }\end{array}$ & & & $\begin{array}{l}\text { PREDACEOUS DIVING } \\
\text { BEETLE LARVAE }\end{array}$ & & \\
\hline $\begin{array}{c}\text { BREEDING } \\
\text { LEOPARD FROGS } \\
\end{array}$ & & & WATER SCORPIONS & & \\
\hline $\begin{array}{c}\text { BREEDING } \\
\text { PICKEREL FROGS }\end{array}$ & & & DRAGONFLY NYMPHS & & \\
\hline $\begin{array}{c}\text { BREEDING } \\
\text { AMERICAN TOADS }\end{array}$ & & & DAMSELFLY NYMPHS & & \\
\hline $\begin{array}{c}\text { BREEDING } \\
\text { FOWLER'S TOADS }\end{array}$ & & & DOBSONFLY LARVAE & & \\
\hline $\begin{array}{c}\text { * BREEDING FOUR-TOED } \\
\text { SALAMANDERS }\end{array}$ & & & $\begin{array}{l}\text { WHIRLIGIG BEETLE } \\
\text { LARVAE }\end{array}$ & & \\
\hline $\begin{array}{l}\text { RED-SPOTTED } \\
\text { NEWT (ADULTS) }\end{array}$ & & & $\begin{array}{l}\text { CADDISFLY } \\
\text { LARVAE }\end{array}$ & & \\
\hline * SPOTtEd TURTLES & & & LEECHES & & \\
\hline * WOOD TURTLES & & & $\begin{array}{l}\text { FINGERNAIL (FRESHWATER) } \\
\text { CLAMS }\end{array}$ & & \\
\hline * BLANDINGS TURTLES & & & $\begin{array}{l}\text { AMPHIBIOUS AIR-BREATHING } \\
\text { SNAILS }\end{array}$ & & \\
\hline
\end{tabular}




\section{Instructions (continued)}

4. INDICATE THE PHOTOGRAPHS BEING

SUBMITTED. LABEL, DATE, AND SIGN ALL PHOTOS.

5. MARK THE POOL CLEARLY ON ALL MAPS. THE POOL MUST BE CLEARLY DISTINGUISHED FROM OTHER WetLANDS AND be Locatable by OtHers. Provide ANY MAPS THAT WOULD HELP SOMEONE UNFAMILIAR WITH THE AREA LOCATE THE VERNAL POOL IN THE FIELD.

6. THE FORM MUST BE SIGNED. UNSIGNED SUBMISSIONS WILL BE RETURNED WITHOUT FURTHER ACTION.

OPTIONAL INFORMATION:

Property owner. Provide information about PROPERTY OWNER(S), IF KNOWN. IT IS RECOMMENDED THAT YOU SEEK PROPERTY OWNER PERMISSION PRIOR TO CERTIFICATION ACTIVITIES.

RARE SPECIES. A PHOTOGRAPH IS NECESSARY FOR DOCUMENTATION OF RARE SPECIES HABITAT.

Description. Provide any information that WILL DISTINGUISH THE POOL FROM OTHER WETLANDS (BOULDERS, DEBRIS, TREE SPECIES, ETC.).

Optional information Although the following information is not required for protect the vernal pool, its habitat and species.

\section{Property owner}

IT IS STRONGLY RECOMMENDED THAT LANDOWNER PERMISSION DE OBTAINED PRIOR TO COLLECTING CERTIFICATION OCUMENTATION.

Name

Address

Town

State

ZIP

Rare wetland $\mathrm{Y}$ ] W Were ANY RARE STATE-LISTED SPECIES OBSERVED USING species THIS POOL?

$\mathrm{Y} N$ IS A PHOTOGRAPH OF THE RARE SPECIES INCLUDED WITH THIS FILING?

\section{Description of pool and surroundings}

DIMENSIONS: APPROXIMATE LENGTH MUST BE LABELED,

4. Photographs

POOL HOLDING WATER

OBLIGATE +/OR FACULTATIVE SPECIES

DRY POOL (REQUIRED FOR EVIDENCE 3C)

\section{Maps submitted}

\footnotetext{
$\square$ USGS TOPOGRAPHIC MAP (REQUIRED)

AND ONE OR MORE OF THE FOLLOWING:

AERIAL PHOTOGRAPH

SKETCH MAP WITH COMPASS DIRECTIONS AND

DISTANCES FROM LAND MARKS

PROFESSIONAL SURVEY

LARGE SCALE TOPO

OPTIONAL EXTRA INFORMATION

SKETCH MAP OF AREA

ASSESSOR'S MAP

GPS LONGITUDE/LATITUDE COORDINATES
}

ARE THERE OTHER DISTINCTMEFEATURES ABOUT THIS POOL (VEGETATON TMPES, ABANDONED VEHICLES, FOOT TRAILS, ETC.) THAT WOULD HEIP SOMEONE RECOGNIZE IT?

\section{Observer information \& signature}

Name

Address

Town

State

ZIP

Telephone

e-mail

I hereby certify under the pains and penalties of perjury that the information contained in this report is true and complete to the best of my knowledge.
SEND COMPLETED FORM AND SUPPORTING DOCUMENTATION TO: r - - - - - - - I NH\&ESP

Vernal Pool Certification MA Division OF FisherIES \& WILDLIFE ROUTE 135

I WestBorough, MA 01581

ᄂ - - - - - - - - -

All submissions and supporting documents will be retained by the Natural Heritage \& Endangered Species Program. Information submitted on this form and other documents is part of the public record and is available to interested parties under the State Documents Request Law. 


\section{Natural Heritage \& Endangered Species Program Massachusetts Division of Fisheries and Wildlife Vernal Pool Field Observation Form}

(For use with Guidelines for Certification of Vernal Pool Habitat)

\section{Pool location}

Town County

USGS Quadrangle name

SERIES $7.5^{\prime} \times 7.5^{\prime}$

WRITTEN DIRECTIONS TO POOL:

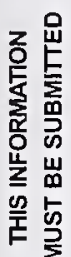

(USE ADDITIONAL PAGES, IF NECESSARY.)

\section{Observation dates}

Last date pool observed

First date pool/species observed

Last date species observed

$3 \mathrm{~A}$. Evidence: obligate amphibians Indicate date of observation.

\begin{tabular}{|c|c|c|c|c|c|}
\hline * = RARE SPECIES & $\begin{array}{l}\text { COURTING } \\
\text { ADULTS }\end{array}$ & SPERMATOPHORES & $\begin{array}{l}\text { EGG } \\
\text { MASSES (2+) }\end{array}$ & $\begin{array}{l}\text { SALAMANDER } \\
\text { LARVAE }\end{array}$ & $\begin{array}{l}\text { TRANSFORMING } \\
\text { JUVENILES }\end{array}$ \\
\hline \multicolumn{6}{|l|}{$\begin{array}{l}\text { SPOTTED } \\
\text { SALAMANDER }\end{array}$} \\
\hline $\begin{array}{r}\text { * } \\
\text { BLUE-SPOTTED } \\
\text { SALAMANDER }\end{array}$ & & & & & \\
\hline $\begin{array}{l}\text { JEFFERSON } \\
\text { SALAMANDER }\end{array}$ & & & & & \\
\hline \multicolumn{6}{|l|}{$\begin{array}{c}\text { MARBLED } \\
\text { SALAMANDER }\end{array}$} \\
\hline \multicolumn{6}{|l|}{$\begin{array}{c}\text { UNIDENTIFIED MOLE } \\
\text { SALAMANDER }\end{array}$} \\
\hline & $\begin{array}{l}\text { BREEDING } \\
\text { CHORUS }\end{array}$ & $\begin{array}{l}\text { MATED } \\
\text { PAIRS }\end{array}$ & $\begin{array}{c}\text { EGG } \\
\text { MASSES (2+) }\end{array}$ & $\begin{array}{c}\text { FROG } \\
\text { TADPOLES }\end{array}$ & $\begin{array}{l}\text { TRANSFORMING } \\
\text { JUVENILES }\end{array}$ \\
\hline \multicolumn{6}{|l|}{ WOOD FROG } \\
\hline SPADEFOOT TOAD & & & & & \\
\hline
\end{tabular}

For office use only.

\section{Instructions}

FOR COMPLETE INFORMATION ABOUT CERTIFICATION, REFER TO GUIDELINES FOR CERTIFICATION OF VERNAL POOL HABITAT.

PROVIDE ALL OF THE INFORMATION REOUESTED IN BOXES 1-6. IF MORE SPACE IS REQUIRED, ATTACH ADDITIONAL PAGES. INCLUDE ALL REQUIRED PHOTOGRAPHS AND DOCUMENTATION. SIGN THE FORM IN THE AREA PROVIDED ON THE REVERSE SIDE. INCOMPLETE OR UNSIGNED SUBMISSIONS WILL BE RETURNED.

THE FOLLOWING INSTRUCTIONS REFER TO EACH OF THE NUMBERED BOXES.

1. THE $7.5 \times 7.5$ SERIES HAS THE LEGEND "7.5 MINUTE SERIES" IN THE UPPER RIGHT HAND CORNER ALONG WITH THE QUADRANGLE NAME. THE $7.5 \times 15$ MINUTE SERIES IS SO LABELED IN THE UPPER RIGHT HAND CORNER AND HAS THE QUADRANGLE NAME IN THE LOWER RIGHT CORNER.

WRITTEN DIRECTIONS MUST BE INCLUDED.

2 INDICATE THE FIRST AND LAST DATES THAT THE POOL OR ITS BIOLOGICAL COMPONENTS WERE OBSERVED.

3. Part A and B are for certification BY OBLIGATE SPECIES. PART $C$ IS EITHER FOR ADDITIONAL INFORMATION (APPRECIATED) OR FOR CERTIFICATION BY THE FACULTATIVE SPECIES. IF CERTIFYING BY OBLIGATE SPECIES, PROVIDE A PHOTOGRAPH OF THE POOL HOLDING WATER AND AT LEAST ONE PHOTOGRAPH (OR AUDIO TAPE FOR CHORUSING) OF BREEDING ACTIVITY.

FOR CERTIFICATION BY FACULTATIVE SPECIES, PROVIDE PHOTOGRAPHS OF THE POOL HOLDING WATER AND PHOTOGRAPHS (OR TAPES) OF THE faCultative SPECIES AS REQUired. AdditionALLY, PROVIDE A PHOTOGRAPH OF THE POOL WHEN DRY OR OTHERWISE PROVE THAT IT HAS NO FISH.

\section{B. Evidence: fairy shrimp}

3 C. Evidence: facultative organisms two or more must be documented. Indicate date of observation.

\begin{tabular}{|c|c|c|}
\hline & & \\
\hline$* \quad=$ RARE SPECIES & $\begin{array}{c}\text { DATE } \\
\text { OBSERVED }\end{array}$ & ACTIVITY OBSERVED \\
\hline $\begin{array}{c}\text { BREEDING } \\
\text { SPRING PEEPERS } \\
\end{array}$ & & \\
\hline $\begin{array}{c}\text { BREEDING } \\
\text { GRAY TREEFROGS }\end{array}$ & & \\
\hline $\begin{array}{l}\text { BREEDING } \\
\text { GREEN FROGS }\end{array}$ & & \\
\hline $\begin{array}{c}\text { BREEDING } \\
\text { LEOPARD FROGS }\end{array}$ & & \\
\hline $\begin{array}{c}\text { BREEDING } \\
\text { PICKEREL FROGS }\end{array}$ & & \\
\hline $\begin{array}{c}\text { BREEDING } \\
\text { AMERICAN TOADS }\end{array}$ & & \\
\hline $\begin{array}{c}\text { BREEDING } \\
\text { FOWLER'S TOADS }\end{array}$ & & \\
\hline $\begin{array}{c}\text { * BREEDING FOUR-TOED } \\
\text { SALAMANDERS }\end{array}$ & & \\
\hline $\begin{array}{l}\text { RED-SPOTTED } \\
\text { NEWT (ADULTS) }\end{array}$ & & \\
\hline * SPOTTED TURTLES & & \\
\hline * WOOD TURTLES & & \\
\hline * BLANDINGS TURTLES & & \\
\hline
\end{tabular}

\begin{tabular}{|c|c|}
\cline { 2 - 2 } \multicolumn{1}{c|}{} & $\begin{array}{c}\text { DATE } \\
\text { OBSERVED }\end{array}$ \\
\hline PAINTED TURTLES & \\
\hline SNAPPING TURTLES & \\
\hline $\begin{array}{c}\text { PREDACEOUS DIVING } \\
\text { BEETLE LARVAE }\end{array}$ & \\
\hline WATER SCORPIONS & \\
\hline DRAGONFLY NYMPHS & \\
\hline DAMSELFLY NYMPHS & \\
\hline DOBSONFLY LARVAE & \\
\hline $\begin{array}{c}\text { WHIRLIGIG BEETLE } \\
\text { LARVAE }\end{array}$ & \\
\hline $\begin{array}{c}\text { CADDISFLY } \\
\text { LARVAE }\end{array}$ & \\
\hline $\begin{array}{c}\text { LEECHES } \\
\text { FINGERNAIL (FRESHWATER) } \\
\text { CLAMS }\end{array}$ & \\
\hline AMPHIBIOUS AIR-BREATHING \\
SNAILS
\end{tabular}
ACTIVITY OBSERVEO 


\section{Instructions (continued)}

4. INDICATE THE PHOTOGRAPHS BEING

SUBMITTED. LABEL, DATE, AND SIGN ALL PHOTOS.

5. MARK THE POOL CLEARLY ON ALL MAPS. THE POOL MUST BE CLEARLY DISTINGUISHED FROM OTHER Wetlands and be locatable by others. Provide ANY MAPS THAT WOULD HELP SOMEONE UNFAMILIAR WITH THE AREA LOCATE THE VERNAL POOL IN THE FIELD.

6. THE FORM MUST BE SIGNED. UNSIGNED SUBMISSIONS WILL BE RETURNED WITHOUT FURTHER ACTION.

Optional INFORMATION:

Property oWner. PRovide information about PROPERTY OWNER(S), IF KNOWN. IT IS RECOMMENDED THAT YOU SEEK PROPERTY OWNER PERMISSION PRIOR TO CERTIFICATION ACTIVITIES.

RARE SPECIES. A PHOTOGRAPH IS NECESSARY FOR DOCUMENTATION OF RARE SPECIES HABITAT.

DESCRIPTION. PROVIDE ANY INFORMATION THAT WILL DISTINGUISH THE POOL FROM OTHER WETLANDS (BOULDERS, DEBRIS, TREE SPECIES, ETC.).
Optional information $\begin{aligned} & \text { Although the following information is not required for } \\ & \text { certification, it is useful to NHESP to possibly better }\end{aligned}$ protect the vernal pool, its habitat and species.

\section{Property owner}

IT IS STRONGLY RECOMMENDED THAT LANDOWNER PERMISSION DE OBTAINEO PRIOR TO COLLECTING CERTIFICATION DOCUMENTATION.

Name

Address

Town

State

ZIP

Rare wetland $\mathrm{Y} N$ WeRE ANY RARE StATE-LISTED SPECIES OBSERVED USING species THIS POOL?

$\checkmark N$ IS A PHOTOGRAPH OF THE RARE SPECIES INCLUDED WITH THIS FILING?

\section{Description of pool and surroundings}

DIMENSIONS: APPROXIMATE LENGTH

APPROXIMATE WIDTH

APPROXIMATE DEPTH

DESCRIBE DISTINCTIVE FEATURES (ROADS, STRUCTURES, BOULDERS, ETC.) WHICH ARE VISIBLE FROM OR NEAR THE POOL.

ARE THERE OTHER DISTINCTIVE FEATURES ABOUT THIS POOL (VEGETATON TYPES, ABANDONED VEHICLES, FOOT TRAILS, ETC.) THAT WOULD HELP SOMEONE RECOGNIZE IT?

\section{Observer information \& signature}

Name

Address

Town

State

ZIP

Telephone

e-mail

I hereby certify under the pains and penalties of perjury that the information contained in this report is true and complete to the best of my knowledge.
SEND COMPLETED FORM AND SUPPORTING DOCUMENTATION TO: r - - - - - - - NH\&ESP

Vernal Pool Certification MA Division OF FisheRIES \& WILdLIFE ROUTE 135

I WestBorough, MA 01581

ᄂ - - - - - - - -

All submissions and supporting documents will be retained by the Natural Heritage \& Endangered Species Program. Information submitted on this form and other documents is part of the public record and is available to interested parties under the State Documents Request Law. 
* Species name (scientific or common):

* Date and time of observation:

Amount of time spent surveying area:

In order for this form to be processed, the sections preceded by an asterisk $\left(^{*}\right)$ must be completed.

* Town: County: Waterbody:

* Please attach a photocopy of the appropriate section of a USGS topo map (or similar map if a topo map is unavailable) with the site of the observation marked. Please indicate available or occupied habitat and extent of population, if known. Indicate area searched including negative results (i.e. apparently suitable habitat was or was not surveyed). USGS ( 7.5 or 15 ) Topographic Map Name:

* Describe how to get to the site using obvious permanent landmarks such as a road intersection (measuring to at least the nearest $1 / 10$ mile).

* Number, age, and sex of individuals:

Please describe how age and sex were determined:

Evidence of reproduction (e.g., eggs, nests, carrying food to young, copulation):

Behavioral notes (e.g., crossing the road, basking):

* Photographs taken? ( $\mathrm{Y} / \mathrm{N}$ ) If $\mathrm{Y}$, please submit one clear photograph.

* Specimen taken? ( $\mathrm{Y} / \mathrm{N}$ ) If $\mathrm{Y}$, where will the specimen be deposited:

* ID is based on what (e.g., sculpted shell, flight pattern):

Have you observed this species at this site in previous years? ( $\mathrm{Y} / \mathrm{N}$ ) If $\mathrm{Y}$, please give details:

Commonwealth of Massachusetts

Division of Fisheries \& Wildlife, Route 135, Westborough, MA 01581 (508)792-7270 ext. 200

http://www.state.ma.us/dfwele 
Describe the habitat where the species is located. List dominant vegetation, size of the habitat, and information on the physical environment such as substrate type, hydrology, moisture regime, slope, aspect. Also, if possible provide information on the surrounding land use.

Associated species:

Alteration of ecological processes (e.g., damming, logging, rip-rapping of stream)? ( Y / N ) If Y, describe:

Observed or potential threats to the species or its habitat at this site:

Landowner's name and address, if known:

Additional comments:

* Observer Information: Name: Phone Number

Address:

Affiliation/Qualifications:

* Form Filled Out By:

Name:

Phone Number:

(if different from above) Address:

Affiliation/Qualifications:

I hereby certify under pains and penalties of perjury that the information contained in this report is true and complete to the best of my knowledge.

* Signature: Date:

Please submit this form and all supporting documentation (USGS map, photo, etc.) to:

Natural Heritage and Endangered Species Program

MA Division of Fisheries and Wildlife

Route 135

Westborough, MA 01581

(508) 792-7270 ext. 200

Revised 5/98

Commonwealth of Massachusetts

Division of Fisheries \& Wildlife, Route 135, Westborough, MA 01581 (508)792-7270 ext. 200

http://www.state.ma.us/dfwele 


\section{Suggested Reading}

Vernal Pool Identification and Certification

Colburn, E.A., ed. 1993. Certified: A Citizen's Step-by-Step Guide to Protecting Vernal Pools.

$5^{\text {th }}$ Edition. Massachusetts Audubon Society, Lincoln, MA.

Kenney, L.P. 1995. Wicked Big Puddles: A Guide to the Study and Certification of Vernal Pools. Vernal Pool Association, Reading, MA.

Kenney, L.P. and M.R. Burne. 2000. A Field Guide to the Animals of Vernal Pools. MA Division of Fisheries \& Wildlife, Westborough, MA.

Amphibians/Reptiles

Behler, J.L. and F.W. King. 1979. The Audubon Society Field Guide to North American Reptiles and Amphibians. Alfred A. Knopf, New York.

Conant, R. and J.T. Collins. 1998. A Field Guide to Reptiles \& Amphibians, Eastern and Central North America. $3^{\text {rd }}$ Edition, Expanded. Houghton Mifflin, Boston, MA.

Hunter, M.L., A.J.K. Calhoun, and M.McCollough, ed. 1999. Maine Amphibians and Reptiles. University of Maine Press, Orono, ME.

Tyning, T.F. 1990. Stokes Nature Guides: A Guide to Amphibians and Reptiles. Little, Brown and Company.

Invertebrates

Lehmkuhl, D.M. 1979. How to Know the Aquatic Insects. The Pictured Key Nature Series, W.C. Brown Company, Iowa.

McCafferty, W.P. 1981. Aquatic Entomology, The Fishermen's and Ecologists' Illustrated Guide to Insects and Their Relatives. Jones and Bartlett Publishers, Boston, MA.

Pecharsky, B.L., P.R. Fraissinet, M.A. Penton, and D.J. Conklin, Jr. 1990. Freshwater Macroinvertebrates of Northeastern North America. Cornell University Press, Ithaca, NY.

Plants

Redington, C.B. 1994. Plants in Wetlands. Kendall/Hunt Publishing Co., Dubuque Iowa.

Newcomb, L. 1977. Newcomb's Wildflower Guide. Little, Brown and Co., Boston, MA.

Magee, D.W. 1981. Freshwater Wetlands: A Guide to Common Indicator Plants of the Northeast. University of Massachusetts Press, Amherst, MA. 


\section{References}

Brooks, R.T., J. Stone, and P. Lyons. 1998. An inventory of seasonal forest ponds on the Quabbin reservoir watershed, MA. Northeast Naturalist 5(3): 219-230.

Burke, V.J. and J.W.Gibbons. 1995. Terrestrial buffer zones and wetland conservation: A case study of freshwater turtles in a Carolina bay. Conservation Biology 9:1365-1369.

Dodd, C.K., Jr. and B.S. Cade. 1998. Movement patterns and the conservation of amphibians breeding in small, temporary wetlands. Conservation Biology 12(2): 331-339.

Semlitsch, R.D. 1998. Biological delineation of terrestrial buffer zones for pond-breeding salamanders. Conservation Biology 12(5): 1113-1119.

Stone, Janice. 1992. Vernal pools in Massachusetts: aerial photographic identification, biological and physiographic characteristics, and state certification. Master's Thesis. University of Massachusetts. 98 pp. 


\section{Appendices}

Model letter for landowner permission

Vernal Pool Protection - the Local Bylaw 



\section{Appendix A}

\section{Model Letter for Landowner Permission}

Following is a model letter for landowner permission. While the information presented in the Massachusetts Aerial Photo Survey of Potential Vernal Pools should be used to increase vernal pool awareness and protection through local efforts or through the official Vernal Pool Certification Program, landowner permission should be obtained, in writing, prior to any field investigation.

The Massachusetts Natural Heritage \& Endangered Species Program is required to release all information contained in our files when an information request is made under the state's public documents request law. The official field form becomes part of the public record and must be released when requested. The name and address of the observer must be included in the documents that are released under this law, so it is strongly recommended that you obtain permission prior to collecting information for certification. 

Name

Address

Phone number

Date

Landowner name

Street address

Town, State, ZIP

I am writing to ask for your permission to study a potential vernal pool. The local assessor's records indicate that you own the parcel containing the potential vernal pool I am interested in. I am (a student / conservation commission member / other). I would like to visit the potential vernal pool on your property to (explain your interest in the pool).

\section{(If certifying)}

Vernal pools are important nurseries for a wide variety of amphibians (frogs, toads and salamanders), and are also important to birds, mammals, reptiles, and a host of invertebrates. I will search for evidence of amphibians or invertebrates that may be breeding in the vernal pool. If the eggs or young of vernal pool species are found, I will take photographs and make notes of the animals that are found. This information, along with maps of the vernal pool, will be submitted to the state's Division of Fisheries and Wildlife for official certification.

The official certification of a vernal pool on your property could result in protection under the Massachusetts Wetlands Protection Act, as well as three other state wetland protection regulations. Although this might result in restriction on certain activities in or immediately around the pool, such as vegetation cutting or dumping, it would greatly help the protection of the wildlife that depends on these important nurseries.

\section{(If not certifying) \\ (Explain specifically what you intend to do and how the information would be used)}

I would greatly appreciate your permission to visit the potential vernal pool that is on your property. I would be happy to talk with you about these important wildlife habitats, and even bring you out to the pool to show you what I find. I also would like to share the information that I collect with you when I am done.

Thank you very much,

Sincerely, 



\section{Appendix B}

\section{Vernal Pool Protection - the Local Bylaw}

The Massachusetts Wetlands Protection Act does not protect vernal pools that are outside of jurisdictional resource areas and does not address the upland habitat needs of terrestrial vernal pool dependent species like the spotted salamander. The exception to these shortfalls is for vernal pools found within the 200 foot "Riverfront Area" associated with perennial (permanent) streams. Vernal pools and their associated uplands, to the extent that they fall within the Riverfront Area are much more effectively protected. To address the shortcomings of the Wetlands Protection Act, many towns throughout the Commonwealth have implemented local bylaws, administered by the conservation commission, that protect any vernal pool (officially certified or not), and upland habitat surrounding them. Some even refine their definition to include extremely small vernal pools. When properly constructed and adequately justified, bylaws are powerful tools for protecting a town's vernal pool resources along with critical upland non-breeding habitat.

Following are excerpts from the Sudbury bylaw and regulations pertaining specifically to the definition and protection of vernal pools. This bylaw is one of the most progressive and comprehensive in the state because it broadens the definition of protectable vernal pools far beyond simply those that are certified by the NHESP, and establishes the upland area surrounding vernal pools (as well as all other wetland resource areas) as a resource area protected under the bylaw. While the specific language is not necessarily applicable for all towns across the Commonwealth, the Sudbury bylaw provides useful hints and ideas for crafting a bylaw that will more effectively protect vernal pools. The complete text can be found at http://home.att.net/ $\sim$ sudbury.concom/bylaw.htm.

Contact the Massachusetts Association of Conservation Commissioners (www.maccweb.org) for additional information and assistance in developing and passing a bylaw for the protection of your town's vernal pools and other critical wetland resources. 



\section{Town of Sudbury Wetlands Administration Bylaw (Revised June 1998)}

\section{Bylaw Section 1. Purpose}

The purpose of this bylaw is to maintain the quality of surface water, the quality and level of the ground water table and water recharge areas for existing, or potential water supplies; to protect the public health and safety; to protect persons and property against the hazards of flood water inundation; to protect the community against the costs which may be incurred when unsuitable development occurs in wetland resource areas; and to provide for the reasonable protection and conservation of certain irreplaceable natural features, resources and amenities for the benefit and welfare of the present and future inhabitants of the Town of Sudbury.

Accordingly, this bylaw protects the wetlands, related water resources, and certain adjoining land areas in the Town by providing for prior review and control of activities deemed to have a significant or cumulative adverse effect upon wetland values, including but not limited to the following: protection of public and private water supply, protection of ground water, flood control, erosion and sedimentation control, storm damage prevention, avoidance of water and soil pollution, protection of fisheries, wildlife habitat, rare species habitat including rare plant species, agriculture, aquaculture, and recreation values, deemed important to the community (collectively, the "wetlands values protected by this bylaw"). This bylaw is intended to utilize the Home Rule authority of this municipality to protect additional resource areas, for additional values, with additional standards and procedures to augment those of the Wetlands Protection Act, G.L. Ch 131, §40 and Regulations thereunder, 310 CMR 10.00.

\section{Bylaw Section 9. Definitions}

The following definitions shall apply in the interpretation and implementation of this bylaw.

The term "adjacent upland resource area" shall include all lands within 100 feet of wetland resource areas as enumerated in section 2, except for perennial streams and rivers for which the adjacent upland resource area extends for 200 feet from the top of bank, and except for vernal pools, ponds under 10,000 square feet in area, and isolated land subject to flooding for which special adjacent upland resource area definitions are described below.

The term "vernal pool" shall include, in addition to that already defined under the Wetlands Protection Act, G.L. Ch. 131, $\$ 40$ and Regulations thereunder, 310 CMR 10.00, any confined 
basin or depression not occurring in existing lawns, gardens, landscaped areas, or driveways which, at least in most years, holds water for a minimum of two continuous months during the spring and/or summer, contains at least 200 cubic feet of water at some time during most years, is free of adult predatory fish populations, and provides essential breeding and rearing habitat functions for amphibian, reptile or other vernal pool community species, regardless of whether the site has been certified by the Massachusetts Division of Wildlife and Fisheries. The presumption of essential habitat value may be overcome by the presentation of credible evidence which in the judgment of the Commission demonstrates that the basin or depression does not provide the habitat functions as specified in the Bylaw regulations. The adjacent upland resource area for vernal pools shall extend 100 feet from the mean annual high-water line defining the depression, or one-half of the distance between the vernal pool and any existing house foundation, which ever is smaller. In either case the adjacent upland resource area for vernal pools shall not extend over existing lawns, gardens, landscaped or developed areas.

\section{Sudbury Wetlands Administration Bylaw Regulations Revised November 2000}

\section{Regulations Section 2. Jurisdiction}

\subsection{Presumption of Vernal Pool Habitat}

The Bylaw presumes vernal pool habitat exists if a wetland's physical characteristics conform with those defined for vernal pools in Section 9 (Definitions) of the bylaw: [see above]

This presumptive definition for vernal pools is based on systematic field observation in the Town of Sudbury by the Sudbury Conservation Commission showing that virtually all basins that possess the above characteristics actually host breeding vernal pool species. Undoubtedly this is a particular consequence of Sudbury's semi-rural character and enduring woodlands and wetlands.

The presumption of vernal pool habitat may be overcome, however, with the presentation of credible evidence which in the judgment of the Conservation Commission demonstrates that the wetland does not provide, or cannot provide, vernal pool habitat functions. 


\subsubsection{Demonstrating that a Ponding Area is not a Vernal Pool}

For the purposes of overcoming the presumption of vernal pool habitat the Commission will consider:

2.1.1.1 Evidence that the ponding area does not hold water for at least two continuous months in most years. As a rule of thumb the term "most years" shall mean three out of five consecutive years.

2.1.1.2 Evidence that vernal pool species do not breed or have not bred in the ponding area. The Conservation Commission shall provide explicit guidelines for this evidence.

2.1.1.3 Evidence that the ponding area could not be a viable breeding site for vernal pool species due to incompatible physical, chemical, biological, or other persistent conditions at the site in most years. Such evidence could include, without limitation, several months of $\mathrm{pH}$ and dissolved oxygen measurements yielding values incompatible with amphibian or reptile breeding.

\subsubsection{Timing of Evidence Collection}

Many of the indicators of vernal pool habitat are seasonal. For example, certain salamander egg clusters are only found between late March and late May. Wood frog chorusing only occurs between late March and May, and then only at night. Consequently, failure to find evidence of breeding must be tied explicitly to those periods during which the evidence is most likely to be available.

Accordingly, in the case of challenges to the presumption of vernal pool habitat the Conservation Commission may require that the determination be postponed until the appropriate time period consistent with the evidence being presented. The Commission may also require its own site visits as necessary to confirm the evidence. 


\section{Regulations Section 7. Permits and Conditions}

\subsection{Performance Standards \& Design Criteria for Adjacent Upland Resources}

As stated in the Bylaw, Section 7 Permits and Conditions lands within 100 feet of wetlands resource areas (25 feet in the case of isolated land subject to flooding):

"... are presumed important to the protection of these resources because activities undertaken in close proximity to wetlands and other resources have a high likelihood of adverse impact upon the wetland or other resource, either immediately, as a consequence of construction, or over time, as a consequence of daily operation or existence of the activities. These adverse impacts from construction and use can include, without limitation, erosion, siltation, loss of groundwater recharge, poor water quality, and harm to wildlife habitat.

The Commission may therefore require that the applicant maintain a strip of continuous, undisturbed vegetative cover in part or all of the 100-foot area and set other conditions on this area, unless the applicant provides evidence deemed sufficient by the Commission that the area or part of it may be disturbed without harm to the values protected by the law."

\subsection{Considerations in Setting Disturbance Restrictions.}

A growing body of research evidence suggests that even "no disturbance" areas reaching 100 feet from wetlands may be insufficient to protect many important wetland resource characteristics and values. Problems of nutrient runoff, water pollution, siltation, erosion, vegetation change, and habitat destruction are greatly exacerbated by activities within 100 feet of wetlands. Thus, in general work and activity within 100 feet of wetlands should be avoided and discouraged and reasonable alternatives pursued.

Accordingly, the Conservation Commission shall begin with the presumption that lands within the adjacent upland resource of a resource are best left in an undisturbed and natural state. [Note: the Bylaw contains a number of exemptions for single family residences existing prior to July 27, 1994] 
However the Commission shall designate areas of the adjacent upland resource to be suitable for temporary, limited, or permanent disturbance as appropriate when the applicant can demonstrate to the Commission's satisfaction that the proposed work or activity will not affect wetland values singularly or cumulatively and that reasonable alternatives to the proposed work or activity do not exist.

In considering designation of adjacent upland resource disturbance areas, the types of work and activities allowable, and conditions to apply, the Conservation Commission shall consider:

\subsubsection{Values and Functions of the Resource Area}

The quantity and quality of resource values and functions should be considered explicitly in placing conditions on adjacent upland resource work. Some isolated land subject to flooding, for example, may serve for temporary flood storage only. Minimal adjacent upland resource restrictions within several feet of the resource might be necessary only to prevent erosion.

Other isolated land subject to flooding might provide vernal pool habitat. It might also provide important flood storage capacity and intersect ground water. In this instance far stronger adjacent upland resource restrictions would be appropriate because a larger number of functions are involved and some functions, such as habitat, are more sensitive to adjacent upland resource activity and require greater protection. If rare or endangered species, such as blue spotted salamanders, were found at the site then still greater levels of restrictions would be appropriate.

\subsubsection{Wildlife Habitat and Rare Species}

The near-upland areas around wetland resources often play important roles in determining and maintaining the wildlife habitat values of associated wetlands. While it is common to think of the protective or "buffering" value of adjacent upland resources in terms of area undisturbed, habitat values may be equally affected by the configuration of the adjacent upland resource perimeter, the inclusion or exclusion of specific topographical and ecological features (such as an abutting sandy knoll or tree canopy), etc. 
Therefore where significant wildlife habitat values and functions are present delineation of non-disturbance areas within the adjacent upland resource shall, as is reasonable, minimize the length of perimeter to area left undisturbed, exclude fingers, islands, or other projections or indentations of the nondisturbance zone, and in general avoid delineating oddly shaped non-disturbed areas. The Commission shall give special attention to inclusion inside the no disturbance area of those topographical and ecological features that it deems important for maintaining the wildlife habitat value of the resource.

The potential presence of rare or endangered species and their specific sensitivity to adjacent upland resource activity shall be considered in determining adjacent upland resource restrictions. Evidence of the presence of such species or evidence of likely habitat shall be considered by the Conservation Commission. Prior designation or rare or endangered species habitat by the Division of Fisheries and Wildlife Natural Heritage Program is not necessary.

The Commission may consult with the Division of Fisheries and Wildlife Natural Heritage Program or other authorities as it deems necessary for guidance and recommendations.

\subsubsection{No Significant Adverse Impact on Wildlife Habitat}

Wildlife habitat serves a variety of functions in support of wildlife. Food, water, breeding space, shelter, security, movement and migration space, and connections to other habitat areas are all equally important. All of these wildlife habitat functions are presumed to exist in all resource areas.

Therefore in accordance with the Bylaw's fundamental purposes (see Bylaw, Section 1 above) no project may have a significant adverse impact - either project-specific or cumulative - on wildlife habitat for more than two growing seasons.

For wildlife habitat purposes, a significant adverse project-specific impact is defined as an impact caused by work in a resource area that would under reasonable assumptions (a) result in a measurable decrease in the extant wildlife populations or biological composition, structure, or richness on the site or in the vicinity exclusive of the present or future state of adjacent and nearby 
properties, or (b) impair, damage, destroy, or reduce in value for wildlife purposes certain specific habitat features.

Wildlife studies have shown that direct impacts from work - filling, grading, vegetation removal, construction of barriers to movement, etc. - in resource areas can severely harm wildlife populations. For example, low stone walls bisecting a resource area can prevent amphibians that live in upland areas from reaching breeding pools, marshes, and streams. Or, removal of large snags (dead trees) can virtually eliminate nesting by barred owls, pileated woodpeckers, mink, etc. Accordingly, the Commission shall prohibit the placement of fences or other barriers to wildlife movement within and between resource areas and the destruction of specific habitat features.

Examples of protected habitat features include (but are not limited to):

Large cavity trees

Turtle nesting areas

Existing nest trees for birds that reuse nests

Beaver dams, dens, and lodges

Mink or otter dens

Vernal pools

Vertical sandy banks

Migration corridors that provide connectivity between wildlife habitats

Sphagnum hummocks and pools suitable to serve as nesting habitat for four-toed salamanders

But indirect impacts - the effects of human activities near wildlife habitat - can have equally harmful effects. Therefore the Commission shall take into account indirect effects on a project by project basis. So, for example, no work within resource areas shall be permitted within 100 feet of existing beaver, mink or otter dens, or within 200 feet of existing osprey or great blue heron nests.

As clearly stated in Section 1 of the Sudbury Wetlands Administration Bylaw the purpose of the Bylaw is to preserve for future generations of residents the natural resources and amenities - including wildlife - we presently enjoy in Sudbury. The Bylaw protects future values as well as current ones. Therefore, the Commission must be especially cognizant of the likely cumulative impact of work within resource areas. 
For wildlife habitat purposes a significant cumulative adverse impact is defined as an impact that would under reasonable assumptions result in a measurable decrease in the extant wildlife populations or biological structure, composition, or richness on the site or in the vicinity taking into account the projected impacts of future projects that could be proposed in the vicinity with similar, comparable, or other significant impacts and disturbance.

This method for assessing cumulative impacts avoids the pitfall of placing an unreasonable burden of resource protection on subsequent applicants/projects in the vicinity while subsidizing those who are first to develop land. It allows the Commission to level the marginal impact of all proposed projects in the vicinity while ensuring appropriate protection - present and future - of the values and interests protected by the Bylaw.

\section{Regulations Section 9 DEFINITIONS}

\subsection{Vernal Pool Species}

Any species of reptile, amphibian, or invertebrate that breeds in a vernal pool. These species may be obligate or facultative. 
The Natural Heritage \& Endangered Species Program is very proud to present the Massachusetts Aerial Survey of Potential Vernal Pools. This Compact Disc contains the program and data files that will allow users to view and print USGS topographic maps with the Potential Vernal Pools identified in this survey. Detailed installation instructions and system requirements are found on pages 22 through 25 . Please make note of the instructions on page 24, these are very important to the proper functioning of the program. 
